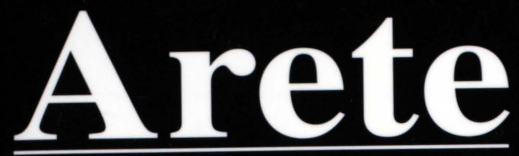

St. Edward's University Student Academic Journal

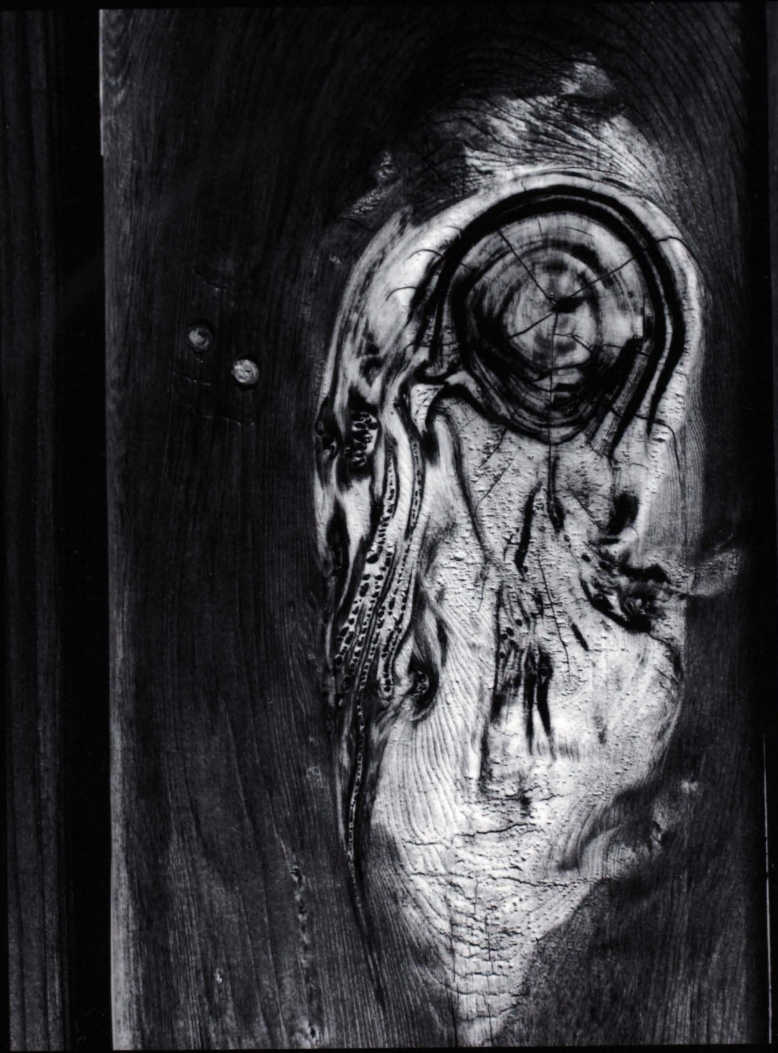

Volume 14

Spring 2004 

St. Edward's University Student Academic Journal

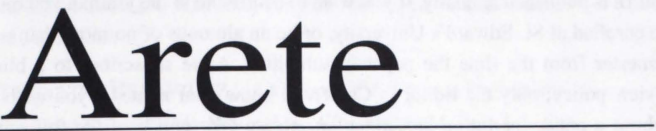

Volume 14 Spring 2004

Editor-in-Chief

CLAYTON SHOPPA

Associate Editors

MARY AVERY

SARAH BUCKINGHAM

SARAH BOND

JASON FORREST

PHILIP JONES

Layout/Design Editor

GEORGE Morrow

Faculty Advisor

LYNN RUDLOFF

Student Life Advisor

PAM VANDER WERF

(c) COPYRIGHT 2004

ALL RIGHTS RESERVED

St. Edward's University

3001 South Congress Avenue

Austin, Texas 78704 
ARETE is published annually. If you wish to contribute to the journal, you must be enrolled at St. Edward's University, or be an alumnus of no more than one semester from the time the paper is submitted. Arete subscribes to a blind review policy; only the Editor-in-Chief will know your name. If you wish to submit a paper for future consideration, please take notice of the following guidelines: papers should be an average of fifteen double spaced, typed pages (papers of other lengths could also be considered); papers should be error free and in an acceptable style (i.e., APA or MLA); your name, address, and phone number should appear on a separate detachable sheet. Send paper to Arete Editor, St. Edward's University, Campus Mail Box 1029, 3001 S. Congress Ave, Austin, Texas, 78704-64889. Visit ARETE on the Web at:

<http://ww.stedwards.edu/stulife/arete/index.html>.

The views expressed in these essays are those of the individual authors and do not necessarily reflect the views of the editorial board or the University. 
Vanessa BaIley Adams, Jungian Individuation in Demian and Fight Club

Fernando Benavidez, A Comparative Look at Dreiser's

Carrie and Conrad's Marlow and the Changeable Modern Identity

Lee Parish-Butler, The Role of Emotional Intelligence in Care Ethics

Aricel Guerrero, The Phenomenon of the Unreliable Narrator as Used by Irving and Poe

William O. Pate II, On Sleeping with Frịends

Paul Hagey, Nihilism in Doctor Faustus and Steppenwolf:

The Struggle for Transcendence

MARGARET JoHnSON, Reinventing the Myth: The West of William Kittredge

Ashlie Kelly, "Them Damned Pictures": A Study of the Cartoons of Thomas Nast and the Breakdown of the Tweed Political Ring

Catherine S. Blackwell, Lesbianism as a Cat's-Paw: The True Role of Mlle. Reisz in The Awakening

Jennifer Wharton, To Create More Worlds: A Discussion of Alternative Worlds in Paradise Lost and His Dark Materials

E K Zimmerman, Lilith: A Brief Biography of a Demoness

$$
\text { Cover: " 001" by Cary Jordan Tijerina, Silver Gelatin } 2003
$$

ARETE was printed by Morton Printing, 900 Old Koenig Ln. Ste. 135 Austin, Texas 78756. It was designed on QuarkXpress 4.0 using Palatino, and Times 

It is with great pleasure and admittedly considerable relief that I introduce the present volume of St. Edward's students' academic pursuits, variegated though distinctly exemplary. Just as our university continues to grow in size and stature, so too has the quality of our scholarship similarly developed. Additionally, where the papers published herein emblematize the range of professional and personal interests of SEU's student community, so too does this year's equally distinguished editorial board, to whom I am most appreciative. This year we worked hard to engineer a journal that represents many facets of academic life at St. Edward's. For this reason I must also extend my thanks to all of the students who took the time to submit their manuscripts for inclusion.

The range of disciplines represented is itself noteworthy. In one paper, the reader will enjoy a precise, historical inquiry in Zimmerman's treatment of the mythic Lilith figure. Kelly's paper solidly asserts the ability of political satire to incite change in the American political landscape. In her paper, Adams treats Hesse's Demian and the contemporary novel-made-film Fight Club as exemplars of Jungian psychology. Parish-Butler's paper argues that the rationalism so endemic to the West has come at considerable cost, requiring us to sacrifice foundational caring for theoretical ethics. Relatedly, Hagey's work examines the failure of the Enlightenment project and its ensuing implications with regard to human finitude and liberation.

As with past issues of Arete, the Literature Department is also fully present. Benavidez uses a comparison of two seminal modern works to argue for a modern conception of identity and self that is ultimately malleable. Long offers some critical remarks about Chopin's treatment of human sexuality in her major work, The Awakening. Though not decidedly literary, Pate's essay, "On Sleeping With Friends," similarly deals with the social construction of sexuality as it examines the palatable limits of its expression. As the exception to the more purely modernist flavor of many of this issue's literature papers, Wharton's work draws striking comparative lines between Milton's famous epic and the contemporary fantasy-fiction of Philip Pullman. Lastly, Guerrero explicates the nature of the modernist convention of the unreliable narrator in Washington Irving and Edgar Allan Poe.

Both those with whom I have worked personally and the papers' authors all surely participate in the virtue from which this journal derives its name. Finally, I extend my thanks also to Cary Jordan Tijerina for his insightful cover art, George Morrow for his creative graphical contributions, and Professor Lynn Rudloff for striking such a tenuous balance between gently corrective and enormously supportive.

\section{Clayton Shoppa}

Editor-in-chief, Arete 



\section{Jungian Individuation in Demian and Fight Club}

Vanessa Bailey Adams, a Psychology major intending to graduate in May 2004, wrote this paper for Dr. Tom Green's Women Writers course in the spring of 2002.

Over the evolution of art, specifically the fields of literature and film, certain patterns have been developed into recognizable structures for creating storylines and characters. Psychoanalyst Carl Gustav Jung would call these structures "archetypes," because they are figures and situations that he felt could be traced to a primordial collective unconscious, and this ability is why such stories and characters are so universal. One theory of Jung's involves a quest for one's inner-self, which he called "Individuation." Despite their differences in media, the Jungian process of individuation is presented quite clearly in both Hermann Hesse's novel, Demian, and David Fincher's film, Fight Club.

In order to understand how the steps of individuation are present in both of these pieces, it is important first to have a clear understanding of the process of individuation itself. According to Jung, there are two types of unconscious, the personal and the collective. The personal unconscious consists simply of items that presently are not in working memory or conscious thought, but can be retrieved on demand. The collective unconscious, however, does not belong to a person specifically, but rather is a larger understanding of the world in which people participate. The collective unconscious is very similar to Emerson's idea of the Over-Soul in that it is a spiritual union between the universe and each individual being. Jung believed that achieving enlightenment meant that the collective and personal unconscious must be equal and synthesized together to form a balanced psyche.

Archetypes are a product of the collective unconscious, and exist as motifs in dreams, literature, film, and life experience, and contain specific characteristics and patterns of action. For example, the archetypal figure of the Shadow symbolizes the dark half of a person's character, and can be seen in film as Darth Vader in the Star Wars trilogy. Although Luke Skywalker is not an evil character, his father (Darth Vader) is a leader of the evil empire, and thus Skywalker must battle the Shadow and come to terms with his evil lineage. These archetypal characters can either stand as an obstacle or act as a guide in the main character's individuation. 
According to Eric Pettifor, there are five functions of psyche that act as an integral part in the individuation process: the persona, the ego, the shadow, the anima/animus, and the Self. (The "Self" is capitalized in order to distinguish the psychological construct from one's physical being). The persona functions as a façade that a person displays openly to the outside world. This façade often changes depending on the company and situations that the person is exposed to, so it does not act as a true definition of the person's Self and is only meaningful on a surface level. The ego is the most conscious portion of the psyche, aware of all senses and feeling. All functioning thoughts, emotions, memories, and desires are under the government of the ego, yet these include very few unconscious motives and desires and thus do not constitute the complete Self. The third element of the psyche is the shadow, which contains all undesirable portions of the personality that the person chooses to repress. The archetypal shadow as a character is merely a projection of one's psychological shadow onto a person or object. Another part of the psyche is the anima or the animus. The anima is the feminine portion of the unconscious in males, while the animus is the masculine portion of the unconscious in females. Anima/animus projection involves projecting characteristics of the anima or animus onto a person, which causes desire for the projected person. The anima/animus can act as an interpreter between the conscious and the unconscious. The final piece of the psyche is the Self, which is "simply, the center and totality of the entire psyche" (Pettifor). This is the area of awareness that contains complete personal enlightenment, which is very hard to discover due to conflicts with the ego.

Individuation is a process that involves cooperation between various parts of the psyche and levels of consciousness. Daryl Sharp defines individuation as:

... a process informed by the archetypal ideal of wholeness, which in turn depends on a vital relationship between ego and unconscious. The aim is not to overcome one's personal psychology, to become perfect, but to become familiar with it. Thus individuation involves an increasing awareness of one's unique psychological reality, including personal strengths and limitations, and at the same time a deeper appreciation of humanity in general. (67-68) 
Individuation is different for each person, but is generally divided into four distinct steps. The first step to discovering one's self is to confront the shadow. Jung called this "the First Act of Courage" (qtd. in Pettifor), because the shadow is such an undesirable portion of the Self that one must face it with unabashed honesty. Second, the individual must confront his anima, which is usually done through anima projection. Usually the individual feels that he is in love with his anima projection and attempts to achieve a relationship with the person he has projected his anima onto. However, in order to complete individuation, one must do it alone, and cannot depend on another being for happiness. Therefore, the person must accept his anima by loving the projection, but then reject the projection, and truly internalize the qualities of the projection back into himself consciously. Once this is done, the individual is prepared to confront the Self as a whole, since he has incorporated each part of the unconscious psyche into consciousness. The process of individuation itself can take a lifetime, and some say that true enlightenment is not reached until death.

Hesse's protagonist Emil Sinclair embarks on a quest for individuation in Demian. Sinclair begins his narration at childhood, where he relished his innocence and the general simplicity of life. He then declares that there is a dichotomy of the world, "two realms" as he puts it, in which his experiences have allowed him to observe. The first realm is that of good, which includes the warmth of his family and his innocent lack of corruptive influences. The other realm is that of evil, which contains all other unknown and dark aspects of the world. He then is coerced by an older boy named Kromer to follow him under a bridge to talk with a few other boys. Emil feels he is being too quiet, so he creates a tale of stealing apples from an orchard to fit in with the other boys. Later that day, Kromer claims that the owner of the orchard would pay him to know who stole his apples and blackmails Sinclair. Although Sinclair's family is wealthy, he is not yet old enough to receive an allowance, so he must steal to pay Kromer. Hesse's choice of fruit is intentional to parallel Sinclair's loss of innocence to Adam's exile from Eden. Hesse furthers the Biblical allusions by having Kromer repeatedly referred to as the Devil, and so he clearly represents Sinclair's shadow because Kromer serves as the projection of Sinclair's thievery onto another person. The confrontation between Kromer and Sinclair symbolizes the internal battle between Sinclair's moralistic ego and his darker impulses, the shadow. Once Sinclair committed the first act of stealing, he had internalized the disliked characteristics of Kromer into his 
consciousness. He even claims that "what Franz Kromer had once represented was now within my own being" (Hesse 31).

His anguish has permeated all aspects of his life, and Sinclair eventually realizes that committing an immoral act (stealing) is the first step in releasing himself from childhood. "It was the first rift in my father's sanctity, it was the first nick in the pillars on which my childish life had rested, and which every human being must destroy before he can become himself" (Hesse 11). Because of the traumatic event of taking the first step of separating from his parents, Sinclair becomes physically ill and must miss school. It is during this distressing time that Sinclair creates an alter-ego named Max Demian to compensate for his inability to overcome his shadow, although it is not revealed until the end of the novel that Demian is in fact a projection of his ego. The novel introduces Demian by saying that he enrolled in Sinclair's school while Sinclair was sick at home. Sinclair sees Demian as being immediately respected and revered by his peers, an extremely intellectual and intimidating boy who is highly mature. Soon, Demian befriends Sinclair and eventually Sinclair trusts Demian enough to tell him about his fear of Kromer and his sinful thefts. Demian tells Sinclair, "A fear like that ruins us, we've go to get rid of it. You've got to get rid of it if you are to become a regular person" (Hesse 25). Demian then speaks to Kromer, and Sinclair immediately notices that Kromer now wants nothing to do with him. He is relieved to be free from his guilt, but feels insecure because he did not provide his own freedom. "I was free from Kromer's hands and the Devil's, but not thanks to my own strength and achievement" (Hesse 28). Here Sinclair realizes that he cannot find the strength to commit his will without the aid of Demian. However, with Demian's assistance, he was able to overcome his shadow and proceed on his path to the next stage of individuation.

Sinclair's next step involved discovering his personal distinction, which he calls "the mark" in reference to the mark of Cain. When Demian is speaking to Sinclair about the mark of Cain, he claims, "Surely it was something strange that was barely noticeable, a little more intelligence and daring in his eyes than people were used to. This man had power, people shied away from this man. He had a "mark'" (Hesse 18). This mark became the more tangible association into the elite group of those Sinclair met who were undergoing individuation. Later in the novel, after Sinclair goes through a brief period of drunken depression, Sinclair would be able to recognize the mark on others and befriend them. 
He describes those who had the mark as having been "awoken, or were awakening and we were striving for an ever perfect state of wakefulness..." (Hesse 95). Throughout most of the novel, Sinclair begins developing those qualities that were once attributed to Demian: he is constantly daydreaming and thus has an unusual countenance of repose, and he has become interested in philosophy and his schoolmates (who he considers intellectually inferior) admire but fear him, as Demian's schoolmates once admired and feared him. Sinclair's internal characteristics become more and more similar to Demian's until he himself understands that he possesses the mark of one who is interacting on a higher plane of intellectual and philosophical thought and is able to see this mark in others.

$\mathrm{He}$ also rejects religion and creates his own spiritual path through the god Abraxas, who is half God, half Devil. Sinclair receives a letter in a book that says, "The bird is fighting its way out of the egg. The egg is the world. Whoever wishes to be born must destroy a world. The bird is flying to God. The god is named Abraxas" (Hesse 59). Sinclair first learns of Abraxas by listening to a teacher briefly lecture about Abraxas as being a synthesis of good and evil, and thus encompassing all characteristics in human nature. This directly symbolizes the Jungian ideal of the collective unconscious in that it is a physical representation of all human qualities. After introducing Abraxas as representing the collective unconscious, Hesse then creates a physical symbol for Abraxas and links it to Demian. Sinclair recalls that Demian was very interested in the coat of arms carved on the keystone above Sinclair's parents' home. He then begins having dreams where the coat of arms comes alive, realizing the coat of arms represents Abraxas. Hesse may have chosen to symbolize this synthesis of good and evil with a coat of arms because of an insight of Jung's: "All the eagles and other predatory creatures that adorn our coats of arms seem to me apt psychological representatives of our true nature" (qtd. in Lorenz and Watkins). This god represents the two realms of Sinclair's childhood, and he explores this newfound spirituality very deeply through conversations with mentor Pistorious and in dream images. The understanding of a higher being that is not represented in formal religion guided Sinclair on his path to individuation by allowing him a symbol of the collective unconscious to understand and analyze.

The next stage in Sinclair's individuation is anima projection. While he is sexually attracted to a woman whom he names Beatrice in honor of Dante, he never meets this woman and merely admires her from afar. It is thoughts of 
Beatrice that save Sinclair from his depression, and he begins working harder in school and searching himself inwardly more often. Sinclair finds himself dreaming more and more, and he begins receding deep within himself and constantly losing awareness of reality and thwarting his perception of time because of his dreams of Beatrice. However, Beatrice soon becomes unsatisfactory as Sinclair has visions of another being, part male and part female, half good and half evil: a synthesis of the realms of his childhood, much like Abraxas but in human form. He paints this vision and realizes, "The picture didn't resemble me - nor was it meant to, I thought - but it depicted that which constituted my life, it was my inner self, my fate, or my daemon" (Hesse 54). When he meets Demian's mother (Lady Eve), he realizes that the portrait is of her, and then realizes she is his anima projection. "Sometimes I was sure I felt that it wasn't her physical person that my whole being was drawn to and strove to win, but that she was only a symbol of my inner self, and she was merely trying to lead me deeper into myself" (99). Here Sinclair clearly states that Lady Eve is his anima. Lady Eve understands that he must reach his individuation alone, and kindly rejects his statements of romantic love. He is hurt at first, but then learns to accept her choice and love her with a psychological distance. It is then that his individuation is near completion. "I felt strength emanating from me. For a few moments something inside me contracted firmly and tightly, something bright and cool; for a moment I had the sensation of carrying a crystal in my heart, and I knew it was my self" (Hesse 104).

Finally, at the end of the novel, Sinclair realizes that Demian and Lady Eve are merely figments of his imagination. After he is wounded in battle, Demian says to Sinclair, "Young Sinclair, pay attention! I'm going to have to depart. Perhaps you'll need me again sometime, to protect you from Kromer or something else. If you do call me then, I will no longer come riding crudely on a horse or on a train. Then you'll have to listen within yourself, and you'll notice that I'm inside you" (Hesse 109). It is not quite clear whether or not Sinclair dies at this point, but his last statement is this: "But whenever I find the key at times, and descend all the way into myself, where the images of destiny slumber in the dark mirror, I need only lean over the black mirror to see my own image, which now looks exactly like him, him, my friend and guide" (109). This realization that the projection of the male characteristics that Sinclair desired (his animus, Demian) and the female characteristics he desired (his anima, Lady Eve) are now internalized is most likely Sinclair's final step 
in individuation. He had slowly, over the course of a lifetime, integrated each part of his unconscious psyche into his consciousness, thus attaining a complete understanding of himself on both conscious and unconscious levels.

David Fincher's film adaptation of Fight Club is similar to Demian in its approach to individuation. The protagonist of Fight Club does not have a name, which serves to symbolize his likeness to every man. However, he is referred to here as "Jack" because of the scene where he finds anatomically educational cards where such phrases as "I am Jack's liver" are printed on them along with an explanation of the said organ's function. This becomes a motif in the film, as he calls himself "Jack's raging bile duct" and "Jack's complete lack of surprise." Jack begins telling his story in his early thirties, beginning with his insomnia. He describes his surreal sleep-deprived settings: "Nothing is real: everything is a copy of a copy of a copy." He works in the gray-collar working class, dressing in slacks and ties, clinging to comfort in his routine life. He collects fine furniture, and claims, "Like so many others, I had become a slave to the Ikea nesting-instinct... where I had once read pornography; I now have the Horchow Collection." His days bleed together; he takes business trip upon business trip. There are long sequences of shots of planes taking off and landing, and this repetition serves to exaggerate the endlessness of Jack's routine life.

It is on a plane that Jack meets Tyler Durden, who is later revealed as his alter-ego. Prior to meeting Tyler, Jack has been going to several support groups for diseases and maladies that he does not have. When he could finally cry with another person who was dying and losing hope, he could finally sleep. "I was lost in oblivion-dark, silent, complete. I found freedom. Losing all hope was freedom." It is here that the theme of rejection of comfort as a means to achieve enlightenment begins. When Jack returns from yet another business trip, he finds that his apartment has exploded and all of his material possessions are littering the street. He sees the contents of his refrigerator shattered on the pavement and exclaims, "How embarrassing! A house full of condiments and no food." This perfectly encapsulates Jack's lifestyle: he has all the materialistic items that embellish a life, but lacks a true sense of being to embellish upon. He calls Tyler, and they go to a bar to discuss Jack's misfortune. Tyler tells Jack, "the things you own, they end up owning you. I say, never be complete. Stop being perfect." The first step in Jack's individuation is rejecting materialism and embracing personal value. He becomes comfortable living with Tyler 
in his dilapidated home on Paper Street, and they soon create Fight Club, which is a group of men who fight each other as a way of rediscovering masculinity in a gray-collar and passive society.

Jack's second step is discovering and understanding the new direction from his life, which he finds in Fight Club. Tyler once asks Jack, "How much can you know about yourself if you haven't been in a fight?" as if fighting revealed a hidden part of the soul. Soon Jack is initiated into Fight Club by Tyler, who holds Jack's hand down while burning it with lye. While Jack is writhing in pain, Tyler says, "Stay with the pain. Without pain we would have nothing...it is only after we have lost everything that we are free to do anything." This scene shows a physical loss of innocence as Jack has now gained a physical mark, symbolizing the same idea of a unique and elite society as in Demian, which will permanently prove his masculinity as a badge of honor. The idea of a mark as evidence of differentiation is apparent in both works.

Although it is not an ascribed step in individuation, both Fight Club and Demian share a common rejection of formal religion. Jack parallels fighting to a religious experience, stating, "It wasn't about winning or losing, it wasn't about words. The hysterical shouting was in tongues, like in a Pentecostal Church. Afterwards we all felt saved." Several times Jack correlates Tyler to God. Often he says, "In Tyler we trusted." During the scene in which Jack is receiving the mark, Tyler tells him that our fathers are our models for God. "If our fathers left us, what does that say about God?" When Tyler leaves Jack alone, Jack laments, "My father dumped me. Tyler dumped me," and it is unclear whether or not by "my father" he means God or his parent. However, it is obvious that the idea of formal religion is being replaced with Fight Club for Jack. None of the characters in Fight Club are religious, and most of them are more concerned with self-love than a religious acceptance. As Sinclair substituted the myth of Abraxas for formal religion, Jack substitutes God with Tyler and his religion with Fight Club. Perhaps this replacement of religion with Fight Club allows Jack a focus which correlates with the purpose he feels he has. This is a positive change for Jack's spiritual journey, although it is done in a socially destructive manner.

Although starting Fight Club is not a socially accepted purpose for one's life because of its destructive consequences, this violent extreme contrasts highly with Jack's former occupation and serves to further the theme of regaining masculinity in a passive and productivity-driven society. The purpose for 
contrasting Jack's erstwhile occupation with Fight Club is to convey to the audience Jack's magnitude of change.

Typically, the third stage of individuation is the projection of one's anima or animus. As for Jack's anima, it is represented by the unlikely character of Marla Singer. Jack meets Marla at his support groups, and immediately dislikes her because she is a "faker" like he is. She is a unique archetypal character because she begins her role as the shadow, a projection of Jack's dislikes about himself. He states at one point, "her lie reflected my lie," as if she were a mirror image of the dark part of his soul. She has a sexual relationship with Tyler, and at first Jack finds her presence in his house disgusting. However, as she begins frequenting his home, he grows to like her. By the end of the film, they stand with their fingers linked, watching the corporate buildings collapse after the bombs Tyler and his army planted explode inside them. Fincher may have chosen not to make Jack appear to be in love with Marla because that might have detracted from the development of his friendship with Tyler. The focal point of the film was not a romantic love story, but the development of a man's differentiated psyche into a unified Self. The idea that Jack never stated he loved Marla in a romantic way reinforces the idea that all the characters in the film seeking self-love rather than a mutually loving relationship between lovers, just as the relationship between Sinclair and Lady Eve is centered on both partners achieving individual harmony. Fight Club views sexuality as merely an animal instinct and does not display sex as involving much emotional attachment. Marla serves as a female reflection of Jack, or Tyler's current desire and in doing so allows Jack to become free. This occurs when Tyler stops taking over Jack's life for a period of time, and Jack realizes he must stop Project Mayhem (Tyler's army and its assignments) because his conscience is awakened by Marla's hurt over his rejection of her.

When Jack confronts Tyler in anger, he realizes that Tyler and he are one and the same. Tyler says, "You were looking for a way to change your life, and you couldn't do it on your own... Most importantly, I am free in all the ways that you aren't...little by little, you're letting yourself become Tyler Durden." Just as Sinclair slowly became one with Demian, Jack had become one with Tyler. Jack decides that the only way to complete himself is to kill Tyler. Jack needed to synthesize the differentiated portion of his personality (Tyler) with his ego, which would then leave Jack a completed person totally conscious of his internal Self. He looks at Tyler and says, "I want you to really listen to me, 
Tyler. I have my eyes open." Perhaps by saying this, Jack is stating to Tyler that he is now aware of his individuational progress and wants to complete his enlightenment. He then proceeds to insert a gun into his mouth and pull the trigger. Jack does not die, but Tyler has departed, leaving Jack with his awareness of the synthesis between Tyler and himself and his complete control over his awareness: the final step in his individuation.

When the individuational method is applied to both of these pieces, it is obvious that Fight Club and Demian have similarities despite personality differences in the protagonists. Sinclair's and Jack's characters appear to be very different; Sinclair is rather passive, while Jack's integration of Tyler changes him into a highly violent person. However, they both share a common struggle to attain enlightenment. Both Jack and Sinclair undergo some method of distinguishing themselves by using a mark of some sort; Sinclair's is physically less noticeable while Jack's is a tangible scar. The mark then allows both characters to differentiate themselves as beginning the individuation process. Second, Sinclair and Jack both have alter-egos which are presented as physical beings until the end of the works when it becomes apparent that both Demian and Tyler are differentiated portions of Sinclair and Jack's respective egos. To integrate their alter-egos into their conscious, Jack and Sinclair both use a method involving death. Jack shoots himself to "kill" Tyler, while it can be interpreted that Sinclair dies at the end of Demian and finally realizes Demian was internally created.

Despite the fact that both of these artworks are separated by eighty years, they share the common theme of a man searching for himself as explained with the methodology of Jungian individuation. The comparisons drawn between Fight Club and Demian show that the characters Sinclair and Jack begin their journeys to self discovery on the same path despite the disparity in genre, media, and era of creation. Perhaps the greatest test of a novel or film is its influence on other creative expressions. Certainly both Demian and Fight Club appeal to that universal human need to discover one's true Self and will continue to inspire personal individuation as well as creative inspiration for art. 
Fight Club. Dir. David Fincher. Perf. Brad Pitt, Edward Norton, and Helena Bonham Carter. Fox, 1999.

Hesse, Hermann. Demian. New York: Dover, 2000.

Lorenz, Helene Shulman, and Mary Watkins. Individuation, Seeing-through, and Liberation: Depth Psychology and Colonialism. Jan. 2002 <http://www.mythinglinks.org/LorenzWatkins.html>.

Pettifor, Eric. Process of Individuation. 1995 <http://www.wynja.com/personality/jungarchf.html>.

Sharp, Daryl. Jung Lexicon: A Primer of Terms and Concepts. Toronto: Inner City Books, 1991. <http://emedia.netlibrary.com/reader/reader.asp?product_id=20398>. 


\section{Daylight Darkness: A Comparative Look at Dreiser's Carrie and Conrad's Marlow and the Changeable Modern Identity}

Fernando Benavidez, an English Literature major intending to graduate in May 2004, wrote this paper for Dr. Catherine Rainwater's Turn of the Century Novels course.

Modern literature is defined by the era created by novelists such as Joyce, James, Woolf, Dreiser, and Conrad who reexamined many of the grounded imperatives imposed on society by the former Age of Romanticism. According to Abdulla Al-Dabbagh, part of this ongoing reassessment included the "rejection, or at least a reformulation, of the notion of identity." Many modern novelists illustrate the ambiguous perception of "identity" by creating malleable characters that transform from innocent optimists to corruptive individuals by the perceived imposition of their search for a civilized and modern life.

Theodore Dreiser's novel, Sister Carrie, and Joseph Conrad's novel, Heart of Darkness, are excellent parallel examples of the modern perspective in two literary works. Both novels shaped the way many people thought about the dilemmas society faced during the turn of the century concerning individual identity, western civilization, and human nature. These issues are specifically addressed through the experiences of the main characters Caroline Meeber and Marlow. Dreiser's Carrie and Conrad's Marlow begin their journeys into a vast and powerful darkness that deceives them with images of false light, and manipulates them in monumental ways. The resulting changes in each of the characters' identities may be an indication of the authors' comparable points of view about human nature and modern society, respectively. Throughout each of the novels, Carrie and Marlow experience character transformations that are reflected in their actions and are indicative of the analogous perspectives that Conrad and Dreiser seem to share about individual identity, modern society and basic human nature.

An exploration of the voyages taken by these two distinct, yet conspicuously similar characters, requires the comparison of each of their unique expeditions. In Sister Carrie, the young and apparently naïve creature, Carrie, is the personification of the idealized innocence that many women embodied at the turn of the century. Carrie Meeber is a simple girl from Columbia City, 
Wisconsin, who has an older sister, and a father who is a miller. She sets out for Chicago with unrealistic expectations and nothing but a few dollars in her hand. Carrie's journey straight into the "darkness" of the evidently misleading aesthetics of the big city marks the beginning of her inevitable transformation of identity. Carrie is depicted as young and stupid throughout the novel. She is a girl with an "unsophisticated and natural mind" greatly affected by "superhuman forces" like a "blare of sound, a roar of life, a vast array of human hives that appeal to the astonished senses in equivocal terms" (Dreiser 2). She is further described as someone who is guided by self-interest and "warm with the fancies of youth." Her notable qualities include "native intelligence," but we learn later that "in the intuitive graces, she was crude" (2). Her weakened nature fueled by adolescent aspirations of a better life in the big city prescribes the notion that Carrie will have to change in order to survive in the jungles of Chicago.

Unlike the almost inescapable identity transformation that Carrie experiences, Conrad gives Marlow the opportunity, to some extent, to protect his identity from this kind of transformation in response to Kurtz's diminishing stability in the jungles of Africa. Unlike Carrie, Marlow is able to slow down his metamorphosis by realizing the futility of his journey. According to Abdulla Al-Dabbagh, Kurtz himself is somewhat of an alter ego to Marlow, who in turn may also be an alter ego to Conrad. Furthermore, Marlow is developed as a Buddha-like narrator who is also closely identified with Conrad himself. With similar naïveté to Dreiser's Carrie Meeber, Marlow follows Kurtz into the jungles of Africa. These jungles ironically represent modern life as Conrad might have perceived it. The "heart" of the jungle is as "dark" as can be where the "civilized" Kurtz lives. As Marlow identifies the similarities between himself and Kurtz during his journey, he begins to question his own sense of stability, thus accelerating his identity crisis (Al-Dabbagh).

For Carrie, Chicago becomes the major driving force behind her identity crisis in this novel. According to Karl F. Zender, Dreiser's deliberate exclusion of any information about Carrie's childhood or background combines with his depiction of Chicago as the modern world and creates the perception of an ambiguous identity as variable and flexible as the city itself. This is exactly how Carrie's identity is defined and continually identified. Throughout her experience in Chicago, Dreiser places Carrie in situations that undermine her identity in order to demonstrate her constant desire to "improve" her status and, in effect, compromise her identifiable innocence. This compromise is one of 
the first indications of an identity change. In one of her first encounters with her newly discovered city life, she meets, attaches herself, and moves in with Drouet, a low-echelon socialite in Chicago who seems to have no true status among his pseudo-contemporaries. Zender refers to this definitive encounter as the beginning of the metamorphosis for Carrie as she goes from small-town working girl, to "kept" woman, and then to professional actress by the conclusion of her journey. Again this is Dreiser's indication of how flexible and fragile Carrie's identity is. By the end of the novel, she is someone else entirely. The effects that the outer circumstances have imposed on Carrie's identity are an example of Dreiser's assertion that external forces transform people against their will and that these circumstances can get out of their control when people venture out of their familiar milieus. According to Zender, Carrie's monumental transformation is also illustrated by the instance where she thinks of "her sister in Van Buren Street" and "her home at Columbia City" (Dreiser 239). At this point, she has almost lost all contact with her "real" past and it becomes "something that could not be again" (239).

Likewise, Marlow in Heart of Darkness seeks truth in Kurtz's "universal genius." He fears that his identity might be engulfed by Kurtz's eloquence. According to Al-Dabbagh, Conrad, like his character Marlow, is concerned with the notion of the "surrender" of one's ethnic identity in the process of a transcultural journey. Conrad, not unlike Marlow, fears the same loss of identity and gives his character the opportunity to escape by working and keeping himself occupied. This is why Conrad gives Marlow a "way out", so to speak. His values and identity result in a reluctant change as he changes the value of his own words in a lie illustrated at the end of the novel. Just as Marlow gains on Kurtz's position in the jungle, he experiences the pressures of change that bring about the fears of "evil" in him. This reluctant change not only happens inside Marlow, but it is initiated by outside forces as well. Kurtz's rhetoric, echoed by his followers in Africa, ironically accelerates Marlow's unwilling transformation by gradually uncovering Kurtz's actual identity. As a facet of Marlow, Kurtz represents the "dark" side of Marlow's potential fate (AlDabbagh). Because of these subsequent identity transformations, Marlow, like Carrie, reflects a lack of desire to exist in his proper class. In other words, Carrie and Marlow long to elevate themselves to something they are not. Their desire causes these identity transformations in each to develop uniquely. 
Similar to the effect that Marlow's hardships have on his identity, Carrie's encountered dilemmas influence her identity correspondingly throughout the work. It seems as if Dreiser does this to demonstrate her strong desire to change. Carrie is a girl who wants to rise above her class and become someone she is not born to be. Zender discusses Carrie's metamorphosis as the result of a series of situational problems that mold her every time she has to face them. For example, he states that the employment alternatives that she contemplates before she meets Drouet seem very attractive at first, but later, unbearable because she has seen past her earlier horizons. Furthermore, the façade of her newly acquired and improved appearance mirrors her false sense of elevated self-esteem that leads her into this spiral of identity change (Zender). Consequently, Carrie becomes keenly aware that "her manner has vastly changed" (Dreiser 236). She is also keenly aware that "men, well dressed men, some of the kind who had gazed at her indifferently from behind their polished railings and imposing office partitions- now gazed into her face with a soft light in their eyes" (236). Unlike the shy and naïve young girl from the "country", Carrie becomes a "big city" girl aware of her "commercial" value (Zender).

In the unraveling of Dreiser's Carrie and Conrad's Marlow, each author can be viewed as a cynical objector to the ways of the modern world. Although the darkness each character ventures into is aesthetically different, its similar effects on these characters are uncanny. In Sister Carrie, Dreiser illustrates a luminous beacon of industry where simple girls like Carrie could be easily overwhelmed. This "city on the rise" has many "growing commercial opportunities that give it widespread fame, which made of it a giant magnet, drawing to itself from all quarters, the hopeful and the hopeless-those who had their fortune yet to make and those whose fortunes and affairs had reached a disastrous climax elsewhere" (Dreiser 14). The conditions Dreiser creates, by which Carrie as an innocent arrives in this overwhelming place, point out how Dreiser hoped to present the dramatic effects modern life had on his main character. He reinforces his perspective on modern society in passages that seem to give false light to Carrie's situation.

In Sister Carrie, Carrie Meeber is determined to find employment with no experience or knowledge of much of anything. Her hopes are raised by "the sunlit street" as she wakes up and is reassured by the "sunshine of the morning, beneath the wide blue heavens, with a fresh wind astir" (Dreiser 33). 
Dreiser seems to be indicating that the city can present Carrie with the illusion of hope and "light." The author continues to show this illusion as Carries thinks to herself, "In the night, or the gloomy chambers of the day, fears and misgivings wax strong, but out in the sunlight there is for a time, cessation even of the terror of death" (33). In other words, daylight brings her out of the "darkness" she has constantly been facing since she arrived in Chicago. The sight of a new day and its beautiful morning are signs of hope to her. Carrie is only hypnotized by the false, glittery light of the city.

Similarly, Marlow is drawn by the hypnotic "light" of Western colonial zeal. Conrad's depiction of the deceptive "darkness" is more obvious in the jungles of Africa than in the bright lights of Dreiser's Chicago. Conrad sees the jungle as Marlow's adventure into civilization personified by Kurtz in the story. The fact that Marlow has to literally venture into a dark place is symbolic of Conrad's unique view of civilization. Marlow struggles with his desire to reach civilization and his admiration for Kurtz because he is unsure of the values he once held about him and civilization itself. As Conrad identifies with Marlow in many ways according to Al-Dabbagh, he represents his own similar struggle. Marlow (as an extension of Conrad) preaches at the beginning of the book when he says, "And this also has been one of the dark places of the earth" (Conrad 6). He continues his discussion with citations of elaborate tales of when the Romans occupied Britain. Marlow describes these conquests as fallible attempts at colonization. He criticizes them in rhetoric that reflects distaste for western imperialism. He calls this a "fascination of the abomination" (8). Marlow's point of view echoes like this: "They were no colonists; their administration was merely a squeeze, and nothing more, I suspect. They were conquerors, and for that you only want brute force - nothing to boast of, when you have it, since your strength is just an accident arising from the weakness of others" (9). In this passage, Marlow sees colonization as a form of robbery and this is what modern society personifies for him and, in effect, for Conrad himself. To him, Marlow's journey into the darkness to find "civilization" or "the light" is a failure in that the "jungle," even in the daylight, overpowers his asserted vision. His journey eventually changes his identity by compromising many of his once sacred values.

As Dreiser and Conrad introduce their readers to the journeys of each character into the "darkness," they pose many important questions about human nature, identity, and modern civilization. It seems that Dreiser's Carrie 
represents the kind of person who could easily be influenced by the illusions that a big city life can impose. She really does not know who she is as soon as she begins intertwining her life with the kind of characters that are typical of Chicago at the time. It seems that her exposure to this fast life and essentially the darkness of the city makes Carrie the kind of unstable person who is easily changed. Her identity change from small-town girl to professional actress implies that Carrie, much like anyone who ventures into the darkness, is subject to the power of the external circumstances an unfamiliar world can impose on one's human nature according to Dreiser. It seems that as soon as Carrie leaves her element, these compelling forces take over her identity and reshape it with every situation she faces.

Comparably, Marlow goes through changes in his identity as he ventures into a real darkness looking for something equivalent to Carrie-a better way of living. His search for truth and Kurtz, the representative of civilization, brings him to a crossroads of values and perspectives. The jungle, much like the city, transforms Marlow the closer he gets to his destination. He tries hard to distinguish himself from the evil of which he has been oblivious until he reaches his destination. Marlow's fears are enhanced when he discovers the real truth about Kurtz. Despite these newfound fears of becoming like Kurtz, Marlow falls into the same trap that Carrie unwittingly falls into. He compromises his identity and is equally overwhelmed by the darkness. Unlike Carrie though, Marlow realizes his identity change but reasons with it in his own way. In this respect, Conrad's struggles are more apparent in Marlow's character than Dreiser's are in Carrie's character. He grapples with the restraint that Marlow shows in contradiction to Kurtz's lack of it and sees it as a value that is demonstrated at the end with a lie in contradiction to its purpose.

Dreiser's Carrie and Conrad's Marlow are tragic characters that seem to lose their identities in the search for something better. It seems as though these two authors similarly see human nature as a fragile force that pushes us toward the darkness sometimes. It seems as if Dreiser creates a character that becomes subconsciously irrational and, by virtue of her naïve desire, ventures into a modern world of imminent danger and evil. This push causes Carrie to compromise her well being in order to accomplish the false illusion of better status in a modern society. She risks and loses her identity for a chance to live outside the reach of her original position in life. Similarly, Marlow makes the same journey into the darkness to find higher meaning and civilization per- 
sonified by Kurtz, whom he believes is the answer to all his questions. This similar notion of achieving a better life is motivated by Marlow's fascination with the jungle as if there was a beacon of light at the heart of it. Just like Carrie, Marlow ventures into the jungle with an air of irrationality that attracts his desire to seek the truth. Dreiser and Conrad affirm the notion that civilization as they know it was at the heart of a jungle now. They know it as the darkness even if it is encountered in broad daylight. They know that as Carrie and Marlow search for the notion of a better and more civilized and elevated life, their identities will change or be compromised. In Sister Carrie and Heart of Darkness, it is apparent to Conrad and Dreiser, respectively, that we can never escape the imposing juggernaut of industry and ever-changing civilization that inevitably alters us throughout time. In many ways these authors see a little bit of Carrie and Marlow in all of us who venture into the hypnotic lights of our very own daylight darkness. 
Al-Dabbagh, Abdulla. "Going Native: Conrad and Postcolonial Discourse." English Language Notes 39.4 (2002).

Conrad, Joseph. Heart of Darkness. New York: Bantam Classic, 1981.

Dreiser, Theodore. Sister Carrie. New York: Signet Classic, 2000.

Zender, Karl F. "Walking Away from the Impossible Thing: Identity and Denial in Sister Carrie." Studies in the Novel 30.1 (1998). 


\section{The Role of Emotional Intelligence in Care Ethics}

Lee Parish-Butler, a Liberal Studies major intending to graduate in May 2004, wrote this paper for Dr. Jennifer Greene's Ethics in Community course.

In his Grounding for the Metaphysics of Morals, Immanuel Kant claims that a truly binding moral law cannot be based in any way upon "the nature of man nor in the circumstances of the world in which the man is placed, but must be sought a priori solely in the concepts of pure reason" (828). For Kant and many other philosophers ethical principles may only be devised using humanity's logical reasoning capacities. Yet, the human animal possesses more capacities than logical reason alone, and in particular, emotion. It seems fallacious to deny that human emotion is and ought to be one of the guiding forces behind our ethical decision-making. Nevertheless, our faculties of emotion have been relegated to a sort of second-class citizenship in the study of ethics, and the inclusion of emotional considerations is seen as a muddying of the pure waters of philosophy. However, the traditionally patriarchal view that a human being is rational only when freed from his feelings has begun to give way to a concept which I will refer to as emotional intelligence. From the idea that emotion is tied to human reasoning ability, it is possible to determine a means by which emotion may be legitimately included in the study of ethics. The field of care ethics from its very inception has included emotions, or feelings, in ethical decision-making. Therefore, instead of attempting the onerous task of creating a new form of ethics or attempting to change those already existing, this essay is intended as an endeavor to discern the role of emotional intelligence within the realm of care ethics.

The term emotional intelligence, while it may be used in various ways by different people, is here intended to refer to the way in which people use emotions and feelings in their reasoning process. The inclusion of emotional intelligence in the study of philosophy is not completely new but according to Brian McMullen in his article "Emotional Intelligence," can be found as early as the writings of Aristotle (1). Elizabeth Spelman claims in her essay "Virtue of Feeling and Feeling of Virtue" that Aristotle illustrated how "many of our emotions locate us in moral relation to one another" (220). Perhaps not surprisingly there have been studies undertaken to determine the role that emotion 
plays in our thinking process. One result of such a study has been the coining of the term EQ, which is similar to one's IQ (McMullen 2). In his article, McMullen gives further evidence of the link between emotion and reasoning capacities, citing the case of an individual with a brain injury that caused "emotional impairment" resulting in the fact that "his rational decision making abilities were affected even though he continued to score highly on cognitive tests" (2). This demonstrates that emotions, in fact, do not hamper one's reasoning abilities but are instead an integral aspect of them.

To establish further an understanding of the meaning and role of emotional intelligence, it is important to distinguish between using one's emotions in the reasoning process and being ruled by one's passions. To consider one's feelings in a situation is not the same as to allow one to descend into mere sentimentality or simply to react out of base passion. Nel Noddings writes in Caring: A Feminine Approach To Ethics \& Moral Education, "Jean-Peal Sartre calls this sort of behavior 'degradation of the consciousness'" (34). Noddings illustrates that this "leads us to infer a movement from higher to lower" (34). Instead of allowing the inclusion of emotions to create such degradation, what we should seek is a "lateral move" (34). Rather than being "a movement from appropriate and/or effective to inappropriate and/or ineffective," the proper use of emotion would have results that Noddings calls "affective-receptive" (34). In such a state the effectiveness of the use of emotional intelligence is tied to one's ability to engage in relationships. Noddings claims that it is out of our initial feeling of care towards another person or towards our moral selves that ethics grows, stating, "There can be no ethical sentiment without the initial, enabling sentiment" (79). In that moment when we first approach a situation and begin to make ethical calculations our emotional intelligence is activated, thus emotions act as our primary moral compass. The union of the enabling sentiment and the affective-receptive mode moves us into the realm of relationship, which is central to care ethics.

Care ethics has its roots in the development of feminist philosophy based largely on the concept of maternal thinking. The earliest ideas were formed out of the understanding that it has traditionally been mothers who engage in the day to day caring of individuals in a family. As Noddings asserts, "caregiving was universally expected of women, and those few who refused to meet that expectation were regarded as unnatural" ("The Care Tradition" 29). Furthermore, while mothers were generally considered more nurturing and 
emotionally engaging, fathers were stereotypically seen as more rational and logical. Such differences were once considered part of the very nature of males and females. In Feminist Thought, Rosemarie Tong points out the traditionally perceived places of reason and emotion according to gender in her discussion of Rousseau's work Émile (14). She discusses the ways in which men were encouraged to follow rational and logical pursuits, while women were expected to cultivate more emotionally based disciplines and develop those skills which would better enable them to be good homemakers and caregivers (Tong 14-15). However, emotions were not only considered more a part of the feminine nature, they were considered less a part of masculine nature and thus less associated with reason, because emotions were seen as being in opposition to reason. Even Sara Ruddick acknowledges in her book Maternal Thinking that she perceives her emotions and desires to be "irrational" and something to be overcome (3).

It is from this framework perception of the woman/mother that much of the concept of care ethics is derived. Mothers have held the primary responsibility for raising children and providing them with the fundamental training for living in the world. An essential aspect of that training in morality is, as Ruddick indicates, that "many mothers find that the central challenge of mothering lies in training a child to be the kind of person whom others accept and whom the mothers themselves can actively appreciate" (104). Certainly, this acceptance and appreciation goes beyond admiration of mere accomplishments to the desire that one's child be of sound moral character.

We must now concern ourselves with the nature of the moral education that mothers provide to their children and whether or not it is grounded in emotional intelligence or if it follows a more patriarchal form of logical reasoning. Paul Smeyers points out in "'Care' and Wider Ethical Issues" that when making ethical decisions women "will often in giving reasons point to feelings, needs, impressions and a sense of personal ideal rather than the universal principles and their application" (3). Such statements make it clear that women tend to use emotional intelligence in ethical practice. If women are teaching according to what they follow themselves, then we may conclude that the morality in which women/mothers are training us includes emotional intelligence.

Our earliest learning, moral or otherwise, takes place in the home, which Ruddick calls the "headquarters" for mothers (87). The importance of the home in the role of emotional intelligence in ethics is underscored by the fact 
that, as Ruddick writes, "home is where children are supposed to return when the world turns heartless" (87). Thus, when we face an immoral world, we perceive it to be heartless or unfeeling and we therefore return to the emotionally laden, safe, and loving environment of the home as created by the woman/mother.

It is in relationships that the mother cares for the child, and it is largely through relationships that ethics are brought into practice in the world. Ethics does not take place in a vacuum or simply within our minds, but rather the entire purpose behind ethics is to provide us with the proper tools to act. According to Spelman, "our emotions reveal how seriously we take the concerns of others, what we take to be our responsibility for others' plight, and the extent to which we regard others as even having points of view we need to take seriously" (220). From this we can draw three points that would seemingly advocate the use of emotional intelligence in ethics. First, our moral behavior toward others is dependent upon our emotions. Second, our emotions affect our perceptions of duty. Finally, our emotional perceptions determine whether we consider others autonomous individuals deserving of ethical treatment.

The quality of the relationship is also of important consideration in ethics and is further tied to emotion. Spelman points out that there is a difference between a case in which I hurt you and one in which I hurt my father (221). There is an ethical difference, which may be largely grounded in feelings, in that I have a greater duty to behave morally towards my father than I do to you. Additionally, since my father and I have a different relationship than you and $\mathrm{I}$, there is an emotional difference in the way we each feel about the injury. Virginia Held points out in "Caring Relations and Principle of Justice" that if asked why we care about our children, we will respond "because she is my child" as opposed to "because she has a conscious life, like all children" (70). Such examples help to illustrate the point that our emotions, and thus emotional intelligence, tie directly into the reasons why we should treat people ethically. It is not enough to say that an individual is a rational being and thus worthy of ethical treatment, because in fact we generally place greater importance on the proper ethical treatment of those with whom we have special relationships.

Some of traditional philosophy has focused on the importance of ethical behavior in duty to the self, meaning that we owe it to ourselves to behave morally towards others in order that we are not corrupted. This traditional 
view often fails to account for the relationships that are occurring. Care ethics, however, focuses much more on how the morality of our actions affects others in caring relationship. It is in the act of caring that emotional intelligence becomes of utmost importance. According to Noddings "Caring involves stepping out of one's own personal frame of reference into the other's. When we care, we consider the other's point of view" (Caring 24). This sort of stepping into another's shoes means that we must consider not only their logically based perceptions of our actions in relation to them, but that we must also consider the emotional impact that our actions might have. We do need to consider the probable consequences of our actions, not just in a utilitarian manner, but also in the manner of care. While a utilitarian might be concerned with consequences in terms of the greatest good, a care ethicist must be concerned with the feelings of the other person. Furthermore, the one who acts must consider the impact upon himself or herself as Noddings writes:

As one-caring I am not seeking justification for my action; I am not standing alone before some tribunal. What I seek is completion in the other - the sense of being cared for and, I hope, the renewed commitment of the cared-for to turn about and act as one-caring in the circles and chains within which he is defined. Thus, I am not justified but somehow fulfilled and completed in my own life and in the lives of those I have thus influenced. (95)

Thus, the application of care ethics is concerned with the way in which our actions impact those towards whom we act; and how the impact of our actions will come full circle to effect us either through the direct actions of the other in response or in the relationship in which one engages with oneself. The completion of which Noddings speaks is not one of being able to defend one's actions before some ethical standard, but instead is concerned with the emotional fulfillment of both oneself and the other.

Smeyers writes about the "ought" of our ethical behavior as resulting out of our feelings of caring and how, insofar as our actions are likely to "increase or decrease" our sense of caring, we view them as being ethical or not (4). Beyond this, Smeyers asserts that care "means that we pay attention to others' needs, that we take up our responsibility to do something about these" (11). So, our sense of ethical duty is once again not drawn from some requirement 
to follow a particular set of rules, but is instead born out of a sense of feeling compassion for others and respect for their feelings.

Many moral theories, most particularly Kant's, seek to provide us with a template that can be imposed onto any particular situation and thus provide us the means to arrive at a proper ethical decision. This sense of objective universalism is at the very center of much of the study of ethics. It seems that what has been sought has been some sort of rulebook for human behavior, but such pursuits fail to adequately address the extreme specificity of any given situation. Noddings points out that such a system might give us a clean "mathematical appearance, but it also moves discussion beyond the sphere of actual human activity and the feeling that pervades such activity" (1). In fact, a large part of the human condition is that we live in an ever-changing world with innumerable variables at play. Furthermore, we all exist subjectively thus making objective theories merely that, theories. Perhaps these theories can provide us with a sort of macro view of how to proceed through life and of the human condition, but they fail to be practically applicable. As Noddings points out, "Moral decisions are, after all, made in real situations; they are qualitatively different from the solution of geometry problems" (Caring 3). Therefore, the mathematical template approach to ethics fails in its lack of considerations for the specifics of a situation, particularly the emotional impact created by attempted use of a formulaic approach. Certainly, we can see that it is not enough to claim that "I thought I was doing the right thing, and I followed the rules for ethical behavior," even if one's actions in fact have negative consequences on the lives or emotions of others or oneself. The point is that we must be considerate of the feelings of others and in order to do so we must use feelings and emotional intelligence in order to understand how emotions will play into a given situation.

The ability to defend our use of emotional intelligence is important because, according to Noddings, "When we care, we should, ideally, be able to present reasons for our action/inaction which would persuade a reasonable, disinterested observer that we have acted in behalf of the cared-for" (Caring 23). In other words, our use of emotion in deciding on right action must reflect an ethical basis. Again, the rigidity of rule based theories fails to account for the unpredictable nature of life. In order for us to actually live ethical lives, it seems that we must have a more applicable ethical formula, malleable to specific circumstances. A realistic ethical theory must recognize our emotional 
reasoning capabilities and the subjectivity of human existence. The field of care ethics helps to remove ethics from a seemingly sterile realm of theory and bring it into a more practical and applicable state. The basic idea is that as we make actual ethical decisions in the real world we necessarily consider our relationship to those with whom we interact, and that we consider the ways that we feel about a situation and those involved. The use of emotional intelligence in this way may not bring us to a perfect, objective moral theory freed from the tyranny of the empirical, but such an ethical approach to life has the greater potential for actual application. A moral theory that is unusable is as useless as the theoretical frictionless airplane wing. Both may be beautiful in their perfection, but if we cannot bring either into the real world, then neither will take us anywhere.

We are creatures of emotion as well as logic. In order to live fully we must use all of the abilities given to us. In order to live ethically we must likewise use all of the capacities that we have at hand to make choices. Emotional intelligence has a legitimate role to play in the world of ethics, and care ethics provides us with a start toward understanding that role. 
Held, Virginia. "Caring Relations and Principles of Justice." Controversies in Feminism. Ed. James P. Sterba. Lanham: Rowman \& Littlefield, 2001. $67-81$.

Kant, Immanuel. "Grounding for the Metaphysics of Morals." Classics of Western Philosophy. Ed. Stephen M. Cahn. 5th ed. Indianapolis: Hackett Publishing. 1999. 827-866.

McMullen, Brian. "Emotional Intelligence." Student BMJ 11 (2003):1820.

Noddings, Nell. "The Care Tradition: Beyond 'Add Women and Stir'." Theory Into Practice 40 (2001): 29-34.

--.- Caring: A Feminine Approach to Ethics \& Moral Education. Berkeley: University of California Press, 1984.

Ruddick, Sara. Maternal Thinking. Boston: Beacon Press, 1989.

Smeyers, Paul. " 'Care' and Wider Ethical Issues." Journal of Philosophy of Education 33 (1999): 233-242.

Spelman, Elizabeth V. "The Virtue of Feeling and the Feeling of Virtue." Feminist Ethics. Ed. Claudia Card. Lawrence: University Press of Kansas, 1991. 213-232.

Tong, Rosemarie. Feminist Thought. Boulder: Westview Press, 1989. 


\section{The Phenomenon of the Unreliable Narrator as Used by Irving and Poe}

Aricel Guerrero, a Liberal Studies major intending to graduate in the fall of 2004, wrote the following paper for Dr: Catherine Rainwater's American Literature I course.

When a reader becomes involved with a story, he or she expects to find certain rules used throughout the text to aid their individual understanding of events and characters. Characters are expected to be explained and analyzed; clues are expected to be dropped concerning the setting and the time frame a story references. A sound conclusion is almost demanded by the reader to provide a sense of closure to his or her account of what really happened in the story. Since the reader looks for this systematic continuity throughout a text, Washington Irving and Edgar Allan Poe attempt to remove this feeling of reader comfort from their literature. They in turn want the reader to question whether the events really happened or whether they were all fantasy or delusion. Irving and Poe play this game by allowing the narrators of their stories to be of questionable status. Since they understand readers rely on the credibility of the narrator to fill in the missing pieces by dropping little hints and projecting an unbiased yet truthful account, Irving and Poe attempt to create a narrator that does none of these things. The creation and use of the unreliable narrator turns the reader's sense of truth upside down. Both Irving's "Rip Van Winkle" and Poe's "The Fall of the House of Usher" demonstrate how the reader's understanding of the events in the story can be skewed when their ability to trust in the narrator is compromised.

Irving is the original creator of the unreliable narrator. The earnest, pleasant, and sincere tone he gives his narrators initially causes the reader's suspicion of the narrator's credibility. Perhaps because he tries so hard to make one believe that he is telling the truth, the reader finds cause to raise an eyebrow. In his piece entitled "Rip Van Winkle," Irving begins his account by immediately stating that the story is not in fact his own but was found among some old papers of a New York gentleman. This disclaimer is interesting because it is given before the story even starts, shifting the spotlight from the author (narrator) to a completely different party, Diedrich Knickerbocker. The narrator 
wants the reader to know who he considers responsible for the tale. This Knickerbocker is explained as a man "very curious in the Dutch history" (Irving 637). He is not considered a true historian in the sense that he should look for concrete evidence in books or old documents. Instead, he looked for evidence "among men; for the former are lamentably scanty on his favorite topics" (637). It is apparent that Knickerbocker was not too worried with truths, but instead with "that legendary lore, so invaluable to true history" (637). Tales of mystery and fantasy seem more important to him than those events that occurred daily among a people of a new, growing nation.

While the narrator makes obvious that Knickerbocker's "facts" are more like folklore, he later attests to their truth. As he admits, Knickerbocker's documents were not at first wholly believed, though later they had been determined to be "a book of unquestionable authority" (Irving 637). So far, it is obvious that the narrator cannot make up his mind. As stated earlier, he begins his story with a disclaimer, stating that the story is not originally his, but that of a man who loves folklore. Then, he goes on to say that the stories and accounts published by the author are in fact the most accurate of any account there could be. Again, he contradicts his case by explaining Knickerbocker to be a flighty man, obsessed with his work. While this work was important to Knickerbocker, others saw that "his time might have been much better employed in weightier labors" (637). The narrator finishes this ambiguous description of Knickerbocker as someone who the critics were always pulling apart. Yet, it is important to realize that his memory "is still held dear by many folks, whose good opinion is well worth having" (637). After all, even the bakers especially wanted to give him "a chance for immortality" for all his hard work (638). It is obvious that the narrator is trying to shake the ground that the reader stands on for this story.

Throughout the story, the narrator does not make too many personal comments outside of the actual story line. However, once again, at the end of the short story, Irving supplies the reader with last minute notes to further demonstrate the story's truth. It is not enough that the reader was already given a disclaimer before engaging in the actual story; this truth must be emphasized again. The repetition of "factual" information in this piece only makes the reader more suspicious. The narrator even alerts the audience of an account given by Knickerbocker, who agrees that the original legend "may seem incredible to many, but nevertheless I give it my full belief" (Irving 649). To 
Knickerbocker, it is obvious that Dutch settlements "have been very subject to marvelous events and appearances," making this kind of a wild legend a possible occurrence in their society (649). He feels certain that others will believe this story. Of course, one cannot overlook that Knickerbocker has done his research and actually talked to old Rip Van Winkle. The description of him in the story, making him look like a dreamer and a lazy man, contradicts the fact that Knickerbocker finds him to be "perfectly rational and consistent" (649). The narrator's addition of "necessary notes" to demonstrate Knickerbocker's and his own reliability only further incriminates the pair.

In Irving's tradition, Poe runs with the idea of the unreliable narrator. $\mathrm{He}$ loves nothing more than to cause his audience unease and a sense of incredulity at events. This style of his is amplified in his story "The Fall of the House of Usher." The aspect that really makes this story work so well for this technique is the fact that the narrator does seem of sound mind in the beginning. Because he is a great guy, he is going to go help out his friend who expresses "an earnest desire to see me, as his best, and indeed his only personal friend, with a view of attempting, by the cheerfulness of my society some alleviation of his malady" (Poe 772). This sounds innocent enough, but not far into the story, the reader begins to notice that the narrator has some quirks of his own. His first mistake is to liken his gloomy feelings about Usher's house to that of "the after-dream of the reveller upon opium" (772). It is obvious how unreliable drug addicts are. As the narrator becomes reacquainted with this friend he has not seen since childhood (another strange fact), he attests to his friend's suffering from "morbid acuteness of the senses" (775). He later realizes that Usher's ill sister is affecting his sanity as well. As Usher's deterioration continues, the narrator's own insanity becomes more apparent. It is strange that he would not remember that Usher had a twin sister. Also, the narrator explains to the reader, "For several days ensuing, her name was unmentioned by either Usher or myself" (776). If there were a dying relative in the house, most people would be incredibly attentive to that individual, rather than avoiding the mention of his or her name.

While the narrator slowly makes his case of sanity to the reader in the beginning of the story, he wastes no time in joining Usher's madhouse towards the end. After being informed of Madeline's death, the narrator agrees to Usher's plans to bury her in the basement because they were "harmless, and by no means unnatural" (Poe 780). They agree that the death should be hidden 
from the doctors, who were of a "sinister countenance," and for some reason they feel compelled to look at Madeline's dead, un-embalmed body (780). The narrator admits that after doing this, Usher becomes even more weird, and even the narrator is affected by "the wild influences of his own fantastic yet impressive superstitions" (781). His sleepless nights find him "overpowered by an intense sentiment of horror, unaccountable yet unendurable" (781). Things only progressively get worse.

On the final night of horror, the narrator makes the reader feel that everything rational comes crashing down on the two friends. They both begin to see a strange "visible gaseous exhalation" hanging around the house (Poe 782). To soothe Usher, the narrator reads aloud passages from the "Mad Trist," a horrible choice. Through the reading they are hearing noises mimicked in the text. They try to rationalize them, and they ultimately become more and more wild with fright. Finally, the narrator sees the bloody body of Madeline enter the room and "in her violent and now final death agonies" she literally scares Usher to death (784). At this point, the narrator is so frightened that "[he] fled aghast," only to turn around and watch the house crumble (784). It does not make much sense to stand in the middle of a storm to watch a house fall to pieces after seeing one's friends flee in terror and die. Poe was obviously having fun in creating a narrator that seemed at first so concerned and normal, only to reveal to the reader that he was another version of his crazy friend. Readers cannot navigate or distinguish between the facts of the actual events of this story and the fiction of the narrator's imagination.

Washington Irving and Edgar Allan Poe both knew exactly what they were doing when they created their narrators for "Rip Van Winkle" and "The Fall of the House of Usher". They wanted to transport the reader out of the world of truth and reality to one where that truth in statements and meaning was really not discernible. It is an uncomfortable feeling for a reader to not have that voice of reason relaying the story of the fantastic characters. Without the reader's ability to find a basis of reality, a story can quickly become confusing and suspicious. Irving, who was commonly influenced by German folklore, easily created that feeling of confusion when he placed his disclaimers at the very beginning and very end of the story. That overcompensation to make the reader aware of the text's truth is also that which the reader immediately notices. Poe, on the other hand, strategically placed little details within the narrator's explanations to slowly discredit him. Perhaps they both wanted to demonstrate 
that individual perception interferes with the relaying of actual events. It is hard to know what has really happened when a person can only learn of an account. What makes a storyteller trustworthy? Although both authors use different devices, the unreliability of the narrator becomes a new and important literary technique. 
Irving, Washington. "Rip Van Winkle." Anthology of American Literature.

Ed. George McMichael. 8th ed. New Jersey: Pearson Education, 2004. 637-650.

Poe, Edgar Allan. "The Fall of the House of Usher." Anthology of American

Literature. Ed. George McMichael. 8th ed. New Jersey: Pearson Education, 2004. 771-785. 


\section{On Sleeping With Friends}

"What I'm saying is - and this is not a come-on in any way, shape or formis that men and women can't be friends because the sex part always gets in the way."

\section{-When Harry Met Sally}

A recent story in New York Magazine caught my eye. Entitled "The New Position on Casual Sex," it aimed to inform the reader of the new sexual openness brought about by the rise of Internet dating services. The author, Vanessa Grigoriadis, recounted the experiences of numerous New York City women who utilized various online dating services as means of acquiring quick dates and quick sex. In the passage most disturbing to me, a young woman said, "I don't want to give men that I might want to date the wrong idea by having sex with them, but I don't want to live without sex." She went on to add, "Now, isn't that the most bizarre twenty-first-century quandary?" (Grigoriadis).

I'll concede that it is a quandary, but not in the way she intended. Rather, what struck me as odd was this woman's unwillingness to sleep with the guys she already knew and in whom she was interested. Lost in my 1950s-style ideas of courtship, I thought people were supposed to sleep with those they're interested in - friends, dating partners, not just random folks they thought looked good in grainy online photographs. So I did what any young male does who feels that he is soon-to-be marginalized in the dating and sex scenes; I complained to my female friends and begged them for clarification.

"Why," I asked them, "would you sleep with a random guy instead of a friend or a guy you are interested in?"

"Easy," they replied after calming me down and forcing me to speak more slowly. "We don't want to have sex with someone we're really interested in too early because it takes the relationship to a level it isn't ready for."

I mulled this over and decided, "I can understand that logically and still think it's completely ridiculous, can't I?"

The struggle here is not to come off sounding like just another angry guy who's tired of having loads of friends who are girls but never any girlfriends. While, in the abstract, seeking sexual gratification from people you don't know and reserving friends for emotional gratification seems fine, looking at the 
conundrum more closely forces one to wonder, "Why can't friendships encompass both?" I do indeed believe friendships can and should be used to the full extent of emotional and sexual gratification, especially if someone is so desperate that he or she must call up random people from Internet personal ads for sex. However, there are those who disagree.

Talk to almost anyone, especially a girl, and the person will tell you how friends shouldn't have sex with friends. Almost in an ironic play on the antidrinking and driving motto, "Friends Don't Let Friends Drive Drunk," society's conventional wisdom seems to be that "Friends Don't Sleep With Friends." Or, at least, they shouldn't sleep with friends. More often it seems an ideal of which we regularly fall short. But why does this limitation exist? Why the strict distinction between friendship and romance? Why the almost automatic rejection of a dual-use friendship?

Invariably, the predictions of many lay persons focus on the passionate desperation that follows a failure to achieve the ideal of a clear separation between one's friendships and romantic relationships. These predictions often include the belief that there will be an expectation of one member of the friendship desiring more intimacy with the other, an increasing amount of awkwardness stemming from the beloved's not sharing the lover's feelings, and, ultimately, the end of the friendship.

It might be proper to begin by noting that only in conversations with women have I found the "no sex with friends" stance prevalent. While I do not intend this to reflect a scientific study conducted on my part, the random sampling of individuals around the St. Edward's University campus and the city of Austin that $\mathrm{I}$ have spoken to regarding this issue has divided along gender lines as to views in regards to sleeping with friends. No male respondent agreed with the distinction between relationship and physical intimacy roles, and few females crossed over from the "no sex with friends" camp to agree with the male viewpoint. This may be because, as Dr. Lillian B. Rubin, a researcher, writer, and counselor on relationship issues, reports, "For a woman, there's no satisfactory sex without an emotional connection; for a man, the two are more easily separated" (101). Indeed, if, as Rubin goes on to state, "women depend on the emotional attachment to call up the sexual, [and] men rely on the sexual to spark the emotional," the reasons for this division become clearer (104). This extends into the gay and lesbian world where homosexual men derive pleasure from anonymous sexual encounters more often than do homosexual 
females (105). Reasons for this stem from males' and females' differing attachments and identifications in early childhood. On the other hand, more scientific research has found that a majority of men also believe that sex inside a platonic relationship leads to negative outcomes (Afifi and Faulkner 208). Either way, this should not be construed as meaning that women are less sexual than men or that all members of either sex fall into these prescribed categories. There are always exceptions. Indeed, the New York Magazine article quoted above quickly bears this out.

On the contrary, I believe having sex with a friend does not necessarily lead to the end of the friendship. While some researchers and many lay persons have argued that having sex with a friend moves the relationship from the platonic to the romantic level, little quantitative data exist to verify this (Afifi and Faulkner 206). Much more evidence is available that links the sexual attraction of one friend to the other as being a prevalent factor of cross-sex friendships (friendships comprised of two people of opposite sex) (205). Indeed, to the possible revulsion of some of my female friends, I often find that quite a lot of our friendship, especially in the beginning stages, is/was based on my own sexual attraction to them. A recent study conducted by Dr. Walid A. Afifi, a speech communications professor, and Sandra L. Faulkner, a researcher at East Carolina University, found that $51 \%$ of platonic respondents ("people who were not dating at the time and had no intentions of dating at the time,") had engaged in sexual activity, and $34 \%$ claimed to have engaged in sexual activity with an opposite sex friend on multiple occasions, whether that be with more than one friend or the same friend numerous times (217). Their study also produced findings that challenge the usual assertion that sleeping with friends inevitably hurts the friendship. Sixty-seven percent of the participants reported an increase in the quality of the relationship after the sexual encounter with the majority of these not evolving into romantic relationships (218). Another study conducted at the University of Michigan found "no difference in the quality of friendship between men and women that involved sexual relationships and those that did not" (Elkins and Peterson). As the first argument always trotted out by believers in the sanctity of friendships, the corrupting effect sex has upon that hallowed interpersonal territory does not quite wash when viewed through the lens of science. Increasingly, the support for abstaining from sleeping with friends appears to derive from specific individuals' experiences rather than the existence of a general causal relation, thus 
begging the question, "Why, if a majority of platonic sexual encounters end in relationship-enhancement, do some others end so horribly?"

My own experiences in sleeping with friends corroborate this data. As a matter of fact, few people I discussed this topic with would admit to sex having a detrimental effect on their friendships. There are even those who regularly engage in "no-strings" sexual activity with friends and others as a way around the responsibility and large consumption of time that a full-blown relationship entails. One might think that with so much empirical data floating around the world, sexual friendships would be more well-respected and popular. But, still, the cliché persists: having sex with friends is bad because it leads to awkwardness, and those afflicted with the negative effects of sex between friends vaguely repeat. One might ask, then, "Why does sex cause this awkwardness?" If, as shown above, sex does not always cause awkwardness, it may be more appropriate to ask, "What is this awkwardness?" Possibly a cause can be found in the definition.

Much of the awkwardness seems to arise from an uncertainty about the relationship, and the direction it is taking, agreements between parties, reciprocal responsibilities of the parties, jealousy, et cetera. It may be because we are so used to seeing or assuming romantic relationships evolve from platonic friendships, that cross-sex friends are afraid to hold State of the Union discussions, an important aspect of healthy interpersonal interaction (Afifi and Burgoon). There is a great body of literature discussing topic avoidance, the shrinking from broaching certain subjects that might bring discomfort to one or both participants, in cross-sex friends' conversations. This paper avoids this topic. It is important to recognize, though, the significant positive impact communication between friends can have both before and after a sexual encounter. Indeed, many researchers have found that self-disclosure, the discussion with a friend of relationship issues, negative life experiences, dating and sexual experiences, etc., is considered the most important aspect of intimacy in friendships (Afifi and Guerrero).

Friendships should be redefined to describe what they include, not what they exclude. The facts show that a clearer definition of friendship values emotional intimacy bound up with self-disclosure over a lack of sexual intimacy. Indeed, sexual intimacy among friends, it appears, can have a positive effect on friendships too, especially if they are already communicating openly with one another about their relationship. Writing off sex as harmful is a poor 
excuse for refusing to understand the underlying issues that make sleeping with a friend a detrimental experience. Sleeping with friends is not a blackand-white endeavor. Depending on the individuals involved and their willingness to openly discuss their relationship, the challenge of sexual intimacy can have either a positive or negative effect on the relationship (Monsour 145). The oft-spoken cliché that friendships can't survive sexual encounters without becoming romantically involved just isn't true.

In my experience, the most harmful aspect of sleeping with friends is the fact that, thanks to the societal paradigm we operate under which denies us this free expression of our sexual appetites, it often takes place under the influence of heavy amounts of alcohol or other drugs. This leads, inevitably, to a sexual experience that is embarrassing to the participants-who may or may not have bragged about their sexual prowess to one another at other times. In my opinion, we need "pre-emptive sexual strikes" meant to improve the experience of sleeping with friends by having sex while sober, when the act isn't just a release of hormonal urges, but, rather, an expression of physical intimacy intended to match the emotional intimacy we desire in our friendships. Otherwise, we might as well all be strangers. 
Afifi, Walid and J. K Burgoon. "We never talk about that: A comparison of cross-sex friendships and dating relationships on uncertainty and topic avoidance." Personal Relationships 5 (1998): 255-272.

Afifi, Walid and Faulkner, L. Sandra. (2000). "On being 'just friends': The frequency and impact of sexual activity in cross-sex friendships." Journal of Social and Personal Relationships 17.2 (2000): 205-222.

Afifi, Walid and Guerrero, K. Laura. "Some Things Are Better Left Unsaid II: Topic Avoidance in Friendships." Communication Quarterly 46.3 (1998): 231-249.

Elkins, Leigh E., and Christopher Peterson. (1993). "Gender Differences in Best Friendships." Sex Roles 29 (1993): 497-508.

Grigoriadis, Vanessa. "The New Position on Casual Sex." New York Magazine. 13 Jan. 2003 <http://www.metronewyork.com/nymetro/news/features/n_8227/>.

Monsour, Michael. (2002). Women and Men as Friends: Relationships Across the Life Span in the 21st Century. Mahwah, NJ: Lawrence Erlbaum Associates.

When Harry Met Sally. Dir. Rob Reiner. Perf. Billy Crystal, Meg Ryan. Warner Brothers, 1989.

Rubin, Lillian B. Intimate Strangers: Men and Women Together. Philadelphia: Harper \& Row, 1984. 


\section{Nihilism in Doctor Faustus and Steppenwolf: The Struggle for Transcendence}

Paul Hagey, who graduated with a B.S. in Biochemistry in 2002, has nearly completed SEU's Master of Liberal Arts program. This paper was written for Dr. William Zanardi's Great Books: Nihilism in the 20th Century course.

"A sign of the lack of strength to posit for oneself, productively a goal, a why, a faith" - thus Nietzsche writes of the character of nihilism in The Will to Power (18). Nihilism was the result of significant cultural change combined with inadequate cultural reasoning, a combination that left many members of society feeling impotent in their life. This weakness fostered a strong desire for understanding and change. For an individual to confront this situation a transformation was required, both internally and externally: to reconcile personal and cultural meaning to existence. In the novels and lives of two coeval modern German authors, Thomas Mann (1875-1955) and Hermann Hesse (1877-1962), the effort to transcend this nihilism is evident. In Steppenwolf and Doctor Faustus Hesse and Mann relate the story of an individual determined to transcend the nihilism of his age. The dilemma of nihilism, a factor of Western intellectual consciousness for nearly two centuries, is typified by the estrangement resulting from the attempt to answer the general question: Where (what) is the foundation for creating a meaningful existence when the cultural method of reasoning is incomprehensible and degenerate? Through faith and reason Mann and Hesse struggle to recreate meaning in their existence. Their art represents their distinct experience of nihilism and their effort to transcend it.

Mann and Hesse lived during an intense period of the nihilist movement. Nihilism was the philosophy of an era in which culture failed to create a healthy society. This caused a deep feeling of estrangement between many individuals and their culture in the modern age. A large part of the basis for such a culture was the manner in which the process of reasoning had then developed in Western society. The efficacy of reason characterized the modus operandi of the modern age in Western culture, governed primarily by pragmatic thought. The twentieth century began in a promise of utility, with the economics of the industrial revolution taking shape and the consequent power 
of secular politics, technology, and science causing a cultural confidence to develop with regard to many aspects of existence. Confidence in this rationalism, in which cause and effect were linked via a utilitarian, rational reason, was founded on a faith in its efficacy. If nothing else, pragmatic thought was efficient, but not necessarily healthy - in that discrepancy lies the source of the nihilist movement. Until the tragedy of the World Wars, pragmatic reason appeared to be a good guide for society. Michael Novak discusses the discrepancy between well-being and efficiency, the disconnection between function and values, in his book The Experience of Nothingness: "The young are forced to live through the problems of technological consciousness, problems created by generations who built a rational, efficient society without calculating in advance its effect upon human beings" (8). After witnessing the ugly extremity to which pragmatism had led culture, many people refused to and could not connect to a humanity within that kind of framework.

The rational thought that developed and peaked in the first half of the twentieth century represented a change in the kind of reasoning that developed originally in Western culture. This change in the cultural relationship with reason, a mode of thought that aims at answering the question why, comprised the foundation for the experience of nihilism. The process of reasoning originally was established in Western intellectual thought in Classical Greek philosophy. Reason has metaphysical beginnings. The pursuit of knowledge via reason emerged from Plato's analysis of the ethical impulse of the individual in society. What is the origin and character of the impulse to good? Plato pondered the question: the natural drive to good does not appear to be an aspect of society in general, so then why is it present in the individual? This line of questioning established reason as a method in the search for knowledge of oneself, as a means to metaphysical ends-insight into the character of the pull to a higher good. In modernity, this original metaphysical aspect of reasoning was overshadowed by the power of pragmatic reasoning as the values of culture became depersonalized, becoming progressively more estranged from a close relationship with the individual because the social-political structure overpowered individual values. Slowly, culture lost touch with a reasoning that dealt with manifesting the values of its members; society was focusing more on the functional than on the personal. Many intellectuals could see a crisis of reasoning coming long before the climax occurred in World War II, particularly Friedrich Nietzsche. 
Western culture was caught, and is still to some extent, in an age of the psychology of nihilism, characterized by disconnection - where cultural reasoning fails to lend meaning to existence and yet remains the principal framework of cultural identity and action. When understanding one's experience is approached through the discipline of rationalism alone higher values lose intimate connection with the individual. So when society apparently acts as a collection of individuals but does not establish meaningful action, a disconnection results. The attempted objectivity of rationalism is invariably touched by subjective experience. Nietzsche describes the foundation of this psychological experience of estrangement in The Gay Science and The Will to Power. In the late 19th century Nietzsche reacted to a rationalistic culture that he saw was creating societal conditions that would lead to expectations that could never be matched by reality. Much of the intensity in his work is an indication of his frustration at knowing what could happen if the movement were not checked. In his books, Nietzsche repeatedly warns society about the danger of losing touch with healthy values. In his time he had the awareness to perceive, and the skill to describe, the psychology of nihilism; he saw the expectation of understandable answers, for certainty, via pragmatic reason in culture as unsustainable. In The Gay Science, published in 1887, he describes the extent to which reasoning had become empty in his age: "metaphysics is still needed by some; but so is that impetuous demand for certainty that today discharges itself among large numbers of people in a scientific-positivistic form" (Gay 288). The attempt to nail existence down with expectations and certainty, offered then by the culture, led many into a state of meaninglessness.

Nietzsche could foresee how these expectations would eventually, and in many ways already did in his time, clash with reality. He describes the resultant estrangement born of the dependence of personal answers on logical reasoning in a passage from The Will to Power:

What has happened, at bottom? The feeling of valuelessness was reached with the realization that the overall character of existence may not be interpreted by means of the concept of "aim," the concept of "unity," or the concept of "truth." Existence has no goal or end; any comprehensive unity in the plurality of events is lacking: the character of existence is not "true," is false. One simply lacks any reason for convincing oneself that there is a true world. Briefly: the 
categories "aim," "unity," "being" which we used to project some value into the world - we pull out again; so the world looks valueless.

Concepts and values are unreliable foundations for meaning. Even values, a morality, are often dependent on expectations and judgments of "good." Without a mature, metaphysical system that establishes meaning and awareness, values themselves help create the climate that leads to feelings that similarly created the experience of nihilism. When culture offered unreasonable expectations and certainties in values, nihilism appeared. Psychologically, nihilism is the result of an individual's reality, constructed via culture, clashing with his or her personal values. In the tragedy of the World Wars culture manifested immorality, which precipitated a personal crisis of meaning for many people.

Where does meaning lie then if not in the expression of culture? Nietzsche offers a preemptive answer, foreshadowing the dilemma facing many intellectuals in the modern age. He calls for a reformulation of values: to cultivate true reason, logical and spiritual, and to express them. In The Gay Science Nietzsche calls out for a cultural re-connection to spirituality via individuals, a more whole reasoning than then existed in the culture. Yet, he is extremely hostile to all that is referred to as "faith," "believers," and "metaphysics." However, those very ideas he reacts against are the same core components that he sees as essential to composing a whole human being, essential in the process of relieving the tension of nihilism. The apparent discrepancy lies in his problem with the definition of those words in their cultural context-he is really calling for a reformulation of their meaning. He envisions the most spiritual person as sublime-strong, confident, joyous-someone who can merge knowledge and spirit into joy: "the ideal of a spirit who plays naively - that is not deliberately but from overflowing power and abundance-with all that was hitherto called holy, good, untouchable, divine" (347). Nietzsche concludes that to deal healthily with nihilism (and existence) and its characteristic estrangement, individuals must do the work of reasoning themselves and not rely on culture, whether through religion or the political state. This process of re-reasoning he calls for is observed in the lives of the protagonists of Steppenwolf and Doctor Faustus, and in some ways in Hesse and Mann themselves. 
Like most Germans, Mann and Hesse had an extremely personal relationship with their homeland. Both of these German intellectuals, born within three years of each other in the last quarter of the 19th century, they lived through the depravity of culture that Nietzsche was screaming at his society to beware and prevent. The limits of the over-weighted pragmatic approach of reason became blaringly evident with the atrocities of World War I and World War II. Mann was more sensitive to the situation in Germany than Hesse, who had slowly detached himself from a romantic view of his homeland. In this connection to Germany, Mann's nihilism was more outwardly severe than Hesse's. Mann's opinion of German leadership became impossible to keep to himself as the Nazis started to gain power in the thirties. In 1936 he lost his citizenship in Germany because of an anti-Nazi public statement, which he describes in a letter to Hesse:

I had to show my colors by making a clear statement: for the sake of the public, among whom ambivalent, neither-fish-nor-flesh conceptions of my attitude toward the Third Reich were still prevalent, and for my own sake. The need to do something of the kind had long been with me. (Hesse 56)

It is clear that Mann experienced intense physical estrangement from Germany. Hesse, on the other hand, experienced a personal estrangement that was just as intense, if not more so than Mann's, in his general sensitivity to humanity. Mann differed in this respect from Hesse, holding on to his glorious view of Germany, and thus suffering a more personal guilt at its depravity. In a letter to Hesse in 1934, Mann reveals the effect that the events of Germany have on him: "I am in the midst of a grave crisis, both in my life and in my work. I am so plagued by the happenings of Germany, they are such a torment to my moral and critical conscience, that I seem to be unable to carry on with my current literary work" (Hesse 41).

Hesse's and Mann's values made emigration a way of life for them both: Hesse settled and gained citizenship in Switzerland after World War I, and Mann emigrated to the United States before World War II, eventually settling in California. Though they felt estranged, and were to a large extent, from Germany, they clearly saw themselves as Germans. They formed a close relationship, in large part founded on their shared political attitude and grief for 
Germany, a bond that sustained them culturally as a result of an intellectual and meaningful connection with a fellow German. After having established a respectful, professional relationship for nearly a decade since meeting circa 1904, Hesse and Mann slowly cultivated a more intimate relationship, which is illustrated in a collection of their letters titled The Hesse/Mann Letters, in which their shared frustration, confusion, and nihilism of the age are evident.

Though they both suffered with the war, Hesse and Mann had different opinions about publicly dealing with it. Hesse was a staunch pacifist, against reacting publicly to the war or any political event for that matter, a sensibility that is evident in a line he wrote to Mann: "I still don't believe that all mankind must be drawn into politics and I will defend myself to the death against being drawn into politics myself. After all, there have to be unarmed people to kill" (Hesse 58). From the previous passage it is obvious that Mann felt very different. He criticizes Hesse for his self-described apolitical stance later in a letter to him:

If 'spirit' is the principle, the power that desires the good, if it is anxious alertness to changes in the face of truth, if, in a word, it is the 'piety' that tries to come as close as possible to what is right, ordained, and fitting at a given time, then it is political, whether it likes the term or not. (Hesse 93)

Mann felt the need to reform Germany, to criticize its shortcomings and to deal publicly with its evils, while Hesse preferred to detach from personal involvement. Regardless of their differing ideas on political action in the era of Germany's cruelty, both Hesse and Mann took refuge from the tragedy of World War II in their work, and thus naturally expressed their angst and feelings in it. In their writing they were able to express and work out the unease they felt from Germany. Hesse reveals his, and many intellectuals' of the time, frustration of World War II in a 1942 letter to Mann: "time and again one is amazed at the amount of intelligence, method, and organization employed in doing insane things" (Hesse 91). Hesse's 1943 novel The Glass Bead Game was his refuge from the atrocities of the World War II era: "By concentrating on The Glass Bead Game I was able to keep myself together through the Hitler years, but when the work was done and I could no longer take refuge in it, I was left extremely vulnerable to the war of nerves that the whole world was 
raging against anything human" (Hesse 104). Similarly, Mann relied on the work of his Doctor Faustus to help him struggle with the depravity of that era. The book is interjected periodically with lamentations at the political state of Germany, interspersed and related in a style that is reminiscent of a diary entry in Dr. Zeitblom's voice:

The time of which I write was for us Germans an era of national collapse, of capitulation, of uprisings due to exhaustion, of helpless surrender into the hands of strangers. The time in which I write, which must serve me to set down these recollections here in my silence and solitude, this time has a horribly swollen belly, it carries in its womb a national catastrophe compared with which the defeat of those earlier days seems a moderate misfortune, the sensible liquidation of an unsuccessful enterprise. (336)

One may sense Mann's attachment to and despair for his German culture in this passage. The novel climaxes with the finished symphony of Adrian Leverkuhn, The Lamentation of Doctor Faustus, symbolizing all the agony and deviltry that led to Germany's forsaken state in the wake of World War II. Mann refers to Doctor Faustus in a letter to Hesse as "my glass bead game" (102).

Unsurprisingly Hesse's and Mann's feelings of Germany and the release and refuge that became their art influenced the themes of their novels. The personal exploration for re-reasoning is a general theme that both Hesse and Mann attempt to communicate in their novels Steppenwolf and Doctor Faustus. Steppenwolf and Doctor Faustus are reactions to Germany and Western culture at different stages in the modern era. Modernity was a tragic time for Germany. More than any other country, it was at the crux of both World Wars, a condition that caused its countrymen and women to experience a particularly sensitive and deep reaction to the nihilism of the age. With the appearance of the World Wars the nihilistic unrest was no longer confined within; all the anxiety of the modern age manifested itself, and the world was forced to face it.

Steppenwolf was published in 1927, eight years after the ratification of the Treaty of Versailles. It represents a work in the waning German romantic era of literature-German romanticism would soon be crushed by the ugliness of Nazism and World War II. In a passage from Steppenwolf Hesse reveals some of the cultural frustration which he, as a self-described spiritual man, must have 
felt in a culture dealing with World War I: "A man who can understand Buddha and has an intuition of the heaven and hell of humanity ought not to live in a world ruled by 'common sense' and democracy and bourgeois standards" (74). In a 1931 letter to Mann his frustration at his culture is evident, "I see things happening that strike me as absurd [in the German Republic]" (Hesse 11). His political and cultural frustration is expressed through the character of Harry Haller.

In Steppenwolf Hesse expresses his disgust at the bourgeois nature of post World War I society, which is characterized by the sad, lonely, and disillusioned life of Harry Haller. Everything bourgeois is repellent to Harry, yet he cannot escape his relative identity with it, and consequently feels stuck in a sad and estranged condition, as a wolf of the steppes. Reason for his existence in such a culture is empty, a culture in which his instinctual resolution is to "trot alone over the Steppes and now and then gorge himself with blood or to pursue a female wolf" (Hesse 48). Yet, the man in him cannot accept this bloody primeval existence alone, clinging to ideas of "goodness and refinement, and want[ing] to hear Mozart, to read poetry and to cherish human ideals" (49). Is it possible in culture to achieve a resolution? Hesse's answer is no. Hesse concludes in Steppenwolf that to become the complete man of Nietzsche, one must rise above the antipodes of society to experience the transcendent joy of the immortals through laughter - in the realm of Mozart and Goethe, where reason and spirit are not distinct, but transcended. The only way to realize joy, meaning through reasoning, is to establish a resolution within that includes the illogical, because culture could not support the existence of the human and the animal, though they both exist within man. Hesse strongly states that personal meaning may not be reached in a culture of bourgeois life, of "the never-ceasing machinery that prevents their being, like me, the critics of their own lives and recognizing the stupidity and the shallowness, the hopeless tragedy and waste of the lives they lead, and the awful ambiguity grinning over it all" (89).

Harry suffers through cultural and personal estrangement until he meets Hermine, a young woman who helps him break through his despair and reconnect with a reason to live. In this romantic relationship, Harry slowly becomes aware of what a resolution may look like. His connection with reason begins to change as Hermine introduces him to the madness and flexibility possible in life. Their relationship led Harry ultimately to enter the magic theater which prefaces its entrance with "for madmen only." There he learns the answer to transcending his existential woes. The wisdom of the magic theater is a sym- 
bol Hesse uses for the madness and mystery missing in the reasoning of bourgeois culture. Hesse concludes that there is meaning in the sublimity of culture, but to experience it one has to go above the idea of culture into a refined madness. Thus, Harry learns near the end of the book that to transcend his estrangement from the coarser aspects of culture, he must resolve his perceptions within, which is similar to what Nietzsche argues in The Gay Science: to take it upon yourself to revere and learn from the "higher" members of culture. The burden is on the individual however, in the magic theater conductor's words: "you may yourself as an artist develop the game of your life and lend it animation. You may complicate it and enrich it as you please. It is in your hands" (220). In this vein, Harry's personal connection with meaning and his transformative relationship with reason are guided by a spiritual path, learning to laugh in a state beyond culture, which the "highest" members in culture have experienced, and from whom one may learn.

Doctor Faustus is darker. Thomas Mann wrote Doctor Faustus during most of World War II. His "little novel" was finally published in 1948 after he experienced considerable difficulty finding a publisher who would/could print the German language edition. Written during the last half of World War II, Doctor Faustus recreates the well-known Faust legend in a tragedy of modernity. It is composed as a fictional biography of a German composer-the full title is Doctor Faustus: The Life of the German Composer Adrian Leverkühn as Told by a Friend. The story, narrated by Adrian Leverkühn's simpler, more bourgeois friend Dr. Zeitblom, is one of tragic searching. Adrian devotes his life to the art of composition, and through it to the complete expression of his most sincere feelings. Like Harry, who could not resolve his variegated personality alone, Adrian cannot resolve his dilemma of personal expression without help. In his search for the power of complete expression, Adrian finds the necessary inspiration impossible to encounter or experience within his culture. True to the Faust legend, he concludes that the answer lies with the devil. Mann suggests that Adrian must accept all the tragedy (darkness/evil) of the age, of humanity, to be capable of creating his meaningful work. Similar to Harry, he retreats inside himself to resolve his nihilism; however, his retreat is not romantic. Instead of love and bliss, he confronts abhorrence and harsh extremity true to the era of World War II. These two introspections differ in perspective and are evidence of the different bent of the authors; Hesse and Harry are more spiritual beings, Mann and Adrian are more intellectual beings, 
and their relationship with culture is different accordingly.

Mann is very sensitively tied to his culture and cannot/will not transcend nihilism at its expense. Thus, Adrian confronts the tragedy of the culture directly, willingly taking on its despair for the sake of meaning. For the gift of complete expression the devil takes Adrian's soul - he is forbidden love, at the gain of sincere intensity. The result of this intensity is "The Lamentation of Doctor Faustus" and Adrian's collapse into madness. The only way for Adrian to transcend his nihilism, to confront his despair squarely and his disconnection, is to take on ultimate evil, and sell his soul to the devil. The transcendent "madness" of Steppenwolf did not exist in a healthy form in Adrian's era, consequently Adrian is left with the decision to trade with the Devil to become aware of the reasonless rules that would allow one to connect to the divinity of beauty and art. It is a sign of the times: for Harry's madness he gets a woman, for Adrian's madness he gets the Devil. Doctor Faustus concludes that an interaction with the Devil is the only way to achieve meaning in post-World War II German culture. No other conception would make sense. It appears to be the only way to reason the circumstance that Germany and the Western world had found itself in. In his symphony "The Lamentation of Dr. Faustus," Adrian releases all the sincere ugliness inside him, causing him to lose his mind. Though Germans dreamed of celebrating freedom and peace with the Ninth Symphony, as Dr. Zeitblom relates they were confined to the character of Adrian's masterpiece: "the Lamentation of the son of hell, the lament of men and God, issuing from the subjective, but always broadening out and as it were laying hold on the Cosmos; the most frightful lament ever set up on this earth" (485). Doctor Faustus ends with Adrian's death. The last line of the book expresses a prayer for Germany in its fallen state.

Though they have different perspectives both Harry and Adrian conclude that their process of re-reasoning, the process of establishing meaning in life within a depraved culture, involves some form of madness. Both protagonists face it in different ways and through it achieve some meaning, whether healthy or not. In Steppenwolf Hesse writes: "Just as madness, in a higher sense, is the beginning of all wisdom, so is schizomania the beginning of all art and all fantasy" (220). Here Hesse uses madness to refer to the illogical reality of life and the subsequent meaning achieved when it is accepted and understood. Both Harry and Adrian use forms of madness to make sense of their life, to personally reconnect with meaning in the culture of their age. Their schizomania, which Adrian expressed in chords and Harry in identities, led them to the art 
of their transcendence. Harry's madness ends in awareness, with a strong sense of hope for his transcendence. However, Adrian's life ends in madness, though the book ends in hope as well, but in a more tragic hope, a hope for the future generations of Germany that they may learn transcendence at the expense of those like Adrian.

Steppenwolf and Doctor Faustus not only represent two studies in the nihilism of their respective eras, but reflect two different ideologies as well. Hesse's and Mann's novels deal with nihilism in different ways, partly because of the stage of the nihilistic movement in the culture during the time of their writing, and partly because of the natures of Hesse and Mann themselves. Mann identifies strongly with his culture and connects with it in a very external way as witnessed in the tone and content of many of his letters in The Hesse/Mann Letters. Hesse identifies with his culture too; however, he does so through introspection first. Their differing natural affinities for interpreting and living their lives are reflected in their protagonists. Hesse's protagonist, Harry Haller, seeks to transcend his nihilism by resolving issues of his spiritual self-conception, and thus to establish a meaningful connection with culture. Adrian Leverkühn confronts the ugliness of his culture and seeks to manifest it in art, before attempting his own personal resolution. Notwithstanding the differences, the work of Hesse and Mann and the creation of their protagonists are indications of their intense spirituality, indications of their tragic struggle to define a meaning in their culture.

Hesse and Mann were aware of the differences between them. In an essay titled "A Bit of Theology" Hesse discusses his observation that there are two types of human character: the man of reason and the man of piety. Outlined in Hesse's essay is his theory of three constructive stages of human development: (1) innocence, (2) guilt at knowing an ideal but not attaining it, and (3) despair at not being able to attain the ideal, which depending on how it is handled results in either failure or deliverance. Of course Hesse acknowledges that this model is dynamic, no one is in any one stage permanently, but it is those that strive through guilt and despair who are able to surpass the pain of existence, in this case nihilism.

Hesse introduced this essay to Mann, looking for a kindred soul in a man of piety, but Mann expressed "distaste" for those known as spiritual authors in Germany and replied to Hesse that he had settled for "a reputation for dry humanitarian rationalism" (Hesse 14). Looking for a similar partner Hesse found a complement; in their differing natures Mann and Hesse achieve reconciliation in their relationship through each other's different approach to exis- 
tence. Hesse discusses the power of the relationship between pious and rational individuals, which resembles the relationship between himself and Mann, near the end of the same essay:

And so, just as the pious genius and the genius of reason know each other very well, secretly love each other, are attracted to each other, so too the highest spiritual experience of which we human beings are capable is always a reconciliation between reason and reverence, a recognition that the great contradictions are one and the same thing. (199)

Mann and Hesse achieved this type of reconciliation together in the relationship of their spiritual differences between faith and reason. After a lifelong friendship that continued to grow and strengthen, they had a connection that led Mann to write to Hesse in 1952: "don't die before me! In the first place, it would be an impertinence, for I am 'next in line.' And moreover, I should miss you terribly in all this turmoil. For in it you are a good companion, a consolation, prop, example, and encouragement, and without you I should feel very much alone" (Hesse 151).

With their relationship Hesse and Mann achieved the meaning that they never found through their culture. The tragic crash of the pragmatic reason of modernism made their search fruitless. But what they did discover was that in the process of the search itself, in sorting through the madness of their culture, relationships, and art there was meaning in life. There was an answer though not at the end of their question. The answer that Hesse and Mann, and Adrian and Harry find is concurrent to their question. The resolution of nihilism and existence is beyond understanding and logic; it is found in and through madness, the madness of the unexplained and the unexplainable, of gods and devils, the madness of living. This same madness Nietzsche carried to his death. As Mann laments: "[Nietzsche] knew his Germans. If he had only been a better more thoughtful teacher to them" (Hesse 102). From the lives of Hesse and Mann we learn that there is hope, hope in relationships, a reconciliation between reason and madness: "On the third level the warriors begin to recognize each other no longer as strangers but as being dependent upon each other. They begin to love each other, to long for each other. From here the road leads toward possibilities for humanity whose realization has not yet be glimpsed by the human eye" ("Theology" 201). 
Hesse, Hermann. "A Bit of Theology." My Belief: Essays on Life and Art. Ed. Theodore Ziolkowski. Trans. Denver Lindley. New York: Farrar, Straus and Giroux, 1974.

-.-. Steppenwolf. Trans. Basil Creighton. New York: Bantam Books, 1963.

Hesse, Hermann and Thomas Mann. The Hesse/Mann Letters: The Correspondence of Hermann Hesse and Thomas Mann, 1920-1955. Ed. Carlsonn, Anni and Michels, Volker. Trans. Ralph Manheim. New York: Harper \& Row, 1975.

Mann, Thomas. Doctor Faustus. Trans. H. T. Lowe-Porter. New York: Alfred A. Knopf, 1948.

Nietzsche, Friedrich. The Gay Science. Trans. Walter Kaufmann. New York: Vintage Books, 1974.

Nietzsche, Friedrich. The Will to Power. Trans. Walter Kaufmann. New York: Vintage, 1968.

Novak, Michael. The Experience of Nothingness. New York: Harper Row, 1970. 


\section{Reinventing the Myth: The West of William Kittredge}

Mararget Johnson recently graduated from the Master of Liberal Arts program. During a directed study entitled "The Contemporary West in Literature in Film," she read a short essay by Kittredge and was enthralled with his vision of the American West. Born and raised in rural northern Idaho, Kittredge's works appealed to her because she once lived in the regions about which he writes.

"Ask for truth and what do you get? Candor" (Hole 146)

In three books by William Kittredge-Owning It All, Hole in the Sky: A Memoir, and Who Owns the West? - the author çandidly writes about living and working in the American West. He speaks his truth, and it emerges as unvarnished candor. The books contain personal accounts of his life as a rancher, farmer, and writer, much of which are painful reminiscences of family strife, drunkenness, contradictions, and betrayals. But his narratives are much more than kiss-and-tell tales that are all too readily found on bookstore shelves. Rather, through self-reflection, Kittredge dares to expose and demystify the prevailing myths of the West that many people believe are the reality of that region: the Romantic West with its abundance, freedom, and opportunity for paradise through land ownership; the Wild West of stoicism, alcohol, and violence; and the Vanishing West of heedless environmental destruction. In doing so, he offers a "sustaining mythology" for the West that originates from compassion and reverence for the land, its creatures, and its people (Who Owns 166).

Kittredge's native land is the Warner Valley of southeastern Oregon, an extraordinarily isolated area of the Great Basin that borders both California and Nevada. The sagebrush desert spreads over ancient lava flows that lead toward the snow-covered Bidwell and Warner Mountains. Each spring the snow melts, providing the necessary water for the otherwise arid region. This seasonal runoff created fertile valleys that eventually attracted white settlers. Kittredge speaks to the contradictions of the land: "Without [the valleys] that country would have been free of white settlement much longer than it was. The conjunction of wetland and desert seemed like a true condition of life" 
(Hole 16). To him, Warner Valley was a juxtaposition of environmental extremes, a duality that his grandfather found irresistible.

Kittredge addresses the mythology of the Romantic West, writing that the early white settlers "were lured West by promises. Promises of paradise for the taking. Free land, crystalline water, great herds of game roaming the natural meadowlands, good fishing, gold, all in unfettered abundance, a new world every morning" (Owning 8). The desert area of the Warner Valley captivated his grandfather, not by its beauty but for its potential for use. Here he envisioned an endless expanse of land in which to graze cattle, and in 1911, he purchased his first ranch (Hole 26). Throughout his life, his desire for acreage was insatiable. Kittredge writes:

[Before selling the farm and ranch] we had more than twenty-one thousand irrigated acres in Warner Valley, something beyond another million acres of leased Bureau of Land Management rangeland. We ran more than six thousand mother cows. It could have been a paradise; maybe it was, maybe it still is. (6)

Even though the grandfather leased much of his grazing land from the government, he always believed he owned it by and for himself. "It's one of our customs," Kittredge writes in Who Owns the West?, "reverence for having, owning" (79). For the Kittredge family, the myth of land ownership in the West became, if not a reality, at least a solid belief that was acted upon by the grandfather.

His grandfather's vision of paradise was the accumulation of property and the actual labor it took to get it. Kittredge recalls his grandfather's work ethic: "It was his theory that for the common good we should put work ahead of every other thing, including compassion...If you payed the bills, in the philosophy he taught, you got to call the shots" (Hole 39). This belief lead to another contradiction in Kittredge's life. His grandfather's goal was to gain enough power and wealth working on the remote ranch so that he and his family could live in town, away from the very spot that provided for them. The young Kittredge calls this aspiration a story gone "sideways," a skewed ambition as well as a warped sense of the value of the land (39).

During the Great Depression the grandfather bought one of the biggest ranches in the area, "some twenty-odd thousand acres of peat-soil swamplands 
in the valley, and what seemed like in those horseback days to be endless summer range out east on the desert" (Owning 27). The eldest Kittredge believed in using the land as he saw fit, a utilitarian view of nature that was completely human-centered. Land equaled wealth and power. He felt he owned the land and therefore could do as he wished with it, an "anything goes" attitude.

This way of thinking lead to the drainage of those swamplands. Water was needed for the cattle, so Kittredge's grandfather decided to draw off the water from his newly purchased property. At this juncture, Kittredge's father, Oscar, enters the picture. At one time, Oscar had decided to become an attorney, but the grandfather convinced him that the land, his property, was more important than any personal goals. Bowing to the pressure, he gave up his dream of law school to remain in Warner Valley (Hole 55).

The energy that stimulated Oscar's dream of being a lawyer soon shifted to fuel a vision of converting the drained swampland into lush and thriving farmland. Kittredge writes that "[Oscar] got his hands on a heaven of waterbirds and fertility; he remade it into what he understood as useful, a sprawling system of irrigation and drainage canals, and agribusiness fields where the undulating drillrows ran straight for miles" (Who Owns 36). Like the grandfather, Kittredge's father believed the land was there for human use and manipulation. His aim was to fashion the land into perfection. At least his perception of perfection. As Kittredge puts it, "We thought we were doing God's work. We were cultivating, creating order and what we liked to think of as a version of Heaven on Earth" (29).

The Kittredge version included the use of pesticides, herbicides, and mechanization to reshape the land into something "valuable" for mankind without regard for the consequences. After World War II, his family sold all their workhorses for feed to buy tractors, bulldozers, combines, and ditch diggers (Hole 69). Coyotes were trapped with poisons. Rabbits were shot by the hundreds to protect the precious crops, and Kittredge writes of this as "slaughtering, really" (97). Kittredge's father went so far as to use generators to keep the fields lit up so that he and his workers could farm around the clock (41). In the end, Oscar's agricultural techniques allowed him to make huge amounts of money, a payoff that he spent on big cars, airplanes, racehorses, women, and booze.

William Kittredge grew up watching these two men exercise their power over nature. From his early childhood years, he was allowed to work alongside the buckaroos on the ranch. He learned how to manage the herds to get the best 
market price. With his father he learned about balancing water-the essential part of the irrigation process - as well as how to manipulate the soil with chemicals to achieve high crop yields. Most importantly, however, the younger man absorbed the attitudes of his grandfather and father, that is, he had no more regard for the area in which he lived other than to believe it was there for man's personal aims of money, power, and property. Having lived his entire life in virtual isolation from the rest of society, Kittredge had no other frame of reference by which to examine his own life.

When Kittredge attended Oregon State University to study agriculture, he discovered books. All sorts of books. He didn't much care what he read, but his desire to learn things about the world apart from ranches and farms became an almost uncontrollable yearning. He married, finished college, did a stint in the Air Force, and then returned to the Warner Valley to help his father with the family business. But during that time, he was secretly reading books at night and nursing a faint hope of becoming a writer. He also began to question the ranching and farming practices of his family.

Not long after his return home, a giant rift in the family took place. His farmer father, who was hugely successful, was not putting his profits back into the business or using them to acquire more property, much to the consternation of the rancher grandfather. It was the grandfather's policy to always put the profits back into the ranch. The classic Wild West confrontation occurred: the cowman versus the sodbuster. Oscar disregarded his own father's wishes concerning the farming money, so the grandfather disinherited him, a move that caused intense and unwavering hatred between the two older men (Hole 146). Oscar worked the farm, but the ranching side of the family business was managed by one of the grandfather's workers. Eventually, young Kittredge took over the farming business because his father preferred to spend his time drinking, philandering, and playing with cars and racehorses (92). Kittredge spent most of his energy on the farm, although he devoted some of his time to the ranch as well.

Kittredge spent the next several years managing the farm. He continued to read his books surreptitiously, and his longing to be something more than a plowman fueled his increasing dissatisfaction with his current role. He drank heavily and frequently and broke his marriage vows more than once. Like his own life, the land was changing rapidly as well. Kittredge describes some of the damage he and his family did to "their" property: 
We did great damage to the valley as we pursued our sweet impulse to create an agribusiness paradise. The rich peat ground began to go saline, the top layer just blew away. We drilled chemical fertilizers along with our barley seed, and sprayed with 2-4-D Ethyl and Parathion (which killed even the songbirds). Where did the water birds go? (Who Owns 30)

The ranching side of the business also changed. The angry silence between Kittredge's grandfather and father never abated and continued until the grandfather's death. And true to his word, the grandfather left the property to his friend, Jack Nicol, rather than to his own son, Oscar. As time progressed, communication between young Kittredge and the ranch manager also dwindled to the point of silence, an almost eerie replication of his grandfather and father's relationship. He writes of this estrangement in his memoir, Hole in the Sky: "Jack and I were scarcely able to speak to each other...each unable and unwilling to make sense of the other...He gave the orders, and though I hated him for it there was nothing I could do. I'd sold out to his authority a long time before" (206).

After eight years of working the farm and ranch, Kittredge and his two siblings sold off all the properties. "Most of my grandfather's grandchildren wanted out, for reasons having to do with money and power, which in the end is the same as possibility. If we were going to find our own lives, it was time to get started, and we knew it" (Hole 203). By this time in his life, he understood that writing was his true vocation. "Writing was my only purpose, I told myself, and I worked hard at this, my main chance in life" (205). He was divorced by his wife but soon hooked up with a hard-drinking woman who, surprisingly, helped him focus enough to apply for graduate school. Kittredge earned his degree in creative writing, was divorced a second time, and took a position teaching writing at the University of Montana in Missoula, a job he holds to this day $(218,221)$.

After completely stepping away from his life as a rancher and farmer, Kittredge gained some perspective and clarity about his place in the world, particularly the West where he grew up. His writings appear to be his attempt at understanding his family's behavior-and especially his own-concerning the use and abuse of the Western landscape, its flora, and fauna. In writing for catharsis, Kittredge discovered flaws in the myths of the Romantic, Wild, and 
Vanishing West. His life, indeed, is a metaphor for the fallacy of these myths. John Schulian says it best in his review of Kittredge's memoir: "He had been born into a metaphor for the worst aspects of American society" (2).

The myth of the Romantic West inspired Kittredge's grandfather to settle in the Warner Valley. He continued living the myth of land ownership, gobbling up vast acreage and draining swamps to utilize the land more profitably. "He was one of those cowmen we don't see so often anymore, heedless of most everything outside his playground, which was livestock and seasons and property, and, as the seasons turned, more livestock and more property, a game which could be called accumulation" (Owning 65).

The most telling and powerful story connecting the grandfather with the myth of ownership concerns magpies. The old man, for some unknown reason, loathed those birds. He devised a wire cage that trapped the creatures, and when several birds were ensnared, he got out his 12-gauge shotgun and killed them one by one, slowly and methodically. Kittredge never understood his grandfather's hatred for magpies, and when he asked why he shot them as opposed to the blackbirds, which were more of a menace to the crop seedlings, his grandfather replied, "'Because they're mine."' Kittredge continues with the story:

I never did know exactly what he was talking about, the remnants of entrails left over from the butchering of culled stocker cows, or the magpies. But it became clear he was asserting his absolute lordship over both, and over me, too, so long as I was living on his property. For all his life and most of mine the notion of property as absolute seemed like law, even when it never was. (Owning 67)

In the end, the land and its wildlife were not the grandfather's at all. But while he reigned over the ranch and his properties, he ruled it with a harsh, cruel hand.

The Kittredge clan lived the myth of the Wild West with devastating results. Hard drinking, violence, and above all, stoicism were everyday occurrences in the Warner Valley. Kittredge writes of the time when he was 13 years old. He was working with some buckaroos in a cow camp in the desert and was bedded down for the night. "What I recall most vividly is [a buckaroo] standing over me as I came awake, drunk and grinning and sweating, taking a shot at pouring a long stream of whiskey into my open mouth because he loved me and wished me well, and wanted me to be a man" (Hole 86). That incident led 
to a several-day drunken episode on the part of the young boy and buckaroos. Kittredge is the first to say that drinking nearly killed his father and seriously damaged his own life.

His description of the buckaroo life is not one of work under the glorious sun running cattle all day and sleeping contentedly under the stars. It is, rather, a sad tale of alcohol abuse, rambling, and loneliness:

Get on a drunk and get yourself fired and spend a week or so hanging around in town and then hire out to another cow camp where you would know somebody from some other outfit where you'd both worked some other season. And on around until you had worked for most of the big outfits two or three times, and you were an old hand, maybe crippled up a little and due some slack, looking for somewhere to settle. (Hole 87)

The cowboy profession was lonely, unglamorous, and filled with endless hard labor. "History there is a story of ranches and dreams of empire, of land and cattle and great horsemen, but it is more a history of getting the work done, feeding cattle from a creaking hay wagon while the snow blows level to the ground in late January" (Owning 28).

The myth of the Wild West includes silence and stolid endurance, two major components of Kittredge's life. The motto by which he and his family lived was "take care of your own damn self" (Who Owns 73). As a boy, he idolized the head of the cowboys, Ross Dollarhide, because he taught that "such [cowboys] never complained" (Hole 63). He learned at a young age that "buckaroos never carried water. Any giving in to the difficulties of the country was a sure sign of weakness. A kid who yearned to be a cowhand would keep his thirst to himself" (Who Owns 31). Perhaps this explains why Kittredge chose farming over the ranching life.

The stoicism and tight-lipped behavior required by his family created unbearable and unnecessary pain for Kittredge. The ranching life taught him "the necessity of work, for which I cannot say enough, and to keep my mouth shut while I tried to see things through" (Hole 84). Bucking up and staying silent may have been the Western way, but Kittredge concludes that events might have been different had silence not been his family's mode of operation: 
For a little while we owned an empire, and that fact taught us to protect our interests by hardening our hearts against one another. I don't know if I would have understood, but it might've helped if someone had taken the trouble to tell me what was going on inside the councils of my family...Knowing the score would have helped in a practical sense. But nobody did...Maybe we would have moved on before so much was wrecked. (150)

The confrontations and violence associated with the Wild West were also prominent in Kittredge's experiences. In Owning it All, he details the history of the Warner Valley area, much of it created with blood. He tells of land barons who violated riparian rights in their quest for more property, moves that inevitably ended in someone either being beaten up or shot. Kittredge writes of a rancher who chased off a BLM employee with a gun. The BLM man hid in a haystack, to which the rancher struck a match. "'Cooked that sonofabitch,"' the rancher was heard to exclaim (27).

Frontier violence was not always directed at humans. According to Kittredge, his brother took great joy in shredding a section of the Winnemuccato-the-Sea highway. During a particularly bad flood season the road had acted like a dam, causing the water to cover several thousand acres of the Kittredge property. His brother found a solution to the problem:

My brother Pat walked a D-7 Caterpillar out along the asphalt and cut the highway three or four times, deep cuts so the floodwaters could pour through and drain away north. What he liked best, Pat said, was socking that bulldozer blade down and ripping up that asphalt with the yellow lines painted on it. We were still our own people. (Who Owns 28)

Violence to nature is well chronicled by Kittredge and leads to the myth of the Vanishing West. His family's heedlessness reads like a laundry list in his memoir: "In Warner we killed waterbirds for sport, with shotguns, and we hunted deer and antelope, and killed them from a distance, with rifles" (Hole 69). "We baited coyotes with 1080 and hunted them from airplanes; we wiped them out" (153). He writes of leveling acres and acres of land for crops, digging miles of canals for irrigation, and draining off the wildlife habitats. Kittredge 
confesses that all the hard work to make a human paradise failed miserably: "The ecology of the valley was complex beyond our understanding, and it began to die as we went on manipulating it in even more frantic ways. As it went dead and empty of the old life it became a place where no one wanted to live" (171). In the end, their version of heaven turned into a paradoxical betrayal.

Thankfully, Kittredge does not leave his audience with a sense of doom or desperation. Although he writes about the profound changes that have taken place in the Warner Valley specifically and in the West in general-and he does not mince words in detailing their dreadfulness - he offers up hope for the region. His aspirations for a recovering Western ecology suggest that the Vanishing West is, or at least can be, a myth.

Kittredge succinctly states the general myth of the West: "And our mythology tells us we own the West, absolutely and morally...The myth tells us this place is ours, and will always be ours, to do with as we see fit" (Owning 63-64). In the three books, he concludes that this no longer works. He believes it never did. It most certainly did not serve the land, air, water, birds, and other living beings of the West. He recognizes, however, that "there is no single, simple story that will define paradise for us and never will be" (Who Owns 167). He suggests, rather, that we let go of our old beliefs, particularly the Romantic and Wild West myths, and form a new framework based on cherishing the land and treating all life with love and compassion because "killing the natural world [is] a way of killing each other" (142). He insists that "we must define a story which encourages us to make use of the place where we live without killing it, and we must understand that the living world cannot be replicated ... Ruin it and we will have lost ourselves, and that is craziness" (Hole 234-235).

Kittredge presents some ideas for creating a new sustaining myth. He proposes setting aside vast parcels of untouched wilderness (or as untouched as any land can be in the 21 st century) so that it may remain unsullied. He is adamant in his belief that putting this valuable land within the national park system will ultimately fail, and he cites how the last of the wild buffalo were shot on park land (Hole 229). If those beasts could not be spared living in a "protected" area, how can we expect biologically sensitive ecosystems to survive under that same protective system?

In what was probably perceived by those still living in Warner Valley as heartless disloyalty, Kittredge suggested that the entire area be "given back to 
the birds and turned into a wildlife refuge." He had a simple dream of all the people working together -- "ranchers and townspeople, conservationists"- to create a real paradise on earth where all things are valued for their own sake (Who Owns 32-33). As he put it, "We need a story in which the processes of communality and mutual responsibility are fundamental" (142). If people would work together to love nature and treat it as sacred, then the laws of our society could stand a chance of being changed to better protect it. "If we can work our way through to public consensus the bureaucrats and lawmakers will follow" (142).

The simplest idea that Kittredge offers for changing the Western myth is perhaps the most difficult to achieve: be loving and compassionate with one another. His message is so fundamental, many would probably laugh at it. But Kittredge argues that, for our own well-being and that of nature itself, we must actually be love and put that love into practice through compassion. "If we cherish, with proper selfishness, whichever dream we inhabit, we must honor our need to revere ourselves and each other. If we want to be happy at all, we might see that we have no choice but compassion" (Who Owns 46). He carries this notion further by saying that we are connected to all things, and as such we cannot solely love ourselves without loving nature. "We are animals evolved to live in the interpenetrating energies of all the life there is, so far as we know, which coats the rocks of earth like moss. We cannot live, I think, without connection both psychic and physical, and we begin to die of pointlessness when we are isolated" (Hole 234). He concludes his memoir with the same sentiment: "We are part of what is sacred. That is our main defense against craziness, our solace, the source of our best politics, and our only chance at paradise" (238).

The old myths - the Romantic, Wild, and Vanishing West-are obsolete stories that we have built into a potentially annihilative reality. But stories can be changed, "re-imagined" as Kittredge would say (Who Owns 7). Our perception of the Romantic West can be shifted to reflect the intrinsic value of nature rather than its viability. We can express our new mythology through actions of love and compassion rather than domination and destruction. In this way, the West can recover its allure. Breaking our silences and speaking with kindness will cause our actions to follow suit, and the myth of the Wild West will no longer be the creation within which we live our lives. We will neither need alcohol to numb our feelings nor violence to settle disagreements. By 
reinventing these two myths, the Vanishing West can truly be just that: a myth, a simple story with little basis for its existence. These are the hopes of William Kittredge and the hopes that we, too, can embrace. 
Kittredge, William. Hole in the Sky: A Memoir. New York: Vintage Books, 1992.

--. Owning It All. St. Paul: Graywolf Press, 1987.

-.-. Who Owns the West? San Francisco: Mercury House, 1996.

Schulian, John. "Regrets Like Rain, a Review of Hole In the Sky, by William Kittredge." Los Angeles Times 5 July 1992. Online.

Lexis-Nexis Academic. 10 June 2002. $<$ http://web.lexis-nexis.com/>. 


\section{"Them Damned Pictures": A Study of the Cartoons of Thomas Nast and the Breakdown of the Tweed Political Ring}

Ashlie Kelly, an Education major focusing on Social Studies and Secondary Education, wrote this paper as her Honors thesis under the direction of Dr. Patricia Perry. She intends to graduate in May 2005.

Turmoil and change defined nineteenth-century America, especially as the hundred years passed its halfway point. In the post-industrial revolution society known as the Guilded Age, which spanned the years from the end of the Civil War through the late $1890 \mathrm{~s}$, the newly formed nation grappled with human rights concerning the issues of slavery as well as labor laws, immigration and an increasingly widespread wave of political corruption. Cities grew at alarming rates, with the United States population increasing from 23,054,152 in 1850 to $74,607,225$ by the end of the 1890 s ("Geostat"). Especially in the more industrialized North, where this new population tended to settle, the issue of corrupt government and the development of the political machine, a group that controls the activities of a political party, took their toll on society and affected every aspect of politics and everyday life ("Dictionary").

The Tweed Ring became the most infamous of these political machines and it reached its climax in New York City in the late 1860s and early 1870s, only to be foiled by the work of an unlikely patriot, political cartoonist Thomas Nast. This German immigrant and his steadfast dedication to preserving democracy through his powerful pen managed to break down the Tweed Ring comprised of "Boss" William Marcy Tweed, A. Oakly Hall, Peter "Brains" Sweeny and Richard "Slippery Dick" Connolly and other, less infamous characters (Callow 118). Many circumstances led to the rise and eventual fall of Boss Tweed, but arguably the most credit must be given to Nast. Because of high illiteracy rates in the City of New York, Thomas Nast's message through the pictures in his political cartoons shaped public opinion and eventually led to the breakdown of the Tweed Political Ring.

Thomas Nast did not begin his life as a patriotic American citizen, but rather as the child of a musician of the Ninth Regiment Bavarian Band and his wife. Born in the fortified town of Landau, Germany, near the disputed territory of Alsace on September 27, 1840, the young Nast quickly developed an 
interest in everything military and displayed his first artistic talents when he created tiny play soldiers from beeswax. If not for the brewing of the German Revolution, Thomas Nast may likely have followed in his father's footsteps and donned the boots of a soldier, but the elder Mr. Nast's political ideologies did not agree with those of the government he was sworn to defend. Before the revolution broke out, it was recommended by a commanding officer that the elder Nast move his family to America, where opposing one's government would not lead to death. Taking head of the advice given, the Nast family left for Paris, and from Paris sailed to New York, the hub for most immigrants entering the United States (Paine 5-8).

After gaining entrance into the United States, the Nast family settled into a residence on Greenwich Street in New York City. However, the family soon moved to a house on William Street in the vicinity of another school as Thomas had an awful first experience with his first school in which he ended up in line for a paddling from the principal when mischievous boys took advantage of his lack of English proficiency. It was in his new home that Nast first began realizing his talent for art. He lived next door to a man who created crayon sticks to sell to artists, and crayons that he deemed faulty he gave to the pudgy young German immigrant boy next door. With these second rate crayons young Thomas Nast began drawing around the clock (Paine 9-12).

While observing his surroundings and drawing what he saw, Nast was introduced to the symbol that would become his legacy. Common subjects for his drawings were the local fire departments that often spent more time battling each other than actually putting out fires. The most influential of these fire departments was known as the "Big Six" and was run by Nast's later nemesis, William Tweed. The fire engines of the "Big Six" were identified by an illustration of a fierce Tiger head bearing its teeth, which later became the inspiration for one of Nast's most significant symbols, the Tammany Tiger. Little did Nast know, but these early observations and drawings would lead to a life dedicated to defeating Tweed and political corruption (Paine 9-12).

During this time that Nast was drawing constantly on everything from the papers in his composition book for school to the walls of the William Street home, Nast was also moving from school to school. At thirteen, teachers and principals alike praised his art, yet his aptitude for subjects such as reading, writing and arithmetic lacked the same enthusiasm. At the last school he attended, the Forty-seventh Street Academy, Nast's teacher would tell him "Go 
finish your picture, Nast. You will never learn to read or figure" (qtd. in Paine 15). This was Nast's last school before he dropped out and began focusing on truly developing his talent for art.

Studying under some of the most respected artists of his time, Nast was soon admitted to the prestigious Academy of Design where he focused his studies on life drawing. The young artist made a name for himself not only at the Academy, but at galleries copying the works of masters, as well. After gathering a collection of his best work, Nast decided to present it to the publisher Frank Leslie, of Leslie Weekly, and inquired about a position at the paper. Despite the editor's worry that Nast might be a bit young for such a professional job, Leslie hired him at a rate of four dollars a week. It was during this first job at Leslie Weekly that Nast was introduced to the growing corruption of city government and subsequently got his first taste of civic reform. He was hooked. The Leslie Weekly began running into some financial difficulties and often Nast would go for weeks without receiving a paycheck. At 18, Nast applied and received a free-lance job at Harper's Weekly but it was not until two years later that he was hired permanently and was sent to London to cover the Heenan-Sayers boxing match, which was hailed as one of the greatest fights of the era (Paine 31-35).

As young Nast was growing into an accomplished artist in the mid to late 1800 s, America as well as other countries around the world was going through extreme changes. Across the Atlantic Ocean in Italy, a Revolution was taking place, led by the inspiring Giuseppe Garibaldi. So stirring was Garibaldi that in 1860, Thomas Nast decided to join his second expedition that was marching toward Naples. He used this time marching with the Italian revolutionaries to not only develop his personal beliefs about liberty, but also to practice his art. As Garibaldi acted as a liberator of the Italian people and installed a new government, Nast further identified with ideas such as reform and freedom, and these ideas are reflected in his later work depicting Boss Tweed. It was during this time that Nast truly came into his own as a political idealist and reformer (Paine 45-64).

Nast arrived back in New York after his quest with the Garibaldian troops in 1861 with only a dollar and a half in his pocket. Though he had just left a revolution in Italy, he was not lucky enough to return to a peaceful homeland. The Civil War was brewing, and it was only a matter of time before his country was divided in one of the bloodiest wars the world has ever seen. It was during 
this time period that Nast gained fame as a political cartoonist with his depictions of the plight of the soldier. In these cartoons, Nast urged a compromise and was even honored for his work by by "The Union League" which was an organization dedicated to finding ways to preserve the Union and end the Civil War. He received the honor as a "token of their admiration of his Genius, and of his ardent devotion of that Genius to the Preservation of his Country" (Paine 134). During the Civil War, Nast also published a series of Christmas illustrations that first depicted America's secular illustration of Santa Claus (Paine 84). During this time, Nast earned national acclaim and many of his works were reprinted in newspapers and magazines across the nation.

Following the war, beginning in 1867 , Nast began covering city reform movements, which would inevitably lead to his greatest and most memorable work. Nast also traveled to Washington, D.C. and covered the presidential elections of 1868 , in which he undoubtedly supported the Union war hero Ulysses S. Grant. After Grant's win he admitted, "two things elected me, the sword of Sheridan and the pencil of Thomas Nast" (Paine 129). Nast had come onto the scene as a force to be reckoned with when it came to the shaping of public opinion, but he would not realize the power of his pictures until he took on his greatest challenge: the Tweed political machine.

The Tweed political machine developed as just one corrupt city system of many that were popping up all over the United States. Political, or party, machines grew out of a corrupted government and their sphere of influence spread from the big cities, like New York and Chicago, all the way down to small towns. They were once described as "organization[s] capable of delivering a vote with mechanical regularity" (Stone). In order to gain the power they used influence to sway decisions regarding policy-making and other government decisions. In fact, political machines would use patronage by offering money, jobs or even political positions to those that offered some benefit back to the machine. Some tactics were as blatant as paying citizens to vote in favor of the machine's ticket or agenda, while others, like the establishment of social clubs that catered to the needs and interests of the poor and marginal, gained trust and support from the voters in a less overt way. By posing as an organization devoted to reforming, Tweed's ring poured thousands of dollars into charities and Catholic schools and also gave money for improving sewage and water systems. Though not directly bribing the constituents of these poorer neighborhoods that benefited from Tweed's generosity, he gained their vote 
(Kandall 87). The poor were not the only people to whom political machines catered, however. In order to win support of the business and middle classes, political machines would promise jobs, inside information, exceptions, and partiality when it came to the administration of the law. After some protest arose about the legality of some of the city government's spending, six of New York's prominent businessmen were allowed to inspect the Controller's books, and, not surprisingly, they concluded that, "the financial affairs of the city, under the charge of the controller, are administered in a correct and faithful manner." Later, after these same books were made public, the names of these six men were found listed as stockholders and directors of businesses controlled by the Tweed Ring (Paine 144-145).

Patronage was not the only method used by the Tweed political machine to gain power within the government. Theirs was a threefold agenda that would lead to the ultimate control over nearly every aspect of the city they occupied. First, the political machine sought to control the party organization. After ensuring that their candidate was nominated for office (most often by offering bribes to swing the vote) they would use patronage, as mentioned previously, to buy the voters and to control the outcome of elections. Second, once members of the political machine were public officeholders, the machine would gain more patronage opportunities through the control of public offices. Finally, members of the business class who held private interest in the policies of the government, like the approval of new building projects, would offer favors and kick-backs to members of the machine in return for the machine assuring them what they wanted. The use of construction and development was a common way machines would garner profit and keep the loyalty of the classes. Not only did that generate revenue for business supporters, but they also created jobs for blue-collar workers (Garraty 108-114).

Although the machine used unethical means to gain power in the government, the work they did creating jobs and income for the poor and middle classes gave them the guise of a positive political entity. Machines presented themselves as friends of the poor and disillusioned by creating social organizations that offered fun and recreation for the poor, who at the time were living in the slums of the city. They also adopted political agendas that appeared to aid the lower classes by creating jobs that were filled with those that supported them (Garraty 109). It not only paid to support the political machine, but it also paid handsomely to be on the inside of the machine. While the 
machine may have controled the city or local government, it was typically only a small group of insiders that received the most generous benefits of pay-offs and kickbacks. They preferred a small, controllable group of insiders in order to limit the intelligence of what was really going on. Political machines reached their height in the late nineteenth and early twentieth centuries in such major cities as New York and Chicago, and while it is not as apparent in politics today, some argue that they have not completely died out (Stone).

William Marcy Tweed led the way for political corruptness at its height in New York City as the infamous leader of the Tweed political ring. Tweed was born in 1832 on the lower East side of New York City. Although young Tweed grew up in a middle-class home, some of the worst tenement homes and poverty of New York surrounded him. Seeing the conditions that his neighbors lived in inevitably would influence his future political policies. Tweed never finished school, and after he dropped out he became the leader of the local "Big 6" firehouse run by the Tammany Hall political machine, that same firehouse observed by young Thomas Nast as he was developing his artistic and political skills. It was during this time Tweed spent working with the Big 6 that he gained the trust of Tammany Hall by demonstrating his leadership abilities and interest in government; this experience would define a relationship that would flower into the most powerful political machine the United States has ever seen (Kandell 86). Tweed did not begin on top, however. With the backing of Tammany Hall, Tweed was first elected as a city alderman, before he moved on to a seat in Congress. Unhappy and bored with Congress, Tweed returned to New York in 1855 to find new demographics in the population and an opportunity he could not pass up (Kandell 86-87).

Taking advantage of his city's new demographics, Tweed saw that nearly half foreign-born population comprised his constituency. Once he returned to city government, Tweed was elected to the Board of Supervisors, which oversaw the financing of public projects. At the same time, he gained support from his new voters by promising them jobs on the city's construction projects. Just a few years after Tweed returned to New York, the Civil War was on the brink of beginning, which meant the North had a surge of industrial production. Tweed was suddenly overseeing the building of new railroads, streets, docks, warehouses and even office buildings, and he was making a hefty profit from the favors and kickbacks he received. During this time the Tweed political ring was formed. Taking advantage of his increased responsibilities, Tweed began placing his personal cronies into key city posts (Kandell 87). 
The inside ring consisted of "Boss" Tweed and three others handpicked to serve and profit from the corrupt dealings of the political machine. A. Oakly Hall, known as "The Elegant," was the candidate for mayor chosen by Tweed and backed by Tammany Hall. Originally a playwright and an actor, Hall became the perfect mouthpiece for Tweed, who eventually managed to manipulate the city government to grant the mayor more power. The second of Tweed's hand-picked men was Peter "The Brains" Sweeny. He served several posts under Boss Tweed, which included park commissioner and city chamberlain, but his most influential role in the ring was as one of the directors for the Erie Railroad Board. Finally, Richard "Slippery Dick" Connally held probably the most pivotal position in Tweed's scheme to get rich off of the city treasury: controller of public expenditures. With this title Connally had control of the city's books as well as of who saw them. In his infamy, Connally was known as the "sneak-thief" of the organization. Together, the members of the Tweed political ring worked within the Tammany Hall political machine to lie, cheat and steal their way into millions.

In 1867 , after the ring was in place, Tweed was elected to a seat in the New York State Senate. While serving in this position he wrote a charter that allowed the city of New York to have more control over its city budget, and after he bribed the members of the Senate with over $\$ 600,000$, the charter was passed (Kandell 87). However, while Tweed was in the Senate, not all of his acts were completely self-serving; he did use some of his power compassionately. It was during his time in Senate that Tweed donated to charities and schools, worked to improve the water and sewage system, and provided jobs for immigrants. He also worked to pass charters that led to the creation of two of New York Cities landmarks: the Metropolitan Museum of Art and the American Museum of Natural History (Kandell 87). Despite the philanthropic nature of these actions by Tweed, the debt accrued by the city far outweighed any prosperity that could have come from the city's development. Instead of raising taxes to pay for these improvements, the city issued bonds that were constantly renewed as they expired, resulting in New York's debt tripling in just four years (Kandell 87).

Other practices of the Tweed Ring also added to New York's skyrocketing debt. Contractors hired by the Tweed Ring inflated invoices to allow profits to be skimmed off the top for both the Ring and the contractor. After the invoices were filed with the city, thirty-five percent of the profit was paid to the contrac- 
tor for his work, and Tweed, as the new leader of Tammany Hall, took twentyfive percent, while the remaining forty percent was divided among his associates. These kinds of embezzling and favor continued until the ring was broken in 1871 (Kandell 88). Along with these tactics, checks that were written to imaginary recipients such as "T.C. Cash," and then given to various members of the ring. Over the few years it is estimated that anywhere from 20 to 200 million dollars in tax revenue was stolen by the Tweed Ring (Kandell 89).

While Tweed and his ring continued their embezzling escapades, many of the people of New York City continued to live in dangerous and unhealthy conditions. In 1855, the population of New York was recorded as approximately 630,000 . Of this, over half were immigrants born outside of the United States ("Geostats"). With recent turmoil breaking out across Europe, such as Ireland's potato famine and the German Revolution, many immigrants made their way to New York City. This rapid growth continued for several decades. So, in only thirty years, the population surged by nearly two million new inhabitants, with most of the growth taking place in the before 1860 . This growth in population not only supplied Boss Tweed with a multitude of new constituents, but more importantly, it placed a huge burden on the cities housing systems. What developed, as a result of the sudden increase in population, was the birth of the tenement houses that eventually would come to line the streets. These tenements were overpopulated, lacked proper ventilation and sewage systems, and they quickly became the worst slums the United States had ever seen. Mortality rates soared in the tenements and were higher there than in any other part of the city. In their height, it was recorded that one in every five babies born to a family living in a tenement home died, and in one house alone, over twenty cases of typhoid fever were recorded. Along with an increase in death and disease, the tenement houses of New York became a hotbed for child crime. Poverty led to desperation and many children took up picking-pockets and other, more violent crimes to help their families make ends meet (Riis 9-35).

In such conditions it is easy to see how education and literacy would be the least of the population's worries, despite the fact that laws had been passed concerning school attendance. Early in the 1800 s many states began passing laws requiring all free white children of school age to attend school. Although the laws were passed with good intentions, they were often neglected and not strictly enforced, as is evident in the development of crime in the slums of New 
York City. During this time, there were several different types of schools offered because free public education had not evolved into the system Americans know today. The Latin Grammar school was the most traditional form of education offered in America and it stressed the teaching of subjects such as Latin, Greek, Geometry, Algebra and Trigonometry. Because many thought it was no longer important to study the classical languages, the English school was developed to teach Reading, Writing, Math, History and Geography. For those who wanted a more elite education, Academies were founded which combined the curriculum of the Latin Grammar and English schools, often in a boarding school setting. While all of these forms of education welcomed boys, sometimes at a nominal fee, education was limited for females to the home in what was known as a Dame school. Dame schools focused less on training for a career and more on domestic skills like basic reading, sewing and cooking (Gordon 81-117).

While families had several choices for the kind of education their children would receive, very few actually attended school. In the 1800 s less than half of school-aged children were enrolled in school and less than that actually attended. Children often were forced to work at ages as young as age five or six to help provide for their family that was usually living in poverty. Also important to remember is that at this time in the North, the population of free blacks was also increasing, but before the Civil War only two schools were open to them despite an expanding population of 15,000 . This lack of education led to alarmingly low literacy rates as are recorded in the censuses taken during the mid to late 1800 s (Gordon 227-261).

While changing demographics proved ill-fated for those uneducated immigrants stuck in the slums of the tenement homes, these trends in illiteracy became increasingly important to Boss Tweed who depended on and courted this uneducated population. He saw these new immigrants as his constituency, and because he had grown up not far from these slums, he knew first hand of their struggles and needs (Kandell 86). With his increasing power in city government, Tweed offered these people labor-based jobs, while counting on their lack of education to prevent them from questioning his actions and policies. Because they were so grateful for the opportunity to work and improve their means for survival, they gave Tweed their trust and their vote: a menacing combination for the city's treasury. As immigration rates increased and Tweed continued to grow in power, Thomas Nast was taking notice. 
Inspired by the revolution for liberty, Nast followed in Italy and, disgusted by the immense gap between the have's and the have-not's, Nast used his platform as a nationally recognized political cartoonist to take on the Tweed political ring and spark a movement for civil reform. Tweed made his first appearance in a Nast cartoon on September 11, 1869. Entitled "The Democratic Scapegoat," Nast's cartoon depicted politician August Belmont as the scapegoat for the New York Democratic Party's failures. In that cartoon, Tweed serves as the presiding officer in the trial against Belmont, and though not the focus of the cartoon, Tweed's role defines his growing power in New York's politics. The second cartoon in which Tweed makes an appearance was published at the end of the same year, but its significance was not just that it depicted Tweed, but that it was the first illustration to recognize all of the prominent members of the Tweed Political Ring.

"The Economic Counsel" pictured Tweed, Sweeny, Hall, and Connolly as high priests hoarding the cities tax revenue. In these early pictures, it becomes evident that Nast had developed an extreme hatred of corruption for personal gain, and that hatred combined with his feelings of patriotism and duty to fight for liberty, inspired his fight against the Tweed Ring. After these early works, it is not evident that Tweed and his ring were tuned into the passion on which Nast drew. They paid little attention to the drawings and may even have thought that the bad press would simply blow over. It was not until early 1870 that Tweed took notice of the cartoonist and began assailing his work in a most peculiar venue:

Finally a bill was presented to the State Legislature — a Ring provision for a school-tax levy-but chiefly prepared as an official protest against "an artist encouraged to send forth in a paper that calls itself a 'Journal of Civilization' pictures vulgar and blasphemous, for the purpose of arousing the prejudices of the community against a wrong which exists only in their imagination." Curiously personal language, this would seem, to be dignified by embodiment in Assembly Bill No. 169, of March 31, 1870. (Paine 150)

The bill, which disguised itself as a call for school taxes, was really a personal attack on Thomas Nast. Other Ring-controlled publications began criticizing Nast's work, but with no success of slowing Nast down (Paine 140-154). 
Despite criticism from his journalistic peers and some scathing accusations from the Tweed Ring, Nast continued his crusade against Tweed. The battle really heated up with the publication of Nast's cartoon entitled "Tweedledee and Sweedledum." Appearing as Nast's first cartoon of 1871, the picture depicted Tweed and Sweeny handing out money from the city treasury to various contractors and businessmen with whom they had made deals. At this point, Tweed went beyond written protests and attempted to cut Nast (and Harper's Weekly) off where it hurt: in profits. With his seemingly limitless influence over the city government, Tweed ordered the Board of Education to refuse Harper's bid to publish new schoolbooks to be adopted by the district, and even to destroy all those books already in use that had been published by Harper. This reaction seemed only to fuel Nast's intent to uncover the corrupt practices of Tweed and his ring, and the cartoons branding them as thieves continued to be published. The public thus was becoming increasingly aware, and other major publications, such as The New York Times and The Tribune, joined Nast's efforts with their own editorial articles (Paine 158-165).

With all of the negative publicity the Tweed Ring was suffering, it was just a matter of time before it would crack. Tammany Hall chose Governor John T. Hoffman as their presidential candidate for the 1871 elections. Samuel Tilden, who was not an inside member of the Tweed Ring, but did have connections to the political machine, had his own presidential plans, however. Upset that he was not nominated for candidacy, Tilden began plotting to overthrow the Ring. Tilden used his connections with the Ring's sheriff, James O'Brien, to ensure an appointment for his friend William Copeland. Using Copeland, who had been employed by the Controller, Tilden gained access to the Ring's confidential books and had Copeland start making copies of all of the records. After compiling all of the incriminating evidence he needed, Tilden leaked the information to The New York Times. Despite attempts by the Ring to bribe The Times with five million dollars not to print the exposé, the newspaper printed the facts and challenged the Ring to produce the original copy of their books and disprove what was printed (Paine 166-170).

With this public affirmation of what he had been arguing for two years, Nast intensified his assaults on Tweed and his ring, and in this time published one of his most famous works. The characature entitled "The Brains" pictured the bulbous Tweed with a moneybag for a head. He followed this cartoon with the scathing double-picture entitled "Two Great Questions," asking "Who is 
Ingersoll's Co.?" and "Who stole the people's money?" (Paine 177-181). With these, Tweed responded by demanding, "Let's stop them damned pictures...I don't care so much what the papers write about me-my constituents can't read; but damn it, they can see pictures!" (Hess 13) To stop the pictures, Tweed's Ring began threatening Nast with anonymous letters and "rough characters" loitering around his home. When that did not work, "a party of rich men" visited Nast and offered to pay all of the expenses to send Nast to work abroad for an indefinite period of time. When Nast refused, a representative from Broadway Bank offered Nast $\$ 500,000$ to "drop this ring business and get out of the country" (Paine 182). But in some ways, this only strengthened Nast's resolve to do everything he could to bring down the Ring.

The Tweed Ring continued to crumble, and Nast brought out his biggest assault yet. Nast remembered the Tammany Tiger painted on the side of the Big 6, and it inspired the cartoon entitled "The Tammany Tiger Loose Again." A committee, entitled the Booth Committee, had been commissioned to investigate the practices of the Tweed Ring, and they eventually proved what The Times had printed. Tweed was subsequently arrested but was then released on bail. Tweed intended to continue his corrupt practices and to stuff the ballot boxes in the city's upcoming elections, but after seeing Nast's latest work, he was scared into having an honest vote. However, the honest vote shattered the Tweed Ring. Tweed was later arrested two more times for crimes involving embezzlement conducted by his political machine, but he eventually was able to escape from the arguably lax prison in which he was held. He then sailed to Cuba and then Spain. While some may have given up at this point, Nast continued to assail Tweed, and it was one of his cartoons that actually led to Tweed's arrest in Spain. "Tweed-ledee and Tilden-dum" depicted Tweed in prison stripes, dragging two lesser thieves to justice while pointing to posters promising rewards for information leading to the arrest of anyone involved in the Ring's plundering. Police in Spain, not understanding the posters written in English, believed the picture was of a man wanted in the kidnapping of two children. But because of the remarkable resemblance Nast's caricature had to Tweed, the Spanish Police were able to arrest Tweed and have him extradited back to the United States. When he returned to New York, his bags were checked and it was discovered that Tweed had saved a copy of every drawing Nast ever drew of him (Paine 183-202). 
Of all of the editorials and newspapers opposed to Tweed's scandals, interestingly it was Nast's cartoons that Tweed saw as his greatest juggernaut. Others also protested the Tweed Ring's infamous acts, though they were met with less fame and success. At Harper's Weekly, along with Nast, was editor and editorialist George William Curtis. His accusations were less blunt, and Nast often criticized that Curtis was too apologetic in his editorials. Louis John Jennings of The New York Times proved more pivotal than Curtis in helping Nast break down the Tweed Ring. Jennings was, in fact, the journalist who received and published the Ring's records from O'Brien, the sheriff under that ring that secured a copy of the city's financial books. But despite the role of others in the fight against Tweed, it was Nast's cartoons that were most influential in shaping public opinion. Because of the demographics of New York City, including a rising immigrant class and illiterate masses, the people most seduced by Tweed's promises of jobs and social improvement were those that Tweed was able to reach. Honesty was also a major player in shaping public opinion. Nast and other journalists continually damaged Tweed's reputation, but it was Nast's unrelenting cartoons depicting Tweed's questionable morality that eventually caused the public to question Tweed's motives. Nast, like modern political cartoonists, used a comedic medium not only to enlighten his audience of the corrupt practices of the Tweed Ring, but also to reinforce the public's common sense of what is right and wrong (Greenberg). Here, it is truly an example of Good against Evil as Nast maintained his morals despite threats and bribes to abandon his crusade. The people of New York also built up their trust in Nast's unrelenting patriotism. He initially had gained their trust with his work during the Civil War, when he fought for the rights and benefits of the army and called for a compromise to end the bloody warfare. Nast also proved that it was not only Tweed he was after, but all who stood in the way of liberty and democracy. Those that Nast had supported for years, including Theodore Roosevelt, were not exempt from caricature in Nast's work. This impartiality proved to his public that they could expect honesty without partisanship from him (Paine 477-480).

Nast provided America with more than just popular cartoons. He created lasting symbols including the Democratic Donkey, Republican Elephant and Uncle Sam, which have shaped American politics for over a century, as well as images, such as Santa Clause, which permeate pop-culture even today. Nast's cartoons provided his audience with a visual illustration to help them interpret 
the events going on around them (Greenberg). He was able to pose questions, make his audience think, and inspire action by putting his ideas into a universal language: art (Greenberg). With this power of his pen, Nast was able to bring down corrupt government. Despite Tweed's manipulation of the predominately illiterate public through smoke-screens of civil reform promises, Nast was able to shape public opinion and breakdown Tweed's corrupt city government before it was able to spread its influence to the national spectrum. His life-like pictures and extreme, unforgiving honesty inspired a new movement in political cartoons and civic reform, but more importantly, proved that pictures are worth well more than a thousand words. To Nast, pictures were priceless. 
Callow, Alexander B. "What Are Your Going to Do About It?: The Crusade Against the Tweed Ring." The New-York Historical Society Quarterly 49 (1965): 117-142.

Dictionary.Com. Lexico Publishing Group, LLC. 15 Nov. 2003. $<$ http://www.dictionary.com>.

Gordon, Edward E., and Elaine H. Gordon. Literacy in America: Historic Journey and Contemporary Solutions. Westport: Praeger, 2003.

Greenburg, Josh. "Framing and Temporality in Political Cartoons: A Critical Analysis of Visual News Discourse." Canadian Review of Sociology and Anthropology. 39 (2002): 181-198. EbscoHost. ScarboroughPhillips Library, Austin. 15 Nov. 2003 <http://search.epnet.com/>.

Hess, Stephen, and Milton Kaplan. The Ungentlemanly Art: A History of American Political Cartoons. New York: Macmillan Publishing Co, Inc., 1975.

Geostat Historical Census Browswer. 23 Sept. 2003. University of Virginia Library. 6 Sept. 2003. <http://www.fisher.lib.virginia.edu>.

Kandell, Jonathon. "Boss." Smithsonian 32 (2002): 84-90.

Paine, Albert B. Thomas Nast: His Period and His Pictures. New York: Chelsea House, 1980.

Riis, Jacob A. The Battle with the Slum. Mineola: Dover Publications Inc., 1998.

Shannon, William V. "The Age of the Bosses." Historical Viewpoints: Notable Articles from American Heritage. Ed. John A. Garraty. 2 vols. New York: Harper \& Row, 1987.

Spartacus Educational. 13 September 2003. $<$ http://www.spartacus.schoolnet.co.uk>.

Stone, Clarence N. "Urban Political Machines: Taking Stock." PS: Political Science \& Politics 29 (1996): 446-450. InfoTrac. Expanded Academic ASAP. Scarborough-Phillips Library, Austin. 6 Sept. 2003 $<$ http://infotrac.galegroup.com/itweb/seu_main/>. 


\section{Lesbianism as a Cat's-Paw: The True Role of Mlle. Reisz in The Awakening}

Catherine S. Blackwell, an English Literature major intending to graduate in May 2004, wrote this paper for Dr. Tim Green's Women Writers course in the spring of 2002.

It is said that true genius is timeless, sparking human imagination with its complexity long after its creator has died. Kate Chopin's novel The Awakening is a fine example of such virtuosity, provoking as much controversy today as it did in 1899. Yet while the novel is hailed as an archetypical feminist demand for sexual independence, its criticism of suppressed passion is generally overlooked. I submit that the core issue of this novel is not sex, but passion, specifically artistic passion, and that The Awakening was Chopin's proclamation of a woman's right to pursue art without being branded sexually aberrant.

A woman stepping outside the tightly-drawn Victorian definition of feminine normalcy was socially disastrous, albeit shockingly easy. A proper woman of the era was expected to devote herself entirely to her husband and the bearing of his children; a childless woman, by definition, was thus far from ideal. Indeed, normal women were considered incapable of any passion not maternal in nature. Critic Cynthia Griffin Wolff writes that these stringent "normative pronouncements" were not mere social biases, but were in fact views propounded by the medical community (3). Dr. William Acton, widely accepted as the era's leading authority on female sexuality, wrote in 1875 , "Love of home, of children, and of domestic duties are the only passions [women] feel" (qtd. in Wolff 3).

Chopin acknowledges this philosophy by drawing her female characters according to its standards. Madame Adéle Ratignolle is obviously a paragon among the "mother-women ... who idolized their children, worshiped their husbands, and esteemed it a holy privilege to efface themselves as individuals" (Chopin 10). Indeed, Madame is the "embodiment of every womanly grace and charm" (10). However, the mere act of giving birth does not render one a mother-woman, Chopin warns. The reader learns quickly that Edna Pontellier falls short of the ideal, for her soul is not concentrated on her family: "I would give my money, I would give my life for my children; but I wouldn't give myself" 
(63). Still, while Edna initially exists within social boundaries, the testy, gifted and childless Mlle. Reisz does not. Eschewing male companionship, the pianist unquestionably represents the inverse of the mother-woman; her consummate musical skill is her only socially-acceptable attribute.

An analysis of Mlle. Reisz requires consideration of the dilemma facing the gifted Victorian-era female artist. Essentially, art and feminine responsibility were mutually exclusive; to pursue one was to neglect the other. The true artist faced a particularly difficult decision: she must either submit to social mores, only to be tormented by frustrated artistic energy, or defy society and satisfy the Muse. By adopting the latter course, the artist chose a life of censure, regardless of her sexual persuasion.

The character of Mlle. Reisz, of course, includes the element of homosexuality. In "Art Is an Unnatural Act: Mademoiselle Reisz in The Awakening," Kathryn Lee Seidel notes that Mademoiselle "embodies the traits of the female artist as lesbian, at least as the late nineteenth century understood this concept" (1). Such traits are duly reflected in her appearance, as she is the novel's sole example of physical ugliness amidst a cast of lovely characters (Chopin 33, 82, 84). Critic Gerri Brightwell adds that Mademoiselle's rather mannish personality, with its tendency toward "aggression and assertion, taboo in women," enhances her abnormal image and ensures her position as a social outcast (5).

Nineteenth-century society deemed overt lesbians both distasteful and threatening. Lillian Faderman, in To Believe in Women: What Lesbians Have Done for America, remarks that such women were viewed by sexologists as neurotic "sexual inverts" seeking to usurp traditional male roles (5-6). Faderman adds that these women, in fact, did claim entitlement to male privileges and hoped to "neuter the notion of gender-appropriate spheres" (10). It is a small wonder, then, that women who refused the domestic yoke were seen as threats to the accepted order. An unmarried career musician would have been considered deviant and unnatural, rejecting men in favor of women and babies in favor of art.

Chopin's none-too-subtle pairing of great artistic talent and blatant homosexuality in Mademoiselle's character is clear indication that she is aware of these stereotypes and intends to treat them satirically. Accordingly, she creates in Mlle. Reisz a caricature, a homely "non-woman" with false hair, a large nose, a habit of shuffling or creeping rather than walking, and a wholly unpleasant demeanor (Brightwell 5). In short, Chopin has taken great pains to 
render Mlle. Reisz a veritable freak of nature.

Mademoiselle's negative attributes do not end with her repugnant appearance, for we see at once her predatory, subversive lesbian nature. In Grand Isle, she follows Edna about and profusely admires her appearance, making excuses to converse with or touch the younger woman (Chopin 34, 60, 64). Later, in New Orleans, she seduces Edna with music, encouraging her to pursue her art and leave her husband $(83-84,104)$. Elizabeth LeBlanc, in her essay "The Metaphorical Lesbian: Edna Pontellier in The Awakening," writes of Mlle. Reisz:

Through her advice and friendship, but most of all through her artistry, Mademoiselle Reisz fosters in Edna a sense of the possibilities for joy and fulfillment outside the realm of male tradition and meaningless codes. (303)

Mlle. Reisz thus satisfies the basest nineteenth-century expectations of a lesbian: by aiding in the disruption of one marriage, she symbolically attempts to destroy society's patriarchal order. Implicit in Chopin's caricatural treatment of Mlle. Reisz is the concept that a heterosexual person could recognize a homosexual on sight. Chopin hints at her own disbelief in such a presumption by redirecting the suspicious reader. To accomplish this, she raises subtle questions about the true nature of Edna's friendship with Mme. Ratignolle: "Mrs. Pontellier liked to sit and gaze at her fair companion as she might look upon a faultless Madonna" (Chopin 13).

The excessive physical charm of the Creole had first attracted her, for Edna had a sensuous susceptibility to beauty. Then the candor of the woman's whole existence, which every one might read, and which formed so striking a contrast to her own habitual reserve might have furnished a link. Who can tell what metals the gods use in forging the subtle bond which we call sympathy, which we might as well call love. (Chopin 18)

And:

Madame Ratignolle laid her hand over that of Mrs. Pontellier, which 
was near her. Seeing that the hand was not withdrawn, she clasped it firmly and warmly. She even stroked it a little, fondly, with the other hand, murmuring in an undertone, "Pauvre chérie." (22)

Although such passages have caused critics Seidler and LeBlanc to read The Awakening as a lesbian text, biographer Emily Toth interprets them differently. In Unveiling Kate Chopin, she explains: "Readers a century later, confusing sexuality and sensuality, sometimes see more than what is there, and think there is a 'lesbian' connection between [Adéle and Edna]" (211). Like Toth, I believe Chopin's inclusion of this dynamic was intended to recognize that women could be "intimate friends" without being "unnatural" sexual partners, and to further mock the stereotype of lesbian-subversive (Toth 212). There is no doubt that Mme. Ratignolle is a mother-woman and adores her husband; it is thus unthinkable that she might threaten the social order she herself values.

Turning her attention to another facet of the stereotype, Chopin pointedly includes many references to feminine, non-lesbian art. Certainly we know that Edna is rapidly developing into a talented painter. But we should not overlook the fact that Mme. Ratignolle, like Mlle. Reisz, is a musician: Edna enjoys listening to her friend practice at the piano in Grand Isle, and in fact Monsieur Pontellier remarks to Edna that Mme. Ratignolle is "more of a musician than [Edna is] a painter" (Chopin 75). The Ratignolles host frequent soirées musicales for musically-inclined friends (72).

There is one additional genre of traditional feminine artistry upon which Chopin touches repeatedly but does not overtly acknowledge. Mme. Ratignolle and Mme. Lebrun are both avid seamstresses: Mme. Lebrun is often "busily engaged at the sewing machin," and Mme. Ratignolle even goes so far as to carry her piecework to the beach (Chopin 28). This subtle, almost offhand inclusion of needlework, well-known to have been the primary form of artistic expression among nineteenth-century women, further erodes any link between art and subversion. "Real women," after all, sewed; as a matter of fact, one key element in Edna's failure to meet the mother-women standard is her disinterest in the past-time (11).

That Chopin intended to debunk the artist-lesbian stereotype seems clear. The question becomes why, as a non-lesbian and a mother-woman, she chose to do so. The issue becomes even more curious when viewed against Kate Chopin's distaste for causes. Per Seyersted, in Kate Chopin: A Critical 
Biography, mulls this very issue:

Kate Chopin was never a feminist in the dictionary sense of the term, that is, she never joined or supported any of the organizations through which women fought to get "political, economic, and social rights equal to those of men." (102)

Critic Nancy Walker agrees that Chopin was "never a reformer or even a particularly political person" (Walker 95), but also notes that "Chopin's fiction of the early 1890 s demonstrates her engagement with the controversial issues of the day" (74).

Homosexuality was indeed a hot topic in the years immediately preceding publication of The Awakening, having been thrust out of the closet by events in the news. The suffrage movement kept women's rights issues in the public eye, with such mannish women as Susan B. Anthony leading the march. More specifically, the 1892 case of Alice Mitchell and Freda Ward, two wealthy young women whose affair ended in murder, must have shocked the nation. Carroll Smith-Rosenberg, author of Disorderly Conduct: Visions of Gender in Victorian America, explains:

In 1892 a cause cèlébre catapulted the discussion of lesbianism, until now quite a minor theme in the medical and asylum journals, into polite and influential circles...The violent ending of a plan by two women to flee family and friends and live as husband and wife in New Orleans electrified the country and drew popular attention to the existing body of literature on lesbian transvestism. (273)

The Mitchell-Ward matter was, of course, followed by Oscar Wilde's infamous sodomy trial in 1895 , landing the subject squarely in the literary arena. These events, and the anti-homosexual sentiment which ensued, may have convinced Chopin to address this particular brand of prejudice.

Given her dislike for causes, however, it is likely that Chopin was making a precise point rather than broadly protesting bigotry. She seems to have provoked awareness of Mlle. Reisz's lesbianism explicitly to catch readers in the act of judging the artist's lifestyle rather than her art. Chopin's loathing for public interest in artists' private lives sounds clearly in her reaction to the 1893 
biography of Shakespearian actor Edwin Booth, the brother of John Wilkes Booth. Biographer Daniel Rankin noted her response to the inclusion of Booth's personal letters, excerpting the following remarks:

\begin{abstract}
...it is not here that we are to look for the real Edwin Booth, in a puerile collection of letters ... The real Edwin Booth gave himself to the public through his art. Those of us who most felt its magnetic power are the ones who knew him best, and as he would have wanted to be known. (qtd. in Walker 96)
\end{abstract}

Chopin resented invasions of her own privacy as well. Simply put, she appears to have grown tired of being questioned more often about her lifestyle than her work. Anne Goodwyn Jones reflects upon this frustration in Tomorrow is Another Day: The Woman Writer in the South, 1859-1936:

A rather overt expression of discontent came in an article Chopin wrote for the St. Louis Post-Dispatch:

Many readers would be surprised, perhaps shocked, at the questions which some newspaper editors will put to a defenseless woman [writer] under the guise of flattery.

..."Do you smoke cigarettes?" is a question which I consider impertinent, and I think most women will agree with me. Suppose I do smoke cigarettes? Am I going to tell it out in a meeting? Suppose I don't smoke cigarettes. Am I going to admit such a reflection upon my artistic integrity, and thereby bring upon myself the contempt of the guild? (144145)

Yet Chopin was not merely annoyed about the interest in her cigarette smoking and other aspects of her personal life; she was concerned about it, and she had good reason to be. If society disapproved of a particular author, her work would neither be read nor taken seriously. With the prudish Victorian population on one end of the spectrum suspiciously eying the mannish New Women on the other end, the woman writer would have to tread lightly. Working too diligently or exhibiting too much ambition might very well appear unladylike. Cigarette-smoking and card-playing - two of Chopin's pet vices - might have 
been deemed mannish (Toth 203). Chopin sought to avoid such traps by projecting a self-deprecating and feminine persona, creating the impression that she wrote only when not occupied with her children, her sewing or domestic duties (Jones 145). Jones observes: "Publicly, then, Chopin was fully conscious of the implicit contradictions between lady and artist and made the best of them, largely through irony. More privately, her views on art were, in fact, quite serious" (146).

Chopin must have scoffed at the notion that her literary success depended less on her skill as an author than on her ability to appear ultra-feminine. Further, she almost certainly resented having to strive for literary success beneath a veil of unambitious modesty. As Emily Toth insightfully muses: "I began to suspect that ambition, not adultery, may have been [Chopin's] biggest secret-for her manuscripts show that she worked much harder at her craft than she ever admitted in print" (xxi).

Openly attacking public perception of the female artist as mannish/lesbian, it seems, was a battle Kate Chopin wisely chose not to undertake. Instead, she engaged the enemy in a fictional setting, taking care to disguise her personal interest by creating a musician rather than an author as her lesbian artist. She urged readers to note that while Mlle. Reisz was a truly gifted artist, her talent did not save her from becoming something of an outcast. She pained readers with the awareness that for Edna Pontellier, choosing to pursue art seriously meant choosing to live Mademoiselle's lifestyle. She shamed readers with the realization that for a Victorian woman to engage her artistic talents, she would have to do so under the auspices of motherhood—as did Mme. Ratignolle-or face the consequences.

Above all, perhaps, Kate Chopin wanted her readers to understand that sexual preference does not negate great art; that to focus on an artist's lifestyle rather than her art is unjust; and that self-righteous judgment of artists results in a tremendous waste of artistic talent and passion. Let us hope that twenty-first century readers can finally see, as nineteenth-century readers could not, that what is truly shocking in The Awakening is not sex, but repression of feminine art. 
Chopin, Kate. The Awakening. New York: Bantam Books, 1981.

Brightwell, Gerri. "Charting the Nebula: Gender, Language and Power in Kate Chopin's The Awakening." Women and Language, Fall (1995). Expanded Academic ASAP. InfoTrac. Scarborough-Phillips Lib., Austin. 7 Apr. 2002 $<$ http://infotract.galgroup.com/itweb/seu_main>.

Eagleton, Mary. Feminist Literary Theory: A Reader. New York: Basil Blackwell Inc., 1986.

Faderman, Lillian. To Believe in Women: What Lesbians Have Done for America. New York: Houghton Mifflin Company, 1999.

Fisher, Trevor. "The Musteries of Oscar Wilde." History Today, 50.12 (2000): 18-21.

Jones, Anne Goodwyn. Tomorrow Is Another Day: The Woman Writer in the South, 1859 - 1936. Baton Rouge: Louisiana State University Press, 1981.

LeBlanc, Elizabeth. "The Metaphorical Lesbian: Edna Pontellier in The Awakening." Tulsa Studies in Women's Literature 15 (1996): 289 307.

Patterson, Katherine. "Out of a Convention of Awakening: Defining a Space Beyond Awareness." Feminist Issues 11.2 (1991): 101-113.

Pizer, Donald. "A Note on Kate Chopin's The Awakening as Naturalistic Fiction." Southern Literary Journal 33.2 (2001): 5-13.

Seidel, Kathryn Lee. "Art is an unnatural act: Mademoiselle Reisz in The Awakening." The Mississippi Quarterly, Spring (1993).

Expanded Academic ASAP. InfoTrac. Scarborough-Phillips Lib., Austin. 7 Apr. 2002

$<$ http://infotract.galgroup.com/itweb/seu_main>.

Seyersted, Per. Kate Chopin: A Critical Biography. Baton Rouge: Louisiana State University Press, 1969.

Smith-Rosenberg, Carroll. Disorderly Conduct: Visions of Gender in Victorian America. New York: Alfred A. Knopf, Inc., 1985. 
Stone, Carole. "The Female Artist in Kate Chopin's The Awakening: Birth and Creativity." Women's Studies, 13 (1986): 23-32.

Thomas, Heather Kirk. "Kate Chopin's Scribbling Women and the American Literary Marketplace." Studies in American Fiction 23 (1995): 19-27.

Toth, Emily. Unveiling Kate Chopin. Jackson: University Press of Mississippi, 1999.

Walker, Nancy A. Kate Chopin: A Literary Life. New York: Palgrave, 2001.

Wolff, Cynthia Griffin. "Un-utterable longing: the discourse of feminine sexuality in The Awakening." Studies in American Fiction 24 (1996): 3-23. 


\section{To Create More Worlds: A Discussion of Alternative Worlds in Paradise Lost and His Dark Materials}

Jennifer Wharton, an Education major focusing on Language Arts and Reading and intending to graduate in May 2006, wrote this paper for Brother George Klawitter's Age of Milton course.

The existence and creation of worlds has always fascinated the human mind. Modern fantasy has explored the ideas of alternate worlds, parallel worlds, and their history without exhausting this endless subject. Philip Pullman, one of the best fantasy writers today, has written a trilogy that discusses the existence of these worlds and the scientific ramifications of travel between them. The trilogy, His Dark Materials, consists of three books: The Golden Compass, The Subtle Knife, and The Amber Spyglass. His work deals with an amazing array of theological, philosophical, literary, and scientific ideas. Although the scientific and literary components of the books are based on parallel worlds, the thematic elements are centered on Milton's great epic, Paradise Lost. Pullman has presented his work as a retelling of Paradise Lost although he admits that it includes many other ideas and theories. However, there is another interpretation for this work: seeing the trilogy as the history of an alternate world. By using this interpretation, many discrepancies in the work are resolved and a new and interesting perspective of Paradise Lost itself emerges.

There have been many fantasies based on alternate and parallel worlds. Modern writers of this genre include Piers Anthony, Joan Aiken, C. S. Lewis, and Diana Wynne Jones. The idea of alternate worlds can best be seen in Diana Wynne Jones' Witch Week. In this story, a world exists that condemns and destroys witches. When a group of children accidentally call Chrestomanci the enchanter out of his world to help them, he explains the high occurrence of magic and witchcraft in their world by telling them about alternate worlds:

[There are] a multitude of worlds, all very different from one another...If-worlds, counterfactuals...they are made from the great events in history...like the Battle of Waterloo. In our world, Napoleon lost [this battle], but another world at once split off from ours, in which 
Napoleon won the battle. (Jones 172-173)

Joan Aiken has also created alternate worlds, although in her stories their difference is not overtly obvious. In Black Hearts in Battersea the story appears to be historical fiction, until the reader realizes that in Aiken's world English history is turned upside down: "[they were] Hanoverian plotters, bent on removing good King James from the throne, and bringing in the young pretender, Bonnie Prince Georgie" (90). In Aiken's stories, King James has the throne, and the Hanoverians are always prevented from taking over. Another type of alternate world is seen in C. S. Lewis' Perelandra. Perelandra is Venus, and in Lewis' tale the Fall has not occurred and the world is still in an Edenic state: "Lewis imagines a new myth of the Fall—only this time there is no Fall" (Tanner). It is Dr. Ransom's mission to journey there and prevent the Eve of Perelandra from sinning as the Eve of earth has done. In this tale, Perelandra is the possibility of either an alternate world or a parallel world. Either it can become another Earth, with a history differentiated only by its major events, or it can become a completely different world in the proximity of earth. Parallel worlds and universes are together in space but not in time. Most science fiction planets are parallel worlds, accessible to each other but with no linking history. In short, alternate worlds are infinite versions of each other, while parallel worlds are unique creations.

Keeping the ideas of alternate and parallel worlds in mind, we next look at the conventional views of Paradise Lost and Pullman's trilogy. The purpose of Paradise Lost, according to Milton and the majority of his critics, is to retell the story of Satan's rebellion, the creation of earth, and the Fall in Eden and to explain God's deeds in these events. Milton states this purpose at the beginning of the first book, "That to the highth of this great Argument/I may assert Eternal Providence, / And justifie the wayes of God to men." (1.24-26). Pullman's purpose is the opposite of Milton's; he declares that his intent is to declare God dead, to reverse the ideas and beliefs of Paradise Lost and set up a Republic of Heaven, creating a different system of life and belief. He explains this, saying: "We need a story, a myth that does what the traditional religious stories did: it must explain." ("Republic"). In Pullman's version, Satan wins, God dies, and Adam and Eve take control of their destinies: "we've got to study and think and work hard, all of us, in our different worlds, and then we'll build...The Republic of Heaven." (Amber 464-465). 
However, there are problems with these views of Milton and Pullman. Milton did not simply retell the Biblical account in verse. He expanded a story that occupies a few chapters into a twelve-book epic. For example, compare the Biblical account of the creation of living creatures and Milton's retelling. The Biblical account is as follows:

And God said, "Let the land produce living creatures according to their kinds: livestock, creatures that move along the ground, and wild animals, each according to its kind." And it was so. God made the wild animals according to their kinds, the livestock according to their kinds, and all the creatures that move along the ground according to their kinds. And God saw that it was good. (1:24-25)

Milton's recreation of these two verses lasts for almost fifty lines. It begins:

The Sixt, and of Creation last arose

With Eevning Harps and Mattin, when God said,

Let th'Earth bring forth Soul living in her kinde,

Cattel and Creeping things, and Beast of the earth,

Each in their kinde. The Earth obey'd, and strait

Op'ning her fertil Woomb teem'd at a Birth. (7:449-454)

This is only a small example of the many added ideas, images, and personal views of Milton that are woven into Paradise Lost. He also includes discourses on astronomy, information on angels and how they live, and a description of a battle in heaven between Satan and God. Like Milton, Pullman widely diverges from his original text. He rewrites the characters of Eve, Adam, Satan, God, and the angels. Lyra, the new Eve, is a twelve-year-old child. Her personality and flaws are far more developed than Milton's Eve, and she has many fantastical adventures that have no parallel in Milton. Pullman's character that adheres most closely to one of Milton's characters is Lord Asriel, the counterpart of Satan. Asriel is not a perfect person; he is, like Satan, a heroic personage. He is noble and courageous and also cruel and deceitful; "Lyra was reminded, as she always was when she saw him... of how much he frightened her" (Golden 10). In addition, after Lord Asriel kills Lyra's friend to open up other worlds, he says, "We've gone beyond being allowed, as if we were children" (Golden 346). 
Pullman's story is more properly a continuation of Paradise Lost, possibly a description of the final battle between God and Satan. From this point of view, the trilogy is much clearer, since many of Pullman's inventions have no correlation in Milton's epic. However, there are still several major flaws. One of the most unstable parts of the story is Pullman's description of the Church, which represents authority. Despite Pullman's depiction and proclaimed belief in balanced characters, people like Will and Lyra who are capable of both good and evil, all the characters related to the church are completely corrupted. Even Mrs. Coulter, who probably represents Lilith, shows a hint of goodness at the end of the story when she saves Lyra. But there is no goodness shown in the priests and ministers of the church. They are all power-hungry, fanatical beings. The church itself is censorious and forces people to retain outmoded beliefs, "myriad worlds which the Church would suppress all knowledge of" (FitzHerbert). Another flaw, and one of the weakest points in the story, is the counter-fall, where Lyra and Will reverse the flow of dust and defeat the Authority with their first kiss. As Townsend points out, "Eve's sin is not sex; it is disobedience." The empathy readers have felt with the rebels is given a severe blow, "to seize Heaven on the ground that it straitjackets desire, what a bore!" (Donnelly). If Pullman's reversal of Milton's story were consistent here, Lyra and Will would have committed some heroic act of disobedience. A true retelling of the Fall would have been more similar to Lewis' Perelandra, where Tor and Tinidril face a choice of obedience and disobedience and choose to obey. In Tor's words, "And then it was before me like a thing coming towards my hand...what I should do in like case. There I learned of evil and good, of anguish and joy" (210). In view of the discrepancies in these retellings, it is difficult to see Milton as a retelling of Scripture or Pullman as a retelling of Milton.

If Milton expanded and changed the Biblical account and Pullman has formed his "retelling" of Paradise Lost according to his own prejudices about religion, how can these stories be connected to each other or the original Biblical story? If both accounts are viewed with the conception of alternate worlds in mind, they become connected. Pullman himself draws attention to the fantastical elements in Paradise Lost: "Milton was using the apparatus of fantasy...He was aware that the geography of paradise didn't actually correspond to the real world" (Lyall). Whether or not Milton actually believed in the physical reality of the paradise he envisioned, he created his world out of the bare bones of the Biblical account. This is the essence of alternate-world fan- 
tasy: taking an existing world order and creating variations of it. Pullman notices this idea in Milton and uses it to create Lyra's world, an early 20th century Oxford with fantastical elements: daemons, talking bears, and Dust, the strange particles that escape when doorways between worlds are opened. Pullman's universe consists of alternate and parallel worlds. Will's world is ordinary, everyday England. Lyra's country is an alternate world with fantastical elements. The parallel worlds are Cittàgazze, the underworld, and other worlds that are assumed to be in existence, although Lyra and Will do not visit them. Will meets Lyra when he discovers an opening between their worlds: "It looked as if someone had cut a patch out of the air" (Subtle 15). The worlds that Lyra and Will discover are within the comprehension of the children, but are not related to the history of their own worlds.

If Milton created an alternate world in order to expand the Biblical account, is it not possible that Pullman's Republic is actually an alternate world in and of itself? This would explain the discrepancies in his representation of religion. The alternate world that Pullman has created is a world where the church has become corrupt and evil angels are masquerading as God. Although Pullman explains the existence of "God" in scientific terms and represents him as an angel who has taken over the universe, he never adequately explains where the angels themselves come from; "The Ancient of Days, unceremoniously spilled from His carriage... is God but seems not to be the creator; whence, then, did He get His authority?... who organized destiny in a universe wherein God is supposed to be senile?" (Maguire). According to Moloney, he "[explained] how everything we think and feel can be explained simply by scientific materialism." However, if Pullman's world is an alternate world, then the reader simply accepts that in Pullman's world history has flipped in a different direction and Lyra and Will's worlds are both suffering from a great famine of love. The Church or Authority in Pullman's worlds, which bears no resemblance to any contemporary denomination, is the church gone bad, a glitch in history. Pullman's alternate worlds and parallel worlds are themselves part of an alternate universe. Maloney inadvertently gives the history of this alternate universe when he sums up Pullman's work from a Christian perspective, "imagine if at the beginning of the world Satan's rebellion had been successful, that he had reigned for two thousand years, and that a messiah was necessary to conquer lust and the spirit of domination with innocence, humility, and generous love at great personal cost." In this reading of the story, Pullman triumphs over the dis- 
crepancies of his own atheistic and materialistic world view to present people as they are; corrupt and loving, generous and cruel, and the adventures of Lyra and Will tell us how two people conquer oppressive Authority to allow people once more to strive for morality and virtue.

The human tendency to recreate and explain events and ideas within their own framework is inescapable. Milton attempted to create an understandable God and an earthly Paradise; Pullman has succeeded in illustrating human responsibility and morality in a world of oppression and changing values, despite his own intentions. For example, Lord Asriel (Satan) is intended as the hero of the trilogy. But while both Lord Asriel and Lyra betray and kill those who depend on them, it is Lyra who risks her life to repair the damage she has done. Readers may admire the heroic Lord Asriel, but they identify with the faulty Lyra, who struggles to do good. In this respect, Pullman has exceeded the aims of Milton by portraying a more worthy hero for human understanding. By using the theory of alternate worlds, Pullman's own prejudices and discrepancies can be explained and the reader is free to revel in the adventure and moral questions of His Dark Materials. 
Aiken, Joan. Black Hearts in Battersea. New York: Dell Publishing Co., Inc., 1973.

Donnelly, Daria. "Big Questions for Small Readers." Commonweal 17 Nov. 2000: <http://search.epnet.com/>.

FitzHerbert, Claudia. "More Than a Handful of Dust." Spectator 11 Nov. 2000. Expanded Academic ASAP. InfoTrac. Scarborough-Philips Lib., Austin. 7 Ap. $2004<$ http://infotrac.galegroup.com/>.

Jones, Diana Wynne. Witch Week. New York: Greenwillow Books, 1982.

The Holy Bible: New International Version. Grand Rapids: Zondervan, 1997.

Lewis, C. S. Perelandra. New York: Collier Books, 1965.

Lyall, Sarah. "The Man Who Dared Make Religion the Villian; In British Author's Trilogy, Great Adventures aren't pegged to the Great

Beyond." New York Times 7 Nov. 2000, late ed.:

$<$ http://proquest.umi.com>.

Maguire, Gregory. "Untitled". The Horn Book Magazine. Nov. 2000. Expanded Academic ASAP. InfoTrac. Scarborough-Philips Lib., Austin. 7 Apr. $2004<$ http://infotrac.galegroup.com>.

Milton, John. Paradise Lost. Ed. Roy Flannagan. New York: Macmillan Publishing Company, 1993.

Moloney, Daniel P. "An Almost Christian Fantasy." Rev. of His Dark Materials, by Philip Pullman. First Things: A Monthly Journal of Religion and Public Life 113 May 2001: <http://search.epnet.com>.

Pullman, Philip. The Amber Spyglass. New York: Ballantine Books, 2001.

---. The Golden Compass. New York: Ballantine Books, 1997.

-.-. The Subtle Knife. New York: Ballantine Books, 1998.

---. "The Republic of Heaven." The Horn Book Magazine Nov.-Dec. 2001: $<$ http://search.epnet.com/>. 
Tanner, John S. "The Psychology of Temptation in Perelandra and Paradise Lost: What Lewis Learned From Milton." Renaisance 52.2 (2000): $<$ http://search.epnet.com/ $>$.

Townsend, John Rowe. "Paradise Reshaped." The Horn Book Magazine Jul.Aug. 2002: <http://search.epnet.com/direct.asp >. 


\section{Lilith: A Brief Biography of a Demoness}

\section{E.K. Zimmerman, double majoring in Religious Studies and English} Literature, wrote this paper for Dr. Kelly Bautch's Women in the Bible course. He intends to graduate in May 2005.

A mythological relic whose appearance in art and literature almost consistently signifies the danger or inherent evil associated with wanton women or female sexuality, Lilith, the antediluvian demon turned prodigal first wife of Adam, has captured the imagination of post-Renaissance literature nearly as intensely as the ancient rabbis responsible for such Jewish literature as the Talmud of Babylonia, the Zohar, and the dubious "Alphabet of Ben Sira." English poets John Keats, Robert Browning and Dante Gabriel Rossetti have paid tribute to her in renowned sonnets such as Rossetti's "Body's Beauty": "Of Adam's first wife, Lilith, it is told... That, ere the snake's, her sweet tongue could deceive" (Rossetti 1581). German playwrights have included her heinous wiles vis-à-vis cameos such as Goethe's seminal Faust: "That's Lilith...Adam's first wife. / Watch out for that pretty hair of hers: / Its beauty's quite incomparable. / When she's got some young fellow tangled in it, / She won't let go again so very soon" (Goethe 250-1), or starring roles in the anonymous Jutta and Isolde Kurz's Die Kinder Der Lilith. Victor Hugo combined her with Isis and called her "l'âme noire du monde [the world's black soul]." George Bernard Shaw portrayed her as something of a hero, whereas Remy de Gourmont and Anais Nin both depict her as erotically deceitful as does the Talmud of Babylonia. By the end of the twentieth century even horror novelist Whitley Streiber and sequential-art icon Neil Gaiman bestowed center stage to Lilith, the former adding vampirism to her list of malevolent attributes! Curiously enough, the legend of Lilith,unswervingly related in each of the above examples as the licentious first wife of Adam, did not only begin in exegesis of the Genesis creation account, but she further appears to predate Genesis itself. The following analysis will examine the course of the Lilith legend from its apparent origin, explore her transformation from an ambiguous demon of the night to her contemporary association with the Hebrew creation account, and survey her additional conversion from a formidable fiend to an icon of feminism. 
The designation of Lilith, an Anglicization of the Hebrew lîlitt, as the demoness traditionally associated with Isaiah 34:14 derives from the Hebrew laylâ, or night, though Hutter traces the term further still to the Akkadian lil_tu, which ultimately stems from the Sumerian lí (Hutter 520-1). Indeed, the demon can be traced back to the third millennium BCE, her earliest extant emergence, in the Epic of Gilgamesh. Discovered upon tablets at Nippur and at Ur, the epic poem concerns, in part, the creation of the universe, its subsequent organization, and the creation of man. The segment of the subordinate account Gilgamesh and the Huluppu-Tree contains the earliest extant mention of the demon Lilith. While roaming the banks of the Euphrates, the Sumerian goddess Inanna discovers a dying huluppu tree (probably a willow tree) drowning its roots in the water. Determining its wood ideal for a chair and couch, Inanna uproots the tree and brings it with her to Erech, the "seat of her main sanctuary," where she places the tree into her holy garden in order to nurture it until the tree is large enough to serve her purpose. In summary of his own translation of the huluppu-tree account, Samuel Noah Kramer writes:

Years passed, the tree matured and grew big. But Inanna found herself unable to cut down the tree. For at its base the snake "who knows no charm" had built its nest. In its crown, the Zu-bird - a mythological creature which at times wrought mischief - had placed its young. In the middle Lilith, the maid of desolation, had built her house. And so poor Inanna, the light-hearted and ever joyful maid, shed bitter tears. (Kramer 33)

Kramer's actual translation names this third intruder as "the demoness Lilith" who, after observing the arrival of Gilgamesh and the subsequent slaying of the snake "who knows no charm," flees "to the desolate places which she was accustomed to haunt," or, "to the desert" ("Epic" 9-10). In subsequent Lilith accounts, as we shall see later, Lilith's home in the desert as established in Gilgamesh and the Huluppu-Tree will figure in prominently.

Roughly contemporaneous to the Gilgamesh creation account is the Babylonian terracotta plaque known as the Burney Relief, which depicts a winged female figure with talons wearing a horned crown and flanked by two owls and two lions (Franfort 128-35). (The attribution of wings as such is common in Near Eastern mythology to inhabitants of the underworld; the 
Akkadian Descent of Ishtar to the Netherworld, for example, illustrates a bevy of winged demons who reside with the queen of the underworld, Irkalla [Baumgarten 133-43].) In the 1930s, scholars ascertained that this figure was none other than the Babylonian demoness Lilith of the Huluppu-Tree legend. More recently, modern scholars have tended to associate the figure more with Inanna than with Lilith, citing that although the presence of the owls signifies a relationship with Lilith, the lions are traditionally associated with the Sumerian goddess (Gaines 12). Still, relics from an eighth century BCE limestone plaque discovered in Arslan Tash, Syria to a seventh century CE ceramic bowl from Mesopotamia bespeak the lasting legend of Lilith and the threats she posed. The plaque, discovered in 1933, is thought to have hung in the home of a pregnant woman, thus serving as protection against Lilith in the same manner an amulet would have (14). An inscription on the plaque reads:

O you who fly in darkened room,

Be off with you this instant, this instant, Lilith.

Thief, breaker of bones. (Hurwitz 66)

The admonition to Lilith inscribed on the plaque retains an etiological element as well as its insight into ancient demonology; during an epoch in which the rate of infant death was tremendous, the culpability of this demoness was logical. "Lilith stories and amulets," writes Janet Gaines, "probably helped generations of people cope with their fear" (15).

Apparently, peoples of the Near East had in time become familiarized with the Babylonian demoness, so familiar indeed that upon her solitary mention in the Hebrew Bible-Isaiah 34:14-it appears assumed that the contemporary audience require no further explanation into the definition of the term lilit. Although her reference in Isaiah is brief, the Lilith allusion does offer extraordinary insight into future understanding of the Lilith myth in Rabbinic communities and beyond. The Revised Standard Version of the Bible, a revision of the 1901 American Standard Version, which was a revision of the 1611 King James Version, utilizes the following prevalent English translation of Isaiah 34:14:

And wild beasts shall meet with hyenas,

the satyr shall cry to his fellow;

yea, there shall the night hag alight, 
and find for herself a resting place.

The "night hag" is, of course, Lilith - but the rendition is problematic. Although the 1956 Interpreters Bible's commentary on Isaiah concurs, affirming that Lilith can be interchangeably defined as "the storm demon or night hag," such classification operates entirely outside the bounds of recent erudition concerning Lilith's Mesopotamian heritage (Buttrick 357). The Oxford Bible Commentary alludes to this "rendering based on false etymology," clarifying Lilith's role as "an aggressive female demon, known also from Mesopotamian incantations," and clearly maintaining that "she was not a 'night hag'" (Barton 462). This "false etymology" appears to stem from the assumption that Lilith's name was a variation on the Hebrew lylh, "night", and was consequently thereafter known to be the "night hag." Yet, as Handy observes, "once her Mesopotamian origins became clear the name was associated with [the Sumerian] lil, 'wind'" (Handy 325). Thus, the more accurate JPS rendition:

Wildcats shall meet hyenas,

Goat-demons shall greet each other;

There too the lilith ["a kind of demon," acc. to footnote] shall repose

And find herself a resting place.

Despite the deficiency in detail concerning Lilith in this succinct reference to her, her placement by the text into barren, desolated environs provides an unequivocal connection to the Lilith of Gilgamesh and the Huluppu-Tree, which places her in the desert to which she fled from Gilgamesh. The barrenness of the desert and the symbolism this later provides interpreters of Lilith will be examined in more detail below; but, prior to pursuing Lilith into the desert, we must first follow a specific community of first-century BCE Jews, the Essenes, to their desert commune in Qumran. It is at Qumran that we find the next stop in Lilith's journey, in the Dead Sea Scrolls.

The appearance of Lilith in the Dead Sea Scrolls is somewhat more contentious, with one indisputable reference in the Song for a Sage (4Q510-511) and a promising additional allusion found by Baumgarten in The Seductress (4Q184). The first and irrefutable Lilith reference in the Song occurs in 
4Q510, fragment 1:

\begin{abstract}
And I, a Sage, declare the spendour of his radiance in order to frighten and terr[ify] all the spirits of the ravaging angels and the bastard spirits, demons, Lilith, owls and [jackals...] and those who strike unexpectantly to lead astray the spirit of knowledge, to make their hearts forlorn. And you have been placed in the era of the rul[e of] wickedness and in the periods of humiliation of the sons of lig[ht], in the guilty periods of /[those] defiled by/ iniquities; not for an ever lasting destruction [but ra]ther for the era of the humiliation of $\sin$. (Martinez 1029)
\end{abstract}

Akin to Isaiah $34: 14$, this liturgical text both cautions against the presence of supernatural malevolence and assumes familiarity 'with Lilith; distinct from the biblical text, however, this passage does not function under any socio-political agenda, but instead serves in the same capacity as "An Exorcism" (4Q560) and "Songs to Disperse Demons" (11Q11) insomuch that it is comprised of incantations - comparable to the Arslan Tash relief examined above - used to "help protect the faithful against the power of these spirits" (Wise 414). To a community, this text, which is an exorcism hymn, "deeply involved in the realm of demonology" (Baumgarten 133-43).

Another text discovered at Qumran, conventionally associated with Book of Proverbs, also credibly appropriates the Lilith tradition in its description of precarious, winsome woman: The Seductress (4Q184). The ancient poem, dated to the first century BCE, but plausibly much older, describes a dangerous woman and consequently warns against encounters with her. Customarily, the woman depicted in this text is equated to the "strange woman" of Proverbs 2 and 5 , and for good reason, the parallels are instantly recognizable:

Her house sinks down to death, And her course leads to the shades.

All who go to her cannot return

And find again the paths of life. (Proverbs 2:18-19) 
And:

Her gates are gates of death,
and from the entrance of the house
she sets out towards Sheol.
None of those who enter there will ever return,
and all who possess her will descend to the Pit. (4Q184)

However, what this association does not take into account are additional descriptions of the "Seductress" from Qumran that cannot be found attributed to the "strange woman" of Proverbs, namely, her horns and her wings: "a multitude of sins is in her wings." The woman illustrated in Proverbs is without question a prostitute, or at the very least the representation of one, and the sort of individual with whom that text's community would have been familiar. The "Seductress" of the Qumran text, conversely, could not possibly have represented an existent social threat given the constraints of this particular ascetic community. Instead, the Qumran text utilizes the imagery of Proverbs to explicate a much broader, supernatural threat, the threat of the demoness Lilith. The possession of wings, as we have seen already, customarily indicates a denizen of the netherworld in Near Eastern mythology; and with the addition of her horns, and in comparison to earlier depictions of Lilith both in text and in various incantation bowls, amulets and reliefs, the correspondence to the "strange woman" of Proverbs diminishes significantly while the correlation to Lilith becomes increasingly more apparent (Baumgarten 133-143). Further is the carnal threat posed therein:

She lifts her eyelids naughtily...

....at upright men to pervert their way,

and the righteous elect to keep them from the commandments, at the firmly established to bring them down wantonly, and those who walk in uprightness to alter the statue; to cause the humble to rebel against God... (4Q184)

Such is a danger little ascribed to Lilith beforehand, but broadly focused upon in later assessments of the evil spirit, particularly in the Talmud of Babylonia. 
The two Talmuds, the Talmud of the Land of Israel (c. $400 \mathrm{CE}$ ) and the Talmud of Babylonia (c. $600 \mathrm{CE}$ ), or Bavli, are the very crux of Rabbinic Judaism, the latter being, as Jacob Neusner decribes it, "the single most important document in Rabbinic Literature" (182). The Talmud is the perpetual study of the "dual Torah": the Torah revealed to Moses at Sinai and the "oral Torah," transmitted orally throughout the centuries until its eventual codification in the Mishnah. The Gemara, or commentary, contained in the Babylonian Talmud is some three times larger than that of the earlier Talmud of the Land of Israel and also more venerated. It is here that we next find Lilith. Although the Talmudic references to Lilith are sparse, these scholarly passages provide the most comprehensive insight into the demoness yet seen in Judaic literature which both echo Lilith's Mesopotamian origins and prefigure her future as the perceived exegetical enigma of the Genesis account.

Recalling the Lilith we have seen, Talmudic allusions to Lilith illustrate her essential wings and long hair, dating back to her earliest extant mention in Gilgamesh:

Rab Judah citing Samuel ruled: If an abortion had the likeness of Lilith its mother is unclean by reason of the birth, for it is a child but it has wings. (Niddah 24b)

And:

[Expounding upon the curses of womanhood] In a Baraitha it was taught: She grows long hair like Lilith, sits when making water like a beast, and serves as a bolster for her husband. ('Erubin 100b)

More unique to the Talmud with regard to Lilith is her insalubrious carnality, alluded to in The Seductress but expanded upon here sans unspecific metaphors as the demoness assuming the form of a woman in order to sexually take men by force while they sleep: "R. Hanina said: One may not sleep in a house alone [in a lonely house], and whoever sleeps in a house alone is seized by Lilith" (Shabbath 151b).

Yet the most innovative perception of Lilith offered by the Talmud appears earlier in 'Erubin, and is more than likely inadvertently responsible for the fate of the Lilith myth for centuries to come: 
R. Jeremiah b. Eleazar further stated: In all those years [130 years after his expulsion from the Garden of Eden] during which Adam was under the ban he begot ghosts and male demons and female demons [or night demons], for it is said in Scripture, And Adam lived a hundred and thirty years and begot a son in own likeness, after his own image, from which it follows that until that time he did not beget after his own image... When he saw that through him death was ordained as punishment he spent a hundred and thirty years in fasting, severed connection with his wife for a hundred and thirty years, and wore clothes of fig on his body for a hundred and thirty years. That statement [of R. Jeremiah] was made in reference to the semen which he emitted accidentally. ('Erubin 18b)

Comparing 'Erubin $18 \mathrm{~b}$ and Shabbath $151 \mathrm{~b}$ with the later passage from the Zohar: "She wanders about a night night, vexing the sons of men and causing them to defiles themselves," (19b) it appears clear that this Talmudic passage indicates such an averse union between Adam and Lilith (Lachower \& Tishby 540-1). Accordingly, the anonymous medieval text "The Alphabet of Ben Sira"'s exegesis of the Hebrew creation account, attempting to explain the apparent inconsistency between the accounts of Genesis 1 and Genesis 2-3, supposes the involvement of Lilith as the key.

Consisting of twenty-two episodes - one for each of the letters in the Hebrew alphabet - "The Alphabet of Ben Sira" operates as a rough narrative concerning the courtier to King Nebuchadnezzar, Ben Sira and, in the fifth section, his charge to cure the king's ill son. In his effort to do so, Ben Sira "immediately sat down and wrote an amulet with the Holy Name, and he inscribed on it the angels in charge of medicine and their names, forms, and images, and by their wings, hands and feet" (Stern \& Mirsky 183). Nebuchadnezzar, unfamiliar with the ritual, inquires into Ben Sira's actions and receives the following story:

[These are] the angels who are in charge of medicine: Snvi, Snsvi, and Smnglof. After God created Adam, who was alone, He said, 'It is not good for man to be alone' (Genesis 2:18). He then created a woman for Adam, from the earth, as He had created Adam himself, 
and called her Lilith. Adam and Lilith immediately began to fight. She said, 'I will not lie below,' and he said, 'I will not lie beneath you, but only on top. For you are fit only to be in the bottom position, while I am to be in the superior one.' Lilith responded, 'We are equal to each other inasmuch as we were both created from the earth.' But they would not listen to one another. When Lilith saw this, she pronounced the Ineffable Name [the Tetragrammaton, or "name that comprises all" (Zohar 19a)] and flew away into the air. Adam stood in prayer before his Creator: 'Sovereign of the Universe!' he said, 'the woman you gave me has run away.' At once, the Holy One, blessed be he, sent three angels to bring her back.

By uttering the unspeakable name of God, Lilith apparently obtains the ability to fly - an instant transformation from earth-made human to "winged devil." God responded to Adam's distress by informing him that "If [Lilith] agrees to come back, fine. If not, she must permit one hundred of her children to die every day," presumably the "ghosts and male demons and female demons" referenced in "Erubin 18b. Upon the meeting of the three pursuant angels and Lilith "in the midst of the sea, in the mighty waters wherein the Egyptians were destined to drown," Lilith stubbornly refused God's command, exclaiming:

Leave me!...I was created only to cause sickness to infants. If the infant is male, I have dominion over him for eight days after his birth [until circumcision], and if female, for twenty days... [but] Whenever I see your names or your forms in an amulet, I will have no power over that infant.

Thereafter, Lilith agrees to God's condition that one hundred of her children will die daily, and Ben Sira concludes by explaining that "every day one hundred demons perish, and for the same reason, we write the angels' names on the amulets of young children...[Lilith] remembers her oath, and the child recovers."

Herein, the barren desert dwelling attributed to Lilith is absent; instead she is depicted fleeing to the abundant Red Sea, which is an appropriate allegory given the one hundred progeny she is said to deliver daily, a plausible feat considering that the "curses" associated with childbirth had not yet been con- 
ceived. In the process, however, Lilith develops into a more terrible entity than she has previously been portrayed: as the vengeful child-slaying demon, evidently immortal (that curse had not yet been conceived, either) and bent on retribution for both Adam's oppression and God's exceptional blight upon her. Ben Sira never explicitly names Lilith as the cause of Nebuchadnezzar's son's illness, but in practicing a sort of medieval preventative medicine he wards off any possibility of Lilith's intercession, his first and foremost undertaking at the sight of a sick child.

The objective of this unusual text is debatable. Gaines suggests the anonymous author sought to reconcile the disparities between Genesis 1 and Genesis 2-3: "God creates woman twice-one with man, once from man's rib-so there must have been two women... The Bible names the second woman Eve; Lilith was identified as the first in order to complete the story" (19). Such analysis is distinctly credible, especially taking the Talmudic report of Adam's association with Lilith during his "ban." The episode also achieves the objective of a concise written history of the demoness Lilith, a history that may not have existed in its own time and other than the Alphabet itself is certainly not extant now. Conversely, this medieval text is by no means considered canonical nor authoritative, and by examining the complete manuscript, many develop the conclusion that the Alphabet was nothing more than "a kind of academic burlesque," a ridiculous and frequently vulgar form of satirical entertainment, perhaps intended for a rabbinic audience (Bronznick 168). Nevertheless, in some communities this text benefited from an extraordinary level of deference, such as the 13th century tosafist Rabbi Peretz, and whether the Alphabet was devised as a sincere form of medieval midrash or merely the irreverent parody Bronznick suggests, the Lilith origin story it produces will influence the vast majority of future perceptions of the Lilith myth. The Zohar, for example the essential kabbalistic text of the 13th century expands upon the notion of Lilith's naissance in Eden set forth by the Alphabet, and is clearly an enormously sacred manuscript.

After recapitulating the Talmudic concept that "at first it was the intention that two should be created but ultimately only one was created," and that "the first man had two full faces," ('Erubin 18a; cf. Zohar III 34b) the Zohar further explains that the "two full faces" (cf. Zohar I 19a) were soon thereafter separated into male and female: 
[God] sawed her off from him and adorned her like a bride and brought her to him. [She was] the original Lilith, who was with [Adam] and who was conceived from him. (Zohar III 34b)

Adam later becomes one of Lilith's victims, consequently fathering "many spirits and demons, through the force of the impurity which he had absorbed" from her as previously illustrated in the Talmud. More uniquely, the Zohar indicates the "secret of secrets," the extremely dualistic notion that for all things good exists a balanced evil, illuminated here by the "other side" of male and female, or Adam and Eve: Samael and Lilith. Echoing The Seductress from Qumran, the Zohar describes Lilith as a sort of supernatural prostitute: "She dressed herself in finery like an abominable harlot and stands at the corners of streets and highways in order to attract men." Reiterating the Talmudic references, the text continues by describing her sexual attacks against oblivious men as well as her trademark long hair (Lachower 538). In this rendering, in contrast, Lilith exists merely as Samael's bait after Lilith has seduced the unwary man and lulled him to sleep with her poison kisses, he awakes to discover not Lilith in his bed but Samael, who then "kills the fool, and throws him into Gehinnom" (Zohar I; 148a-148b). This provides the impetus for Lilith's aforementioned propensity for descending upon sleeping men as well as an etiological explanation of nocturnal emissions. In reaction to the unholy alliance of Samael and Lilith and in fear of the enormous demonic litter they might produce, God commands the castration of Samael, leaving Lilith to gratify her malevolent fervor with these sleeping men and-in apparent reference to her one hundred daily births from the Alphabet-subsequently becomes pregnant each time (Adler 6).

Intriguingly, while incorporating Lilith's Mesopotamian demonological origins with the Hebrew creation account in the vein of the Alphabet and utilizing language directly from the Talmud of Babylonia in the enterprise, the Zohar further endeavors to fully explicate the fleeting reference to Lilith in Isaiah 34:14. As we have seen, the ephemeral allusion in Isaiah clearly suggests a presumption that the audience was wholly aware of the Lilith myth and thus proffers no insight into her nature or origin. Accordingly, the Zohar attempts to fill in these gaps by placing the verse into context: 
When Lilith saw [how God had prepared her to be Adam's bride] she fled, and she is now in the cities of the sea [cf. The Alphabet], and she is still intent on injuring mankind. When the Holy One, blessed be he, destroys wicked Rome, and it becomes an eternal desolation, $\mathrm{He}$ will bring up Lilith and settle her in the ruins, because it will be desolate forever. This is the meaning of "Lilith shall repose there, and find her place of rest. (Zohar III 19a)

In doing so, the text has access to the indisputability of the Scriptures themselves, adding the prophet Isaiah to the document's extensive list of sources in the face of otherwise debatable sources such as "The Alphabet of Ben Sira" or "Pseudo-Ben Sira" (Dan 20).

Despite the dubiousness of the Alphabet in terms of a midrash on Scripture, it is incontrovertible that the manuscript provides both the Genesis origin story of Lilith as well as the unprecedented union of Samael and Lilith in the Zohar. Re-edited by a later compilator centuries after the original text was composed, Lilith's defense to the angels who pursue her to the Red Sea is enlarged to include her statement that "the Great Demon [Samael] has already slept with me," thus rendering her effectively contaminated and thus unworthy of either Adam or Eden. Thus was Rabbi Issac ben Jacob ha-Kohen motivated to include said union in his 13th century "Treatise on the Left Emanation," a kabbalistic document that was later integrated into the Zohar (Dan 22). As a result, a satirical medieval text which offers "discussions of vulgar matters such as masturbation, flatulence and copulation by animals" amasses an abnormal degree of authority and is eventually assimilated, in part, into earnest sacred texts (Gaines 19). However, according to Joseph Dan, early kabbalists such as Issac ben Jacob ha-Kohen frequently "pretended to be using books and treatises by ancient authorities," when in fact the material was original in an effort to lend such authority to their ideas (Dan 17). If this is indeed the case with "A Treatise on the Left Emanation" and the Zohar itself, it is then impossible to determine either the totality or the authenticity of their sources.

Each generation of Lilith literature, from her emergence in the hulupputree of Gilgamesh to the medieval musings on her birth in Eden, has built upon its predecessors while conversely reshaping them into something altogether innovative. The Gilgamesh epic very likely included, taking into account the prevalent inference concerning Isaiah $34: 14$, text that did not require elabora- 
tion upon the persona of Lilith, inferring pre-acquaintance from its audience. Correspondingly, the surviving tablets of the Gilgamesh epic, and specifically Gilgamesh and the Huluppu-Tree, appear to make the same inference, insofar as the pericope never stops to introduce or explain Lilith, but like Isaiah, presents an evidently familiar player in a broader cosmic drama. It is thus conceivable that this, the earliest extant reference to Lilith, also builds upon earlier conceptions of the ancient demoness; yet akin to the Kabbalistic allusions, it is impossible to ascertain the verity of any such sources. Nonetheless, the evolution of the Lilith myth from inhuman night demon to seductress and infant-slayer to the slighted first woman of creation turned vengeful apparition continues to astonish and delight well beyond the kabbalistic texts of medieval Jewry. Indeed, the Lilith of "Pseudo-Ben Sira" has developed into a staple celebrity of numerous works of literature spanning from the Renaissance to the Romantic poets to the present age, capturing the imagination of the likes of Goethe, Rossetti and C.S. Lewis; and whereas the Lilith of the Talmud and Zohar is unquestionably a negative and destructive creature, indeed the very "nightmarish form of the Feminine," she has become in the twentieth and twenty-first centuries a conversely ideal delegate of the most affirmative feminine, the very epitome of autonomous woman (Neumann 146). A modern liberal Jewish women's journal is named for Lilith, as is a popular music festival which donates its proceeds to women's charities (Gaines 12). The essential distinction between these two impressions of Lilith lies in the distinction between the Lilith of a long-dead mythos and the very real threat of antiquity: Lilith was never conceived in order to lay waste to the values of the feminine, but rather, in an etiological capacity, the limestone plaque of Arslan Tash evinces as much by rationalizing the high infant mortality rate of the era. To the community who hung this and comparable plaques and amulets in their homes, Lilith was no representation of the Feminine, negative or constructive, but rather an authentic living menace. It is only with the demise of her authenticity that her danger, and in turn any consideration of her history as murderer of children and men, harlot, and consort to the devil himself, is diminished in tandem. 
Barton, John and John Muddiman, eds. The Oxford Bible Commentary. New York: Oxford University Press, 2001.

Baumgarten, Joseph M. "On the Nature of the Seductress in 4Q184." Revue de Qumrân 15:57-58 (1991-1992): 133-143.

Bronznick, Norman. Introduction. "The Alphabet of Ben Sira." Trans. Norman Bronznick. David Stern and Mark J Mirsky, eds. Rabbinic Fantasies: Imaginative Narratives from Classical Hebrew Literature. New Haven: Yale University Press, 1990.

Buttrick, George A., ed. The Interpreter's Bible, Vol. 5. New York: Abingdon Press, 1956.

Dan, Joseph. "Samael, Lilith, and the Concept of Evil." AJS Review 5 (1980): 17-40.

Franfort, Henri. "The Burney Relief." Archiv für Orientforschung 12 (1937): 128-135.

Gaiman, Neil. The Sandman Library, Volume VI: Fables \& Reflections. New York: DC Comics, 1993.

Gaines, Janet Howe. "Lilith: Seductress, Heroine or Murderer?" Bible Review 17.5 (2001): 12+.

Goethe, Johann Wolfgang von. Faust: A Tragedy, Part One. Trans. Randall Jarrell. New York: Farrar, Straus and Giroux, 1976.

Handy, Lowell K. "Lilith." The Anchor Bible Dictionary, Vol. IV. David Noel Freedman, ed. New York: Doubleday, 1992.

Hebrew-English Edition of the Babylonian Talmud. Rabbi Dr. I. Epstein, ed. Trans. Rabbi Dr. H. Freedman. London: The Soncino Press, 1972. 
Hugo, Victor. La Legende des Siecles - La Fin de Satan - Dieu. Paris: French \& European Publications, 1950.

Hurwitz, Siegmund. Lilith - The First Eve: Historical and Psychological Aspects of the Dark Feminine. Trans. Theodore H. Gaster. Einsiedeln, Switzerland: Daimon, 1992.

Hutter, M. "Lilith" The Dictionary of Deities and Demons in the Bible. 2nd ed. Karel Van Der Toorn, Bob Becking, \& Pieter W. Van Der Horst, eds. Grand Rapids: William B. Eederman's Publishing Co., 1999.

Kramer, Samuel Noah. Sumerian Mythology: A Study of Spiritual and Literary Achievement in the Third Millennium BC. New York: Harper \& Brothers, 1988.

"Gilgamesh and the Huluppu-Tree: A Reconstructed Sumerian Text." The Oriental Institute of Chicago Assyriological Studies 10.

Chicago: University of Chicago Press, 1938.

Lachower, Fischel \& Isaiah Tishby, eds. The Wisdom of the Zohar, vol. II. Oxford: Oxford University Press, 1989.

Martinez, Florentino Garcia and Eibert Tigchelaar, eds. The Dead Sea Scrolls Study Edition. Grand Rapids: William B. Eermans Publishing Company, 1997.

Neumann, Erich. The Great Mother: An Analysis of the Archetype. Trans. Ralph Manheim. Princeton: Princeton University Press, 1963.

Neusner, Jacob. Introduction to Rabbinic Literature. New York: Doubleday, 1994.

Rossetti, Dante Gabriel. "Body's Beauty." The Norton Anthology of English Literature Volume 2B: The Victorian Age. Carol T. Christ, ed. New York: W. W. Norton \& Company, 2000. 
Stern, David and Mark J. Mirsky, eds. "Alphabet of Ben Sira." Rabbinic Fantasies: Imaginative Narratives from Classical Hebrew Literature. Trans. Norman Bronznick. New Haven: Yale University Press, 1990.

Shaw, George Bernard. Back to Methuselah: A Metabiological Pentateuch. New York: Oxford University Press, 1947.

Tanakh: The Holy Scriptures. Philadelphia: The Jewish Publication Society, 1985.

Vermes, Geza, trans. The Complete Dead Sea Scrolls in English. New York: Penguin Press, 1997.

Wise, Michael, Martin Abegg Jr, and Edward Cook, eds. The Dead Sea Scrolls: A New Translation. San Francisco: Harper Collins, 1996.

Zohar, The. 2nd ed. 3 vols. Trans. Harry Sperling and Maurice Simon. London: The Soncino Press, 1984. 
ThE GREEK wORD ARETE, does not translate easily into English. For the ancient Greeks, ARETE was associated with excellence, an abstract sense of virtue, and was embodied in the Goddess Athena. To pursue ARETE in one's life was to pursue all the abilities and potentialities available to a human being. These combined concepts provide a basis for thought and knowledge, as we have tried to represent in the St. Edward's community. 
Mary Avery, a mathematics student at SEU, graduates in May 2004. She was chosen as the Outstanding Student in Mathematics at St. Edward's in 2003. She participated in the Research Experience for Undergraduates in mathematics at Oregon State University in the summer of 2003. Recently, she received first place in the Undergraduate Paper Competition at the annual meeting of the Texas Academy of Science, where she presented her original research in mathematics. She has been an SEU student chapter officer of the Mathematical Association of America for two years and also has presented her research at the Texas meeting of the MAA.

Sarah Bond, an English Writing and Rhetoric major, is in her second year at SEU. In addition to her work with Arete, she is involved with the student newspaper, Hilltop Views, as a copy editor and writer. She is also a member of the SEU Fellows organization and the Honors program. Currently, she is completing an internship with the Austin Bureau of People magazine. She hopes to pursue a career in journalism, a field in which she has received five awards in statewide competitions, including a first place win in on-site News Writing at the 2003 Texas Intercollegiate Press Association conference.

Sarah Buckingham is an English Literature major. This is her third year at St. Edward's, and her second year as an Arete editor. She has no noteworthy hobbies; however, she has been toiling over her first sonnet sequence, although she expects never to finish it.

Jason Forrest is an English Writing and Rhetoric major pursuing a career in professional writing. Although this is his first year at St. Edward's, he has been a member of Phi Theta Kappa, has been on the Dean's List for the last two years, and has received awards for research efforts and for an outstanding original analysis by the North Lake College English Department, in Irving, Texas.

Philip Jones is an English Writing and Philosophy double-major in his second year at SEU. This is his first year on the Arete staff. Besides working with the journal, he is also a member of the Student Government Association and a charter member of St. Edward's debate team. Philip extends his thanks to all of the other editors for their hard work and determination. 
George Morrow, a Photocommunications senior at SEU, graduates in the summer of 2004. In addition to attending St. Edward's, George is a fulltime designer at News 8 Austin where he specializes in 2D motion graphics. A very creative and successful photographer and filmmaker, he was nominated by the Austin Music Network for Best Rock Video in 2003. George has recently been accepted to the American Pavilion Canne's Student Filmmaker Program, for which he will be staying in Canne, France for twenty days working the Canne's Film Festival with full access. There he will screen two films, Rats in My Apartment and Danger Bowl. After graduation George plans to shoot a feature film he wrote during the summer of 2003 titled Color of Black. His long term goals include obtaining a Master of Art History and starting a production company with his friends in New York.

Clayton Shoppa, a philosophy student and member of the Honors program, is this issue's editor-in-chief. Last fall he worked as an intern for the Freshman Studies department, and he was also featured in the university's magazine as an exemplary Humanities student. In April he presented a paper on his philosophy of history at the Pacific University's undergraduate philosophy conference. After graduation he plans to continue studying philosophy with a particular focus on areas of metaphysics and epistemology. 
As awarded by

The American Scholastic Press Association:

\section{2}

ARETE volume 2

Outstanding Academic Journal

\section{4}

ARETE volume 4

Outstanding Academic Journal

First Place with Merit

1995

ARETE volume 5

Outstanding Academic Journal

First Place with Merit

\section{6}

ARETE volume 6

Outstanding Academic Journal

First Place with Merit

1997

ARETE volume 7

Outstanding Academic Journal

First Place with Merit

\section{8}

ARETE volume 8

Outstanding Academic Journal

First Place with Merit 



\section{In This Issue}

Vanessa BaIley Adams, Jungian Individuation in Demian and Fight Club

Fernando Benavidez, A Comparative Look at Dreiser's Carrie and Conrad's Marlow and the Changeable Modern Identity

LeE Parish-ButLer, The Role of Emotional Intelligence in Care Ethics

Aricel Guerrero, The Phenomenon of the Unreliable Narrator as Used by Irving and Poe

William O. Pate II, On Sleeping With Friends

Paul Hagey, Nihilism in Doctor Faustus and Steppenwolf: The Struggle for Transcendence

Margaret Johnson, Reinventing the Myth: The West of William Kittredge

Ashlie Kelly, "Them Damned Pictures": A Study of the Cartoons of Thomas Nast and the Breakdown of the Tweed Political Ring

Catherine S. Blackwell, Lesbianism as a Cat's-Paw: The True Role of Mlle. Reisz in The Awakening

JENNIFER WhaRTon, To Create More Worlds: A Discussion of Alternative Worlds in Paradise Lost and His Dark Materials

E K Zimmerman, Lilith: A Brief Biography of a Demoness 